\title{
Shared Autonomous Vehicle Services: a Comprehensive Review
}

\author{
Santhanakrishnan Narayanan ${ }^{\mathrm{a}}$, Emmanouil Chaniotakis $^{\mathrm{b}}$, Constantinos Antoniou $^{\mathrm{a}}$ \\ ${ }^{a}$ Technical University of Munich, Arcisstrasse 21, 80333 Munich, Germany \\ ${ }^{b}$ MaaSLab, Energy Institute, University College London, 14 Upper Woburn Place, WC1HONN London, UK
}

\begin{abstract}
The actions of autonomous vehicle manufacturers and related industrial partners, as well as the interest from policy makers and researchers, point towards the likely initial deployment of autonomous vehicles as shared autonomous mobility services. Numerous studies are lately being published regarding Shared Autonomous Vehicle (SAV) applications and hence, it is imperative to have a comprehensive outlook, consolidating the existing knowledge base. This work comprehensively consolidates studies in the rapidly emerging field of SAV. The primary focus is the comprehensive review of the foreseen impacts, which are categorised into seven groups, namely (i) Traffic \& Safety, (ii) Travel behaviour, (iii) Economy, (iv) Transport supply, (v) Landuse, (vi) Environment \& (vii) Governance. Pertinently, an SAV typology is presented and the components involved in modelling SAV services are described. Issues relating to the expected demand patterns and a required suitable policy framework are explicitly discussed.
\end{abstract}

Keywords: Autonomous vehicle; Shared Autonomous Vehicle (SAV); Autonomous taxis; Automated transport; Self-driving car; Emerging transport modes; mobility on-demand; Review

\section{Introduction}

Automated vehicles are vehicles with some level of automation to assist or replace human control. The Society of Automotive Engineers (SAE) has defined different levels of automated functionality, ranging from no automated features (Level 0) to full automation (Level 5 - commonly referred to as autonomous, 5 self-driving or driverless vehicles). The term 'autonomous' has been inconsistently used in the literature. However, some state legislation has used the term for highly automated driving systems, i.e., at or above level 3 (SAE International, 2018). Since the term 'automated' can refer to even lower levels of automation and we concentrate on automation levels of 4 and 5, the term 'autonomous' has been used instead of 'automated' throughout this research work to avoid ambiguity. Autonomous Vehicles are expected to lead 10 the next paradigm shift in the field of transportation. While the benefits and issues associated with their introduction are still being critically evaluated and discussed, the active involvement of major technology companies and car manufacturers in a race to build the first operational vehicle is on, for many years now. This has resulted in investments of billions of dollars every year (e.g., Korosec, 2018; Trivedi, 2018). The high recent interest for autonomous vehicles imply that such systems will eventually be introduced (Brown, 15 2018). The questions, however, include when, how and what will the impacts to the transportation system be. Although there still exists uncertainty with regards to their characteristics, actions of the autonomous vehicle manufacturers and related industrial partners point towards the initial deployment of autonomous vehicles in a shared mobility service. To name but a few, BMW Group has partnered with Intel and Mobileye Team to produce autonomous vehicles by 2021 for ride-sharing (BMW Group, 2016). Ford plans to introduce their autonomous vehicles in a ride-hailing or ride-sharing service in 2021 (The Ford Company, 2016). Volkswagen Group and Hyundai have partnered with Aurora Innovations to begin autonomous on-demand services by 2021 (O'Kane, 2018). Daimler has partnered with Uber to enable introduction of autonomous vehicles in Uber's ride-sharing network (Daimler AG, 2017). Toyota has also partnered with Uber with the same goal (Monaghan, 28/08/2018). Waymo has already started commercial autonomous ride-sharing service in Tempe, Mesa and Chandler (LeBeau, 2018). 
Shared use of a vehicle for performing a trip is termed as shared mobility (Shaheen et al., 2015). Services such as car-sharing, bike-sharing, scooter-sharing, on-demand ride services and ride-sharing fall into the category of shared mobility services. Shared mobility services can enable cost savings, provide convenience, and reduce vehicle usage, vehicle ownership and vehicle miles/kilometres travelled (VMT/VKT) (Shaheen \& so Chan, 2015). The diffusion of growing shared mobility services and emerging autonomous vehicle technology has the potential to disrupt transportation system operations (Greenblatt \& Shaheen, 2015), especially when combined with electrification (Sprei, 2018; Walker \& Johnson, 2016; Weiss et al., 2017). Autonomous vehicle technology can accelerate the growth of shared mobility services (Thomas \& Deepti, 2018) and shared mobility services can make the deployment of autonomous vehicles financially viable (Gurumurthy 35 \& Kockelman, 2018; Stocker \& Shaheen, 2018). This diffusion can lead to a more sustainable future with enhanced mobility and equity, when integrated with public transportation systems (International Association of Public Transport, 2017). Their development can be channelised to achieve a beneficial change to the transportation system (Fagnant \& Kockelman, 2015).

Numerous research studies are lately being published regarding SAVs and hence it is imperative to have a 40 comprehensive outlook to consolidate the existing knowledge base. Attempts to consolidate relevant studies are available (Becker \& Axhausen, 2017; Gkartzonikas \& Gkritza, 2019; Miller \& How, 2017; Soteropoulos et al., 2018). However, they do not discuss the expected penetration rate for SAVs, as well as do not identify the business models being simulated in the modelling studies. Business models, travel behaviour and public policy determine how SAV impacts unfold (Shaheen \& Cohen, 2019). Hence, a review connecting expected 45 business models, estimated demand and anticipated policies with identified impacts is a necessity, as it fosters a more holistic approach and reveals interesting research gaps. For example, although studies on SAV-related policy recommend that an integrated Public Transport and SAV system (PT-SAV system) be introduced, no acceptance study exists till now that tries to explore a change in mode share for PT in a scenario wherein SAVs are used for last mile services. Also, studies evaluating impacts of integrated ${ }_{50}$ PT-SAV systems are sparse. Finally, the above-mentioned review works do not stress enough on the need for advanced data management and adjustable policy framework that reacts to the new changes during the transition phase.

In addition, Becker \& Axhausen (2017) review research works related to the acceptance of autonomous vehicles up to 2016, while a large number of papers have been published on this topic since 2017. Research

55 questions that have received attention in later studies include preference between ownership and mobility service, mode shift to SAV services from sustainable modes (public transport, walking and bicycling) and acceptance for car-sharing versus ride-sharing systems. Gkartzonikas \& Gkritza (2019), who reviewed studies related to surveys on autonomous vehicles, have filled the research gap related to the acceptance for car-sharing versus ride-sharing systems. Still, the remaining two research gaps exist. Milakis et al. (2017) and Soteropoulos et al. (2018) discuss the impacts of automated and autonomous vehicles in general, without focusing in detail to some aspects, such as impacts on entertainment and advertising industries. Also, policy reports from governments and other institutions are not considered in both reviews. Hence, they fail to note the possible governance implications like expected shifting of role of public transport authorities and emergence of new stakeholders and forms of cooperation in the field of transportation.

Thus, the main objective of this paper is to provide a comprehensive review of relevant studies in the field of SAV, for various facets of SAV deployment, including but not limited to business models anticipated, impacts identified, demand estimated and policies required. As described earlier, we focus on Level 4 and 5 automation, and bike-sharing and scooter-sharing systems are not part of this study. The reviewed documents include journal papers, conference papers, policy papers and technical reports. A semi-structured approach was followed starting from collecting studies from Scopus, based on 13 keywords (shared autonomous, autonomous mobility(-)on(-)demand, autonomous taxi(s), shared automated, autonomous fleet, autonomous shared, driverless taxi(s), autonomous vehicle sharing, robo(-)taxi(s), autonomous mobility service(s), automated electric taxi, autonomous electric taxi, shared self(-)driving), for the publication year range 1950 to $2019^{1}$. The obtained studies were screened based on their relevance and topics. Additional

${ }^{1}$ The search was completed in January 2019, thus included sources available in the database at that point. 
75 papers were obtained from the references of the screened papers. Some studies not specific to SAVs has been included, since they are applicable to autonomous vehicles in general, i.e., applicable to both personal autonomous vehicles and SAVs. The Scopus results indicated the sources, "Transportation Research Part C: Emerging Technologies", "Transportation Research Record" \& "Transportation Research Procedia", as the most frequent, while in the final collection of considered papers, "Transportation Research Procedia" was replaced by "Transport Reviews". These top three journals account for around $23 \%$ of the reviewed papers.

The contributions of this research work are summarised as follows: 1. Overview of SAV typology, 2. Identification of different components involved in modelling SAV services and the methods used within the identified components, 3. Categorisation of the impacts expected from SAV services, 4. Evaluation of expected demand for SAV services and 5. Exploration of policy and operational requirements for channelising the development and deployment of SAV services. The types of SAV systems described can help policy makers to obtain an overview of different types of services that are being discussed in the literature and are likely to be deployed. Identified modelling components and methods support future development on modelling approaches and the understanding of shortcomings. Categorised impacts help stakeholders to understand the effects of the introduction of SAV services. A comprehensive evaluation of the demand and the policy and operational requirements guide towards a better planning of SAV development. Furthermore, the identified research gaps will aid the future research related to SAV services.

This paper is structured as follows: an overview of the SAV typology and relevant characteristics are presented (Section 2), followed by a description of different components involved in modelling SAV services (Section 3). Then, SAV impacts and demand are consolidated (Section 4 and 5 respectively). Table A1 in the Appendix contains a brief description of studies examined in the Impact and Demand section. Finally, aspects of policy and operational frameworks required are discussed (Section 6) and major conclusions and research gaps are elucidated (Section 7).

\section{SAV Typology and Characteristics}

The concepts of automation and car-sharing are not new. The first known attempt for autonomous vehicles originates back in the early $20^{t h}$ century (1925) in the form of a radio-controlled driverless car by a firm named Houdina Radio Control (Dormehl \& Edelstein, 2018). Widespread exposure to the concept began in 1939 during General Motors' Futurama exhibit, where the concept of autonomous driving was presented in a massive and very costly event (Ferlis, 2007). Japan pioneered advanced automated vehicle

105 technology development in 1977 by developing a car that follows white street markers with a speed of up to 20 miles per hour, followed by Germany and other countries (Forrest \& Konca, 01/05/2007). However, it was the DARPA Grand Challenge (2004 and 2005) and DARPA Urban Challenge (2007), sponsored by the U.S. Defense Advanced Research Projects Agency (DARPA), that popularised the development of autonomous vehicles (Defense Advanced Research Projects Agency, 2014). Furthermore, foundations

110 for current developments were laid by Carnegie Mellon University, Environmental Research Institute of Michigan and SRI International (as indicated in Stocker \& Shaheen, 2017). The first car-sharing system dates back to 1948 in Zurich, Switzerland. For nearly three decades, car-sharing systems failed to attract customers, mainly because of the availability of fast and cheap private motorization (Becker et al., 2016). However, with the increasing awareness of the citizens and the diffusion of Information and Communication Technologies (ICT) and mobile services, car-sharing systems started to become successful in the 1980s, with high growth being evident in the 2000s (Ferrero et al., 2018). Specifically, from 2012 to 2014, car-sharing systems around the world experienced a $65 \%$ increase in membership and $55 \%$ increase in fleet (Shaheen \& Cohen, 2016).

A system combining car-sharing and automated vehicles, named Cybernetics Transportation System (CTS), was first conceptualised in the early 1990s in Europe (Parent \& de La Fortelle, 2005). The concept was investigated in France by INRIA (French national research institute for the digital sciences) and INRETS (former French national institute for transport and safety research, currently called IFSTTAR); details on the concept can be found in Parent \& Daviet (1993). Such a system was first introduced in Netherlands 
in 1977 at Schiphol airport (Parent \& de La Fortelle, 2005). Though the concept has been in development from early 1990s, commercial deployment of such a service in an urban setting is still a challenge.

Different types of SAV systems are studied in the literature, commonly on the basis of their operation (booking time frame and sharing system) and level of their integration with other modes. The typology presented in Figure 1 and discussed in the following paragraphs is based on the system types and characteristics identified in the reviewed literature. Based on booking time frame, SAV services can be divided into on-demand (the customers can book vehicles in real time), reservation-based (booked in advance) and mixed systems. Most of the studies found in the literature are related to on-demand system (e.g., AlonsoMora et al., 2017; Fagnant \& Kockelman, 2018; Gurumurthy \& Kockelman, 2018; Hörl, 2017; Hyland \& Mahmassani, 2018; Levin et al., 2017; Lokhandwala \& Cai, 2018; Mahmassani, 2018; Wang et al., 2006), and only four studies have been found for reservation-based system (Lamotte et al., 2017; Levin, 2017; Ma et al., 2017; Pimenta et al., 2017). The reason may be the current state of operation of shared vehicles, i.e. current request scenarios for shared vehicle services are primarily on-demand. However, reservation-based systems enable better planning of routes and schedules and, if optimally designed, higher efficiency, thereby reducing fleet size, empty cruising time and operating cost, as well as increasing resource utilization (Wang et al., 2014).

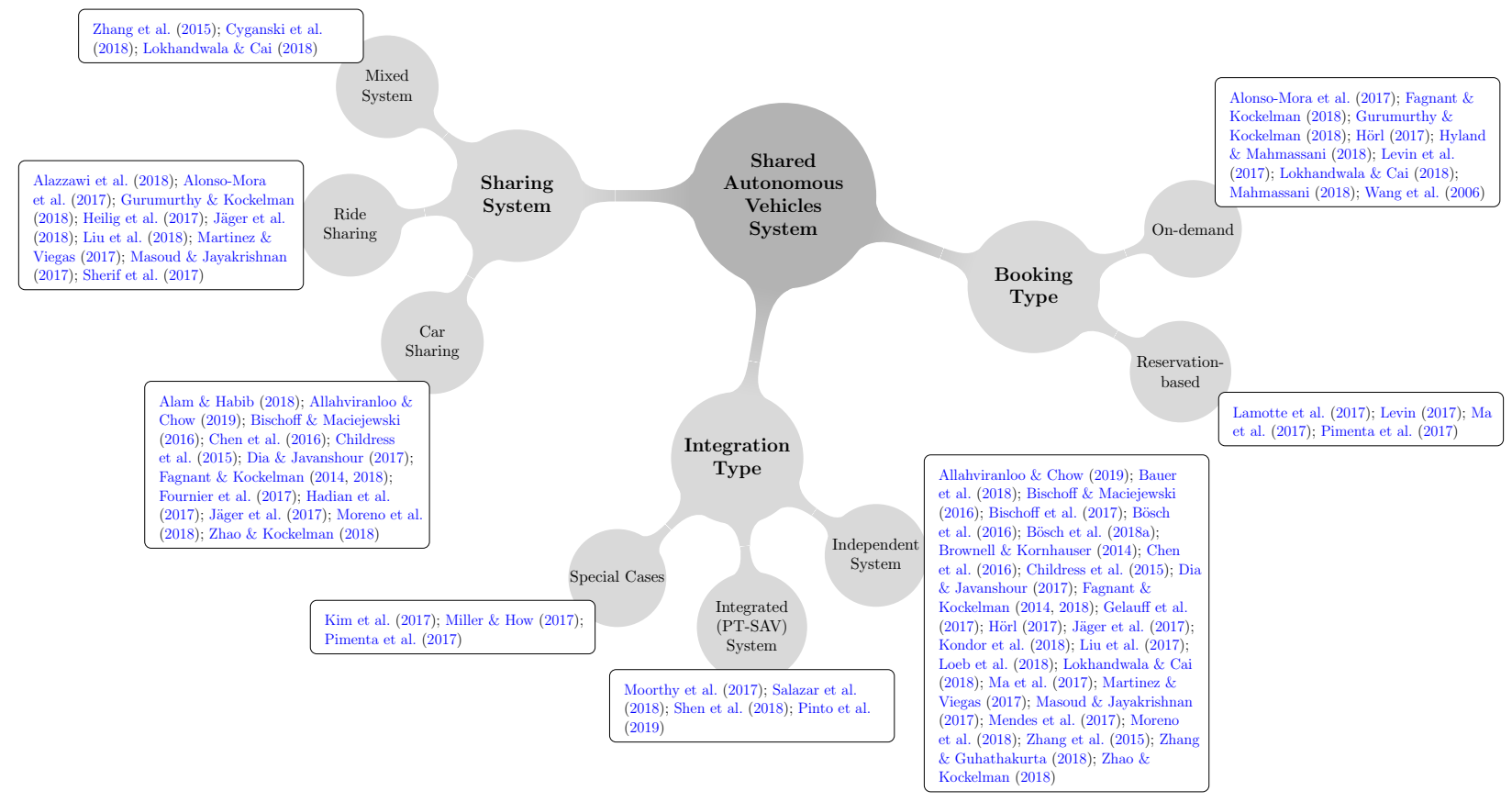

Figure 1: Types of SAV services explored and indicative references

SAV services can be further classified into car-sharing, ride-sharing and mixed systems. In case of ridesharing systems, two or more customers share a vehicle at the same time (Alazzawi et al., 2018; Alonso-Mora et al., 2017; Gurumurthy \& Kockelman, 2018; Heilig et al., 2017; Jäger et al., 2018; Liu et al., 2018; Martinez \& Viegas, 2017; Masoud \& Jayakrishnan, 2017; Sherif et al., 2017), while only one customer request is served in case of a car-sharing system (Alam \& Habib, 2018; Allahviranloo \& Chow, 2019; Bischoff \& Maciejewski, 2016; Chen et al., 2016; Childress et al., 2015; Dia \& Javanshour, 2017; Fagnant \& Kockelman, 2014, 2018; Fournier et al., 2017; Hadian et al., 2017; Jäger et al., 2017; Moreno et al., 2018; Zhao \& Kockelman, 2018). Gurumurthy \& Kockelman (2018) explore two types of dynamic ride-sharing system namely (i) OriginDestination (O-D) dynamic ride-sharing and (ii) dynamic ride-sharing en-route. In case of the former, travellers sharing the same origin and destination are matched in a common ride, while in the latter case, travellers having different origin and destination may share the ride. In mixed systems, the customers are allowed to choose between using the car alone or share with other customers (Zhang et al., 2015; Cyganski 
et al., 2018; Lokhandwala \& Cai, 2018).

With regards to the integration type, independent systems enable the service to be available as an independent mode (without connection to any other mode). Independent systems can be further divided into two, based on who owns the vehicles. Systems similar to current mobility-on-demand (MOD) service providers (like Uber \& Lyft) fall into one category (Alam \& Habib, 2018; Bauer et al., 2018; Bischoff \& Maciejewski, 2016; Bischoff et al., 2017; Bösch et al., 2016; Bösch et al., 2018a; Brownell \& Kornhauser, 2014; Chen et al., 2016; Childress et al., 2015; Dia \& Javanshour, 2017; Fagnant \& Kockelman, 2014, 2018; Gelauff et al., 2017; Hörl, 2017; Jäger et al., 2017; Kondor et al., 2018; Liu et al., 2017; Loeb et al., 2018; ( 2018; Zhang et al., 2015; Zhang \& Guhathakurta, 2018; Zhao \& Kockelman, 2018), while the other category is a fractionally owned system, wherein e.g. a group of households share an autonomous vehicle (e.g., Allahviranloo \& Chow, 2019; Masoud \& Jayakrishnan, 2017). In integrated systems, the SAV services act as complimentary to existing PT for first and last mile service and may replace PT operation in certain 165 areas of low demand (Moorthy et al., 2017; Salazar et al., 2018; Shen et al., 2018; Pinto et al., 2019). Special cases include SAV services inside university campuses and industries (Kim et al., 2017; Miller \& How, 2017; Pimenta et al., 2017).

Földes \& Csiszar (2018) identify four SAV service types, namely: taxi, shared taxi, feeder pod and fixed route pod. The first type is equivalent to the independent car-sharing system and the second type is equivalent to the independent ride-sharing system. The latter two types fall under integrated PT-SAV systems. Both third and fourth types serve as feeder systems to a high capacity line (e.g., a metro system). But the feeder pod system enables flexible boarding points, while in case of fixed route pod systems, the boarding point is fixed. The study of Földes \& Csiszar (2018) describes the first three systems as demanddriven, and the last one as demand-responsive. Based on the same study, demand-driven services are provided when a request is registered, similar to a taxi system. A service based on flexible timetable and capacity with a predetermined route is called demand-responsive service.

Hyland \& Mahmassani (2017) present a taxonomy for classifying vehicle fleet management problems and one of the objectives of this study is to identify business models, which will support future research related to autonomous vehicle fleet management. Based on reservation structure, the authors mention three kinds of system, namely short-term rentals, point-to-point service and mixed service. In case of short-term rentals, the users have control over the car for a particular time slot, i.e, can travel anywhere, similar to current car-sharing systems. In case of point-to-point service, the SAVs move the customers between pickup and dropoff points. The mixed service is described as a combination of the above two. With regards to pricing structure, SAV services can be differentiated as service with fixed or dynamic pricing structure. As the name implies, fixed pricing structure involves charging customers based on mileage or travel time and in the latter case, origin-destination based and time-of-day based pricing schemes are implemented. Based on reservation time-frame, the authors identified service with immediate requests, service with minimum pre-reservation time and mixed service. The first type is equivalent to the on-demand system and the second type is equivalent to the reservation based system. Mixed systems consist of both.

For the era of SAVs, we propose a common term, autonomous car-sharing system, for the autonomous systems based on both conventional car-sharing and ridehailing systems, since the simulation studies usually use the term 'autonomous car-sharing' for the autonomous ridehailing system. However, based on Hyland \& Mahmassani (2017), we propose the following differentiation: short-term car-sharing and point-to-point car-sharing. The autonomous car-sharing system discussed throughout this review paper corresponds to the latter type. Impact research on the former type is still missing in the literature and the same has been mentioned in Section 7.

With regards to business models, Stocker \& Shaheen (2018) discuss some plausible scenarios that can be expected in the future. Based on vehicle ownership and network operations, the study mentions six potential business models: i) Business-to-Consumer (B2C) with single owner-operator, ii) B2C with different entities owning and operating, iii) Peer-to-Peer (P2P) with third-party operator, iv) P2P with decentralized operations, v) Hybrid ownership with same entity operating and vi) Hybrid ownership with third-party operator. Based on vehicle capacity, the study also proposes four potential vehicle types, namely i) large vehicles (20+ Pax), ii) mid-sized vehicles (7 to 20 Pax), iii) small vehicles (3 to 7 Pax) and iv) micro vehicles 
(1 or 2 Pax). The study mentions that the profitability of a business model will depend on many factors, including availability of technology, location of the service, vehicle types used and the ownership schemes. Stocker \& Shaheen (2018) conclude that it is possible for single-occupant vehicles to remain dominant and it is also possible for shared rides to become common, provided that the shared ride service becomes more cost-effective, less onerous to users and leads to fewer deviations, because of the efficiency of automation.

\section{Components of SAV modelling}

Transportation system models that include SAVs are inherently complex and a series of components are involved. These components dictate the actual implementation of the evaluation of SAV systems as well as the required assumptions. In most cases, the reviewed studies focus on some of these components, to keep the complexity and the estimation time manageable. The main modelling components, as shown in Figure 2, are the following: a) Demand, b) Fleet, c) Traffic Assignment, d) Vehicle Assignment, e) Vehicle Redistribution, f) Pricing, g) Charging and h) Parking.

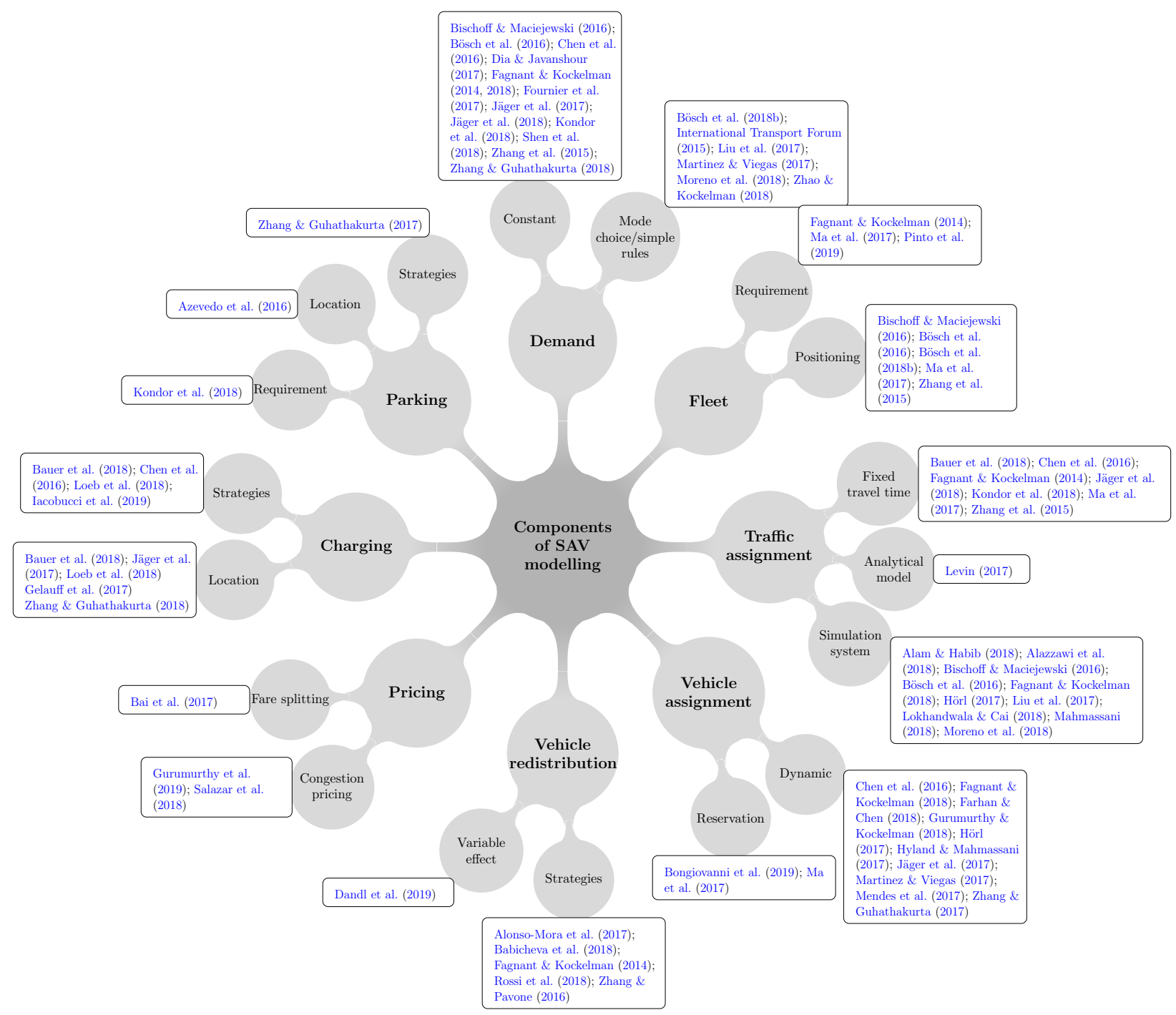

Figure 2: Components of SAV modelling and indicative references 
The component Demand involves estimation of demand in the study area and mode share for SAV services. With regards to the former, trips are generated based on travel survey data (Chen et al., 2016; Dia \& Javanshour, 2017; Fagnant \& Kockelman, 2014, 2018; Martinez \& Viegas, 2017; Zhang et al., 2015), data from existing land-use and transport models (Alam \& Habib, 2018; Bischoff \& Maciejewski, 2016; Bösch et al., 2016; Childress et al., 2015; Gelauff et al., 2017; Jäger et al., 2017; Meyer et al., 2017; Moreno et al., 2018; Zhao \& Kockelman, 2018; Iacobucci et al., 2019), travel records from transit smart card (Shen et al., 2018), cell phone data (Gurumurthy \& Kockelman, 2018; Kondor et al., 2018) or a taxi dataset (Chicago taxi dataset in Hyland \& Mahmassani, 2018 and New York taxi dataset in Alonso-Mora et al., 2017; Bauer et al., 2018; Lokhandwala \& Cai, 2018; Ma et al., 2017; Rossi et al., 2018; Yi et al., 2018; Zhang \& Pavone, 2016. In case exact trip times are not available but only hourly or daily averages (usually the case when using travel survey data), a distribution (e.g. a Poisson distribution) is used to randomly generate trip requests (e.g., Chen et al., 2016; Fagnant \& Kockelman, 2014; Zhang et al., 2015). Many studies assume a constant demand (single or multiple values) for the SAV services from the total trips generated for further analysis and the rest use mode choice models or simple rules to estimate demand. With regards to constant demand, the values assumed range from $1 \%$ to $10 \%$ of the trips made in the service area (Chen et al. (2016) - 10\%, Fagnant \& Kockelman (2014) - 3.5\%, Fagnant \& Kockelman (2018) - 1.3\%, Zhang et al. (2015) - 2\%, Zhang \& Guhathakurta (2018) - 5\%). Few studies assume replacing private car trips (Bischoff \& Maciejewski (2016) and Fournier et al. (2017) - 100\% replacement; Bösch et al. (2016) - 1 to 10\% replacement). Dia \& Javanshour (2017) assume that $25 \%$ of the conventional private car demand will be served by private 235 autonomous vehicle and the remaining $75 \%$ by shared autonomous vehicles. Jäger et al. (2018) consider replacing existing bus system and Shen et al. (2018) consider replacing bus system in low-demand routes.

With regards to the Fleet, studies mainly aim at estimating the required fleet size to serve a given demand and fixing the initial position of the vehicles. Many simulation studies employ a warm up simulation (see Fagnant \& Kockelman (2014) for the method) to determine the fleet size required. Ma et al. (2017) (2019) have formulated a bi-level joint transit network redesign and mobility service fleet size determination problem. The lower level consists of a dynamic combined mode choice-traveler assignment problem and the upper level consists of a modified transit network frequency setting problem with SAV service fleet size as a decision variable. The transit and time-dependent SAV demands from the lower level are used to determine

245 the fleet size for SAV service and to modify transit network frequency, allowing removal of certain transit routes. Assuming a fixed fleet size (single or multiple values) for SAV service is also commonly found in literature (Alam \& Habib, 2018; Lokhandwala \& Cai, 2018; Moreno et al., 2018; Shen et al., 2018). Initial fleet placement can be fixed (Vosooghi et al., 2019), random (Bösch et al., 2016; Zhang et al., 2015), based on the population density (Bischoff \& Maciejewski, 2016; Bösch et al., 2018b) or based on warm-start (Fagnant \& Kockelman, 2014). If depots are present, then the vehicles initially start from the depot (Ma et al., 2017). For a taxonomy on SAV fleet management problems, we recommend reading Hyland \& Mahmassani (2017). The paper describes new taxonomy categories apart from adapting existing categories.

The Traffic Assignment component is used to extract route flows and travel time between origin and destination nodes. In the simple case, fixed travel times between nodes are assumed. Fixed travel time commonly found in the literature is 1) the free flow travel time multiplied by a factor to represent congestion (Jäger et al., 2018), 2) average travel time of off-peak and peak hour (Chen et al., 2016; Fagnant \& Kockelman, 2014; Zhang et al., 2015) and 3) an hour-based value, either extracted from Google Maps (Bauer et al., 2018) or obtained from the transport department of the city where the analysis is carried out (Kondor et al., 2018). Ma et al. (2017) uses the travel time mentioned in the taxi dataset along with a correction factor, when designing a reservation-based system. Dynamic traffic assignment models are closer to reality and can be divided into two categories: simulation-based and analytical models. As the name implies, the former category involves a simulation system, while in the latter, an equilibrium assignment model based on Wardrop's principles is used. For modelling on-demand SAV services, majority of the studies use simulation systems (e.g., Alam \& Habib, 2018; Alazzawi et al., 2018; Bischoff \& Maciejewski, 2016; Bösch et al., 2016; Fagnant \& Kockelman, 2018; Hörl, 2017; Liu et al., 2017; Lokhandwala \& Cai, 2018; Mahmassani, 2018; Moreno et al., 2018). For a list of simulation models being used in the reviewed studies, the readers are referred to Table A1 in the Appendix. Liu et al. (2019) assess the effect of historical 
and real-time traffic information on on-time arrival time ratio (percentage of customers who arrive at their destinations within their specified latest arrival time) and travel time, for an on-demand ride-sharing SAV system. They also examine two different algorithms for finding trip paths, namely reliable and shortest path method. While both mean and variance of travel times are considered for path finding in the former, only the mean is considered in the latter. Results from the study shows that the reliable path algorithm results in a higher on-time arrival ratio than the shortest path algorithm. Similarly, historical traffic information based scenario results in a higher on-time arrival ratio than real-time traffic information based scenario.

275 Furthermore, in the historical traffic information-based scenario, travel time of customers from reliable path algorithm are less than those from shortest path algorithm. As variance is not considered in the shortest path algorithm, an occasionally occurring long travel time can lead to a larger mean travel time. In case of real-time traffic information based scenario, usage of reliable path algorithm results in higher travel time, compared to shortest path algorithm. This is due to the insufficient and imprecise traffic information, causing large variances in link travel times and thereby, leading to inaccurate path finding. Thus, in case of ride-sharing SAV system where detouring can occur, usage of reliable path algorithm based on historical traffic information is beneficial. For reservation-based systems, to the best of authors' knowledge and based on the studies reviewed, only Levin (2017) uses a traffic assignment component by including an analytical model, which is based on dynamic system optimal assignment.

Vehicle Assignment component assigns vehicles to the customers, which can be based on certain rules, heuristics or an optimization algorithm. For modelling dynamic services, a rule-based vehicle assignment method is usually implemented (e.g., Chen et al., 2016; Fagnant \& Kockelman, 2018; Gurumurthy \& Kockelman, 2018; Hörl, 2017; Jäger et al., 2017; Mendes et al., 2017; Zhang \& Guhathakurta, 2017). The most commonly found rule is assigning the nearest vehicle to the request. Realtime optimization models (e.g., Farhan \& Chen, 2018; Martinez \& Viegas, 2017) are seldom used because of their complexity and required computation power. Hyland \& Mahmassani (2018) present and compare six different vehicle assignment strategies for dynamic car-sharing SAV services. The first strategy assigns travellers to the longest idle SAV based on first-come, first-served (FCFS) priority and the second assigns travellers to the nearest idle SAV based on the same priority. While in the first two strategies travellers are assigned sequentially, the third strategy involves simultaneous assignment of travellers. In the third strategy, only unassigned travellers are considered and in the remaining three strategies, both unassigned and assigned travellers are considered when solving the assignment problem. The fourth strategy considers idle and en-route pickup vehicles during vehicle assignment for new requests. In the fifth strategy, idle and en-route drop-off vehicles are considered. Idle, en-route pickup and en-route drop-off vehicles are considered in the last strategy. The study concludes that optimization-based strategies that consider both unassigned and assigned travellers (strategies 4 -6) are more efficient in terms of reducing fleet miles and traveller waiting times. However, this is true only in case of high fleet utilization. Assigning nearest idle SAV is comparable to the complex strategies in case of low fleet utilization. For assigning vehicles to requests in a reservation-based services, formation of SAV chains is generally found in the literature (e.g. Ma et al., 2017). Formulation for SAV chain formation is similar to dial-a-ride problem (DARP) formulation and hence, the algorithms that are used for solving DARP (Braekers et al., 2014; Cordeau, 2006; Cordeau \& Laporte, 2007; Paquette et al., 2013) can be adapted to solve SAV chain formation. It is worth noting that none of the studies reviewed explored a mixed service (combination of dynamic and reservation based services).

Vehicle Redistribution, also referred as "vehicle rebalancing or repositioning", is used to redistribute excess vehicles from low demand areas to high demand areas when modelling on-demand SAV services (Alonso-Mora et al., 2017; Babicheva et al., 2018; Fagnant \& Kockelman, 2014; Rossi et al., 2018; Zhang \& Pavone, 2016). Vosooghi et al. (2019) conclude that redistributing vehicles has a significant effect on service performance, such as modal share and fleet usage. However, empty VMT/VKT increases significantly. We would like to opine here that the extent of change in empty VMT/VKT depends on the algorithm used for redistribution. Alonso-Mora et al. (2017) and Zhang \& Pavone (2016) use a linear program for vehicle redistribution. Fagnant \& Kockelman (2014) explore four different relocation strategies, either individually or in combination, labelled as R1 through R4 with decreasing bound for relocation distance. They found that strategy R1, that allows larger relocation distance, results in lower waiting times for customers. All the relocation strategies resulted in increased vehicle miles travelled. Rossi et al. (2018) propose a congestion-aware 
algorithm that shows good performance in terms of network congestion and customer service times. The algorithm selectively redistributes vehicles through routes that do not increase congestion. Babicheva et al. (2018) evaluate six different methods to apply redistribution and their results show that the combination of simple nearest neighbours and index-based redistribution method provide very promising results. To know the effect of spatial and temporal aggregation of demand forecast which is used for vehicle redistribution, the readers are referred to Dandl et al. (2019). They conclude that higher the spatial disaggregation of demand forecast, better is the fleet performance in terms of user wait time and empty fleet miles, though the demand forecast quality is decreased at higher disaggregation. Having concluded that, they also mention that higher quality demand forecasts, especially at more disaggregate levels, enable better performance of the fleet.

The component Pricing includes estimation of fare of SAV trips based on spatial (customer origin and destination) and temporal parameters (demand levels at different time of the day or based on network congestion). Though the effects of flexible pricing strategies for SAV services are still not much explored (Hyland \& Mahmassani, 2017), use of congestion pricing and strategies for splitting cost between multiple customers in case of ride-sharing are seen in literature. For example, Salazar et al. (2018), to explore the interaction between coordinated SAV services and public transport system, design a congestion pricing scheme to achieve maximum social welfare (system optimality). Another example, Gurumurthy et al. (2019) modelled a system consisting of SAVs with dynamic ride-sharing option and introduced congestion pricing during peak periods. Simoni et al. (2019) tests four different congestion pricing and tolling strategies, grouped into two categories, namely traditional and advanced schemes. Traditional schemes include a link-based (charging on most congested links during peak hour) and a distance-based toll, while advanced schemes include a time-varying link-based toll (dynamic marginal cost pricing scheme at link level) and a travel time-based charge that depends on network conditions. Results from the study show that all the strategies reduce travel demand and delays. In case of traditional schemes, link-based toll performs better than distance-based toll, in terms of travel delay reductions. Further, time-varying link-based toll performs better than the traditional link-based toll. Similarly, travel time-based charge results in better congestion reduction, when compared to the traditional distance-based toll. With regards to strategies for splitting cost between multiple customers, Bai et al. (2017) use the concept of fairness, which is based on envy freeness and maximum utility, to allocate price for different customers sharing the ride. In their scheme, the first passenger onboard can choose to allow boarding of the next passenger in exchange for a reduction of his/her trip cost.

Charging refers to monitoring battery levels of electric vehicles and strategies to charge vehicles (Iacobucci et al., 2018; Iglesias et al., 2018). While the charging vehicles are not allowed to undock and serve a new request in Chen et al. (2016), still-charging vehicles are allowed to serve a new request in Bauer et al. (2018) and Loeb et al. (2018). Iacobucci et al. (2019) propose a methodology to optimize transport service (routing and relocation) and vehicle charging, at two different time scales, using two model-predictive control optimization algorithms. They use electricity price information for optimizing vehicle charging. Jones \& Leibowicz (2019) use an energy optimization model to assess the impact of charging electric SAVs at times that are optimal for the energy system. They show that such a strategy, when SAV services have a high penetration rate (replacing VMT/VKT of private vehicles by $70 \%$ ), provides a greater environmental benefit than the application of carbon tax. With regards to location of charging stations, Jäger et al. (2017) locate charging stations at taxi stands or POIs and Bauer et al. (2018) uses an elimination strategy by initializing charging stations at all possible locations and iteratively removing those locations whose elimination resulted in least impact on the system. Some studies use a warm up simulation to ascertain location of charging stations (see Loeb et al., 2018, for the method).

Finally, the component Parking involves estimating parking requirements and also includes the strategies to park vehicles. Kondor et al. (2018) use a data-driven approach by capping the distance that a SAV can travel to park for estimating parking requirement. Azevedo et al. (2016) use an optimization algorithm (Facility Location problem) to locate parking stations, wherein vehicle charging is also possible. Zhang \& Guhathakurta (2017) minimise cost by routing idle vehicles to low cost parking areas. 


\section{Impacts}

A wide spectrum of research focuses on the identification of impacts that SAVs will bring to transportation. Aiming at providing an overview of the various fields, where impacts are identified, a classification of the relevant studies is provided, as presented in Figure 3.

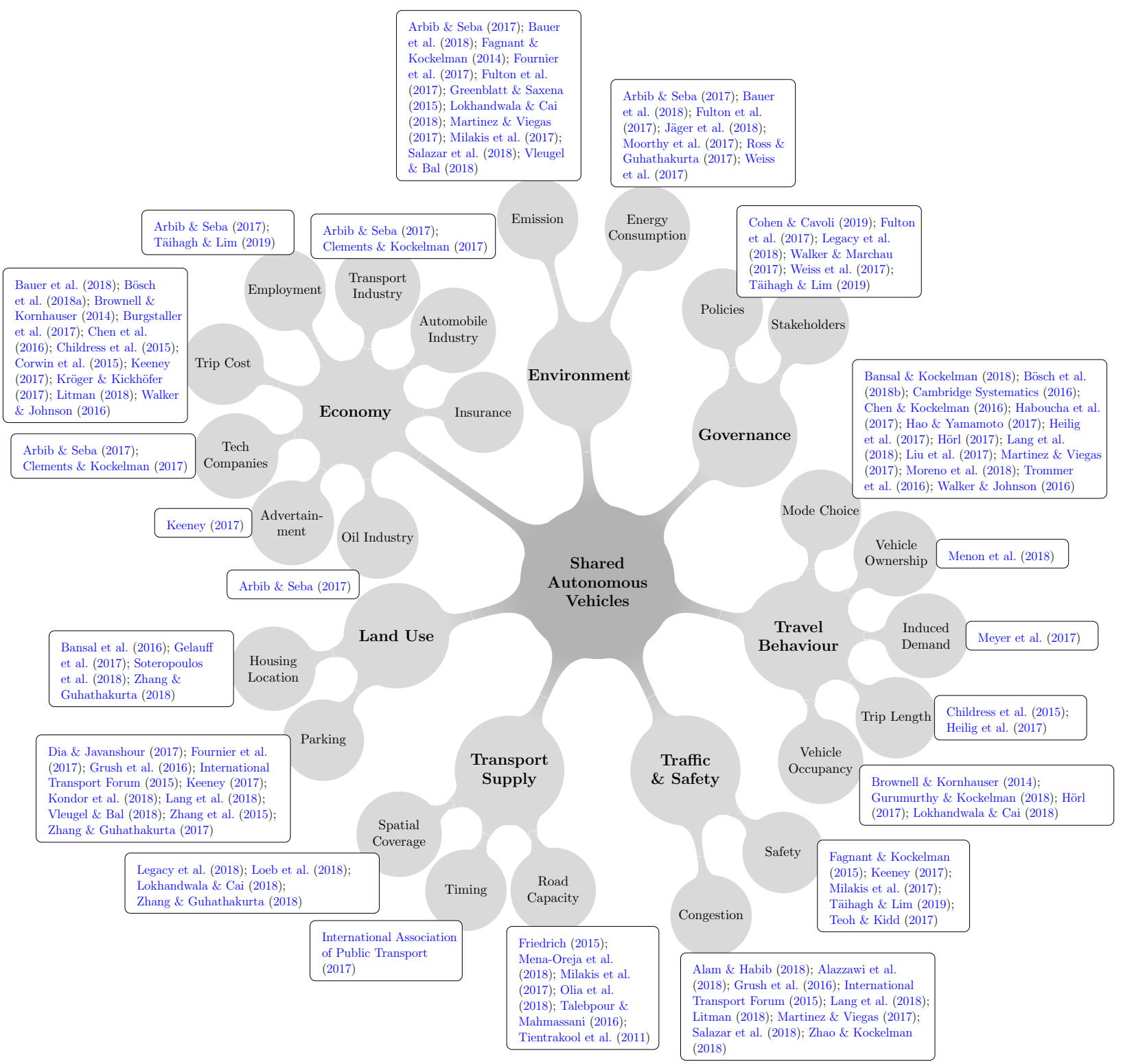

Note: The references for policies and stakeholders are common. Similarly Transport Industry, Automobile industry and Insurance share the same references.

Figure 3: Classification SAV services impacts

A detailed and structured review of the impacts identified in literature is presented in the following paragraphs. Where applicable, the results of this analysis are presented in a tabular form. Of course, the studies examined usually base their analysis on different assumptions, scenarios and methods and hence, it is not appropriate to directly compare the results without taking the context into account. However, 
it is considered beneficial to explore the direction of impact and the range of values that can be expected. Additionally, although SAV services are believed to mainly attract PT users (refer to Section 5.2), the impact of SAV services on PT is not explicitly introduced since the probable impacts are included in subcategories like mode share and transport supply timing. A brief description of all the studies examined in this section is presented in Table A1, which is available in the Appendix. This description includes the modelling approaches, assumptions and place of study.

\subsection{Traffic ES Safety}

Starting from network congestion, as presented in Table 1, the results of the studies examined can be considered rather controversial. On one hand, car-sharing systems are found to increase congestion (Alam \& Habib, 2018; Zhao \& Kockelman, 2018), while on the other hand, ride-sharing systems are found to reduce traffic (Alazzawi et al., 2018; Martinez \& Viegas, 2017). Alazzawi et al. (2018) show that traffic will reduce with at least $50 \%$ mode share for ride-sharing services. Their implementation is based on the use of SUMO for the city of Milan, with an initial demand estimated based on mobile phone data and the matching of passengers to robo-taxis performed using the stable marriage algorithm for unequal sets (McVitie \& Wilson, 1970). We would like to opine here that such a positive impact of ride-sharing depends on many factors, including but not limited to average vehicle occupancy, demand density and pattern, network topology and algorithms used for vehicle assignment and relocation. Salazar et al. (2018) show that car-sharing system, when integrated with PT (integrated PT-SAV system), can reduce traffic. Their approach is based on mesoscopic optimization, with the goal to be the maximization of the welfare (minimizing travelers travel time and operational costs, including congestion effects). Lang et al. (2018) performed a conjoint analysis of mode choice and implemented an agent based simulation framework for the city of Boston, USA. They found that, in urban areas, SAVs will replace both personal car and mass transit, while in suburban areas, they will mainly replace personal car use. Both Lang et al. (2018) and Litman (2018) support that traffic will reduce in the inner city, but increase in suburban areas. This is mainly due to the higher possibility of sharing in inner cities, which is associated with higher demand density. Results from Simoni et al. (2019) show that traffic congestion can be reduced by the application of congestion pricing.

Table 1: Summary of the Traffic \& Safety-related impacts

\begin{tabular}{|c|c|c|}
\hline Variable & Study & Effect \\
\hline Traffic & $\begin{array}{l}\text { International Transport } \text { Forum } \\
(2015) \\
\text { Grush et al. (2016) } \\
\text { Martinez \& Viegas (2017) } \\
\text { Alam \& Habib (2018) } \\
\text { Alazzawi et al. (2018) } \\
\text { Lang et al. (2018) } \\
\text { Litman (2018) } \\
\text { Salazar et al. (2018) } \\
\text { Zhao \& Kockelman (2018) } \\
\text { Simoni et al. (2019) }\end{array}$ & $\begin{array}{l}\text { Local networks: }(+) \\
(+)^{1} \\
(-) \\
\text { Peak hour: First hour }(-) \text { and then next two hours }(+) \\
\text { With at least } 50 \% \text { SAV demand: }(-) \\
\text { Speed: Downtown (PT is mainly replaced): }+5.50 \% \\
\text { Outer (cars are mainly replaced): }-12.10 \% \\
\text { Urban areas: }(-) \\
\text { Suburban and rural areas: }(+) \\
(-)^{2} \\
\text { Average speed: }(-)^{3} \\
(-)^{4}\end{array}$ \\
\hline $\begin{array}{l}\text { Safety } \\
\text { (Accidents) }\end{array}$ & $\begin{array}{l}\text { Fagnant \& Kockelman (2015) } \\
\text { Keeney (2017) } \\
\text { Teoh \& Kidd (2017) }\end{array}$ & $\begin{array}{l}-40 \% \\
-80 \\
(-)\end{array}$ \\
\hline
\end{tabular}

Note: Studies are sorted by year and then alphabetically on authors per each category; (+) indicates increase and (-) indicates decrease; Readers are referred to Table A1 in the Appendix for a description of the studies included in this table.

${ }^{1}$ Mixed traffic (conventional + autonomous); ${ }^{2}$ Integrated PT - SAV services compared with independent SAV services

${ }^{3}$ Combination of private autonomous vehicles and SAVs; ${ }^{4}$ Application of congestion pricing 
In the field of traffic safety (Table 1), Keeney (2017) estimates $80 \%$ reduction in accident rates. The author reaches this conclusion by adjusting the experience from the airline industry, for generally the impact of automation in car traffic. On a more targeted approach, Fagnant \& Kockelman (2015) use the statistics of alcohol consumption, distraction, drug consumption and fatigue, which account for over $40 \%$ of fatal crashes in the USA, suggesting that development of autonomous vehicles can result in at least $40 \%$ reduction in fatal crashes. Though accidents can be reduced to a greater extent, it is not possible to eliminate them completely (Teoh \& Kidd, 2017), as machine errors will persist (Täihagh \& Lim, 2019), leading to the need of new legislative frameworks for the liability (Hayes, 2011). Also, as indicated in Milakis et al. (2017), behavioural adaptation, human-machine interaction and low penetration rates of vehicle automation can compromise the improvements expected in traffic safety.

Autonomous vehicles are also associated with security concerns. Täihagh \& Lim (2019) state that data storage and transmission capabilities of autonomous vehicles may result in privacy risks and the communication networks of autonomous vehicles may be prone to malicious attacks. Petit \& Shladover (2014) explore the security issues related to autonomous vehicles and conclude that the most severe and likely attacks are Global Navigation Satellite Systems (GNSS) spoofing and injection of fake messages. GNSS help positioning vehicles on an accurate map and the data can be manipulated to result in erratic and inaccurate manoeuvres. International Transport Forum (2018) discusses about road safety issues and security vulnerabilities associated with autonomous vehicles and gives recommendations to lessen the issues. Given recommendations include application of Vision Zero thinking to automated driving, uniform safety performance standards for automated driving systems, development and use of a robust safety testing regime, establishment of comprehensive cybersecurity principles for automated driving, functional isolation of safety-critical systems and reporting of and analysis framework for safety-relevant data from automated vehicles.

\subsection{Travel Behaviour}

With regards to trip length, Childress et al. (2015) developed an agent based model to account for SAVs and tested four scenarios for Seattle, USA. A slight increase of trip length is shown, with the exception of a scenario where high cost of service is assumed (decrease of 15\%). Heilig et al. (2017) show an increase in trip length for a pooling-based SAV service, assuming a reduction of cost. On vehicle replacement, which represents the number of conventional vehicles that one SAV can replace, a range of values from 1.17 to 11 is predicted (Table 2). However, by considering dynamic demand and a multimodal network, Vosooghi et al. (2019) conclude that the SAV service is able to reduce at most $1.7 \%$ cars in the network. This shows the distinction between possibility and reality. Thus, although it is difficult to ascertain the exact replacement value, it is asserted that SAV systems have the potential to reduce vehicle ownership, when complemented by strong policies. Based on review of several studies, Milakis et al. (2017) conclude that SAVs can provide equal mobility levels to that of conventional private vehicles and can replace conventional vehicles by $67 \%$ to $90 \%$. Mendes et al. (2017) performed various simulation experiments to test different scenarios for vehicle replacement for light rail. Their results show that 150 to 500 vehicles are needed to replace a 39-vehicle light rail system. Fagnant \& Kockelman (2014) performed a sensitivity analysis of 26 scenarios, using agent based simulation for a synthetic case of a mid-sized city, and the aim was to understand the environmental impacts of SAVs. The result shows a maximum vehicle replacement rate of 10 . Average vehicle occupancy values for SAV services with ride-sharing option are rather consistent in the literature and range between 1.13 to 3. Vosooghi et al. (2019) concludes that 4-seater SAVs are more suitable than 2- and 6-seater SAVs for Rouen Normandie metropolitan area in France. Moderate reduction in the value of time (VOT, in the order of $10 \%$ ) is suggested in Singleton (2018). Singleton (2018) provide a comprehensive discussion of the pertinent studies, asserting that the VOT reduction will be lower than what is anticipated in other studies. Steck et al. (2018) assert that time is valued $10 \%$ less negative than manual driving.

An increase in VMT/VKT is in general expected due to the introduction of SAVs (Table 2) (Alam \& Habib, 2018; Bischoff \& Maciejewski, 2016; Chen et al., 2016; Dia \& Javanshour, 2017; Fagnant \& Kockelman, 2014; International Transport Forum, 2015; Jäger et al., 2017; Kondor et al., 2018; Lang et al., 2018; Moreno et al., 2018; Zhang \& Guhathakurta, 2018), the major reason for this being empty trips. However, Rossi et al. (2018) show that it is possible to route empty vehicles without substantial increase in congestion. Though increase in VMT/VKT is a general trend, Lokhandwala \& Cai (2018) show that, when SAV services with 
Table 2: Summary of the Travel Behaviour-related impacts

\begin{tabular}{|c|c|c|}
\hline Variable & Study & Effect \\
\hline \multirow{4}{*}{$\begin{array}{l}\text { Average } \\
\text { vehicle } \\
\text { occupancy }\end{array}$} & Brownell \& Kornhauser (2014) & 1.17 to 2.16 \\
\hline & Hörl (2017) & 1.13 to 1.6 \\
\hline & Gurumurthy \& Kockelman (2018) & 1.14 to 1.9 \\
\hline & Lokhandwala \& Cai (2018) & 1.2 to $3^{1}$ \\
\hline \multirow[t]{2}{*}{ Trip length } & Childress et al. (2015) & $-15 \%$ to $+14 \%$ \\
\hline & Heilig et al. (2017) & $(+)$ \\
\hline \multirow[t]{20}{*}{ VMT/VKT } & Fagnant \& Kockelman (2014) & $+10 \%$ \\
\hline & Childress et al. (2015) & $-35 \%$ \\
\hline & International Transport Forum (2015) & $+6 \%$ to $+89 \%$ \\
\hline & Bischoff \& Maciejewski (2016) & $(+)$ \\
\hline & Chen et al. (2016) & $+7.1 \%$ to $+14 \%$ \\
\hline & Bischoff et al. (2017) & $-15 \%$ to $-20 \%^{2}$ \\
\hline & Dia \& Javanshour (2017) & $+10 \%$ to $+29 \%$ \\
\hline & Heilig et al. (2017) & $-20 \%$ \\
\hline & Jäger et al. (2017) & $+15.80 \%$ \\
\hline & Masoud \& Jayakrishnan (2017) & $+20 \%$ \\
\hline & Alam \& Habib (2018) & $(+)$ \\
\hline & Fagnant \& Kockelman (2018) & $+4.5 \%$ to $+8.7 \%$ \\
\hline & Jäger et al. (2018) & 10 times more ${ }^{3}$ \\
\hline & Kondor et al. (2018) & $+2 \%$ \\
\hline & Lang et al. (2018) & $+16 \%$ \\
\hline & Lokhandwala \& Cai (2018) & $-18 \%$ to $-45 \%^{1}$ \\
\hline & Moreno et al. (2018) & $+7.40 \%$ \\
\hline & Shen et al. (2018) & $-860 \mathrm{~km}$ (morning peak hour) ${ }^{4}$ \\
\hline & Zhang \& Guhathakurta (2018) & $(+)$ \\
\hline & Zhao \& Kockelman (2018) & $(+)^{5}$ \\
\hline \multirow{17}{*}{$\begin{array}{l}\text { Vehicle } \\
\text { replacement }\end{array}$} & Brownell \& Kornhauser (2014) & 2.72 to 4.75 \\
\hline & Fagnant \& Kockelman (2014) & 10 \\
\hline & International Transport Forum (2015) & 5 to 10 \\
\hline & Pavone (2015) & 1.43 to 3 \\
\hline & Bösch et al. (2016) & 4 to 10 \\
\hline & Chen et al. (2016) & 3.7 to 9 \\
\hline & Zhang \& Pavone (2016) & 1.4 \\
\hline & Dia \& Javanshour (2017) & 1.75 to 8.3 \\
\hline & Heilig et al. (2017) & 6.67 \\
\hline & Levin et al. (2017) & 3.6 \\
\hline & Masoud \& Jayakrishnan (2017) & 9 \\
\hline & Mendes et al. (2017) & $150-500$ vehicles, replace a 39 -vehicle light rail system \\
\hline & Fagnant \& Kockelman (2018) & 8.7 to 10.8 \\
\hline & Gurumurthy \& Kockelman (2018) & 6 to 8 \\
\hline & Lang et al. (2018) & 1.18 \\
\hline & Lokhandwala \& Cai (2018) & 1.93 to 2.451 \\
\hline & Moreno et al. (2018) & 2.5 \\
\hline $\begin{array}{l}\text { Vehicle } \\
\text { ownership }\end{array}$ & Menon et al. (2018) & $\begin{array}{l}18.6 \% \text { are likely and } 7.3 \% \text { are extremely likely to give } \\
\text { up their vehicle ( } 1214 \text { individuals surveyed) }\end{array}$ \\
\hline \multirow{2}{*}{$\begin{array}{l}\text { Value } \\
\text { of Time }\end{array}$} & Singleton (2018) & Modest VOT reductions ${ }^{5}$ \\
\hline & Steck et al. (2018) & $-10 \%$ (private autonomous vehicles $-31 \%)^{6}$ \\
\hline
\end{tabular}

Note: Studies are sorted by year and then alphabetically on authors per each category. Where applicable, green and red text highlights lowest and highest values respectively; (+) indicates increase and (-) indicates decrease; Readers are referred to Table A1 in the Appendix for a description of the studies included in this table.

${ }^{1}$ Conventional taxis compared to ride-sharing SAV; ${ }^{2}$ Autonomous ride-sharing compared to autonomous car-sharing

${ }^{3}$ Comparison with bus fleet; ${ }^{4}$ Integrated PT - SAV system; ${ }^{5}$ Combined results of private autonomous vehicles and SAVs;

${ }^{6}$ Compared to conventional cars 
ride-sharing option replace the current taxi system, there is a reduction in VMT/VKT. Lokhandwala \& Cai (2018) show that usage of conventional vehicles with ride-sharing option reduces VMT/VKT to a greater extent, compared to autonomous vehicles, though the fleet requirement is high. Though the reason is not explicitly discussed in the study, we anticipate that the higher VMT/VKT for autonomous vehicles is due to higher empty travel distance caused by lower fleet utilisation. However, it should be noted that the study is based on New York Taxi data and the pricing structure, induced demand and modal shifts are not considered.

In terms of VMT/VKT, based on literature, it appears that the autonomous ride-sharing is more sustainable than autonomous car-sharing and conventional ride-sharing is more sustainable than autonomous ride-sharing. Bischoff et al. (2017) observe a similar trend and conclude that an autonomous ride-sharing system results in lower VMT/VKT, when compared to an autonomous car-sharing system. Such an advantage of an autonomous ride-sharing system over an autonomous car-sharing system is also concluded in Soteropoulos et al. (2018) and Vosooghi et al. (2019). Heilig et al. (2017) also confirm a similar trend, i.e. reduction in VMT/VKT for an autonomous ride-sharing system; however,the study implements redistribution of vehicles only once during the night. Childress et al. (2015) also find a VMT/VKT reduction, although they did not consider ride-sharing; this is due the assumed comparatively high cost of SAV service $(\$ 1.03 / \mathrm{km})$. Thus, many users shift to transit and walk modes and hence, a reduction in VMT/VKT is seen. Shen et al. (2018) show that an integrated PT-SAV system, wherein the SAV system replaces the PT system in low demand areas, can reduce VMT/VKT.

Change in VMT/VKT and vehicle replacement are the two major impact variables explored in several studies. Figure 4 shows a scatter plot between percentage change in VMT/VKT and vehicle replacement rate. For ride-sharing systems, VMT/VKT decrease at lower vehicle replacement rates and increase at higher rates. On the one hand, there is a decrease in number of trips done due to sharing, resulting in a reduction in VMT/VKT. On the other hand, higher vehicle replacement rates increase the number of empty trips, resulting in greater VMT/VKT. For car-sharing systems, a moderate increase in VMT/VKT is observed, irrespective of vehicle replacement rates. The data corresponding to both SAV systems show that higher vehicle replacement rates are possible with smaller increases in VMT/VKT.

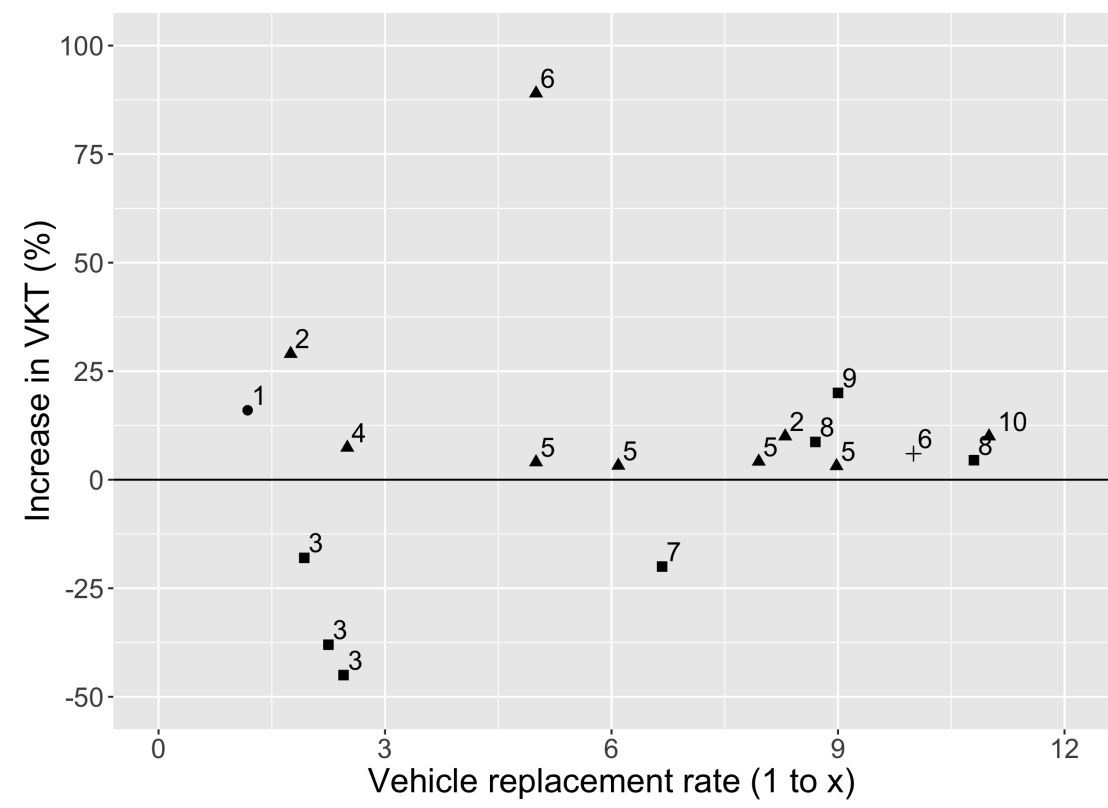

\section{SAV service type:}

- Both Car-sharing \& Ride-sharing

- Car-sharing

- Ride-sharing

+ Ride-sharing integrated with PT

$\begin{array}{cl}\text { Label } & \text { Study } \\ 1 & \text { Lang et al., 2018 } \\ 2 & \text { Dia \& Javanshour, 2017 } \\ 3 & \text { Lokhandwala \& Cai, 2018 } \\ 4 & \text { Moreno at al., 2018 } \\ 5 & \text { Chen et al., 2016 } \\ 6 & \text { ITF, 2015 } \\ 7 & \text { Heilig et al., 2017 } \\ 8 & \text { Fagnant \& Kockelman, 2018 } \\ 9 & \text { Masoud \& Jayakrishnan, 2017 } \\ 10 & \text { Fagnant \& Kockelman, 2014 }\end{array}$

Figure 4: Changes in VMT/VKT from different vehicle replacement as found in the examined literature 


\subsection{Economy}

The cost of SAV services, predicted in the literature (see Table 3), ranges from $\$ 0.11 / \mathrm{km}$ to $\$ 1.03 / \mathrm{km}$, with the range $\$ 0.19 / \mathrm{km}$ to $\$ 0.30 / \mathrm{km}$ being prominent (Bauer et al., 2018; Chen et al., 2016; Corwin et al., 2015; Keeney, 2017; Litman, 2018; Walker \& Marchau, 2017). Litman (2018) provides an overview of costs and predicts that the cost will be between $\$ 0.19 / \mathrm{km}$ and $\$ 0.38 / \mathrm{km}$ for an autonomous micro-transit system (demand responsive transit using vans and minibuses) and $\$ 0.38 / \mathrm{km}$ to $\$ 0.62 / \mathrm{km}$ for an autonomous taxi system. Burgstaller et al. (2017) estimate the cost to be $\$ 0.77 / \mathrm{km}$; this being a conservative reduction from current costs of ride hailing services $(\$ 0.92 / \mathrm{km})$. They believe that savings from the removal of drivers will be substituted by increase in operating costs and additional taxes to compensate loss of taxes from conventional taxi industries. Childress et al. (2015) assume a cost of $\$ 1.03 / \mathrm{km}$, based on the price of Uber services in Seattle in 2014. Brownell \& Kornhauser (2014) predict the cost for a person per day to be $\$ 16.30$ to $\$ 23.50$ for a smart paratransit SAV system, calculated based on the total distance of all trips and the required fleet size. When there is a high penetration of electric SAVs (replacing VMT/VKT of private vehicles by $70 \%$ ) and vehicle charging is optimally scheduled throughout the day, Jones \& Leibowicz (2019) conclude net cost savings, even when carbon tax is imposed, and SAV service results in double the $\mathrm{VMT} / \mathrm{VKT}$ of the replaced VMT/VKT of private vehicles.

Bösch et al. (2018a) conclude that overhead, parking, maintenance and cleaning charges for SAVs, which are neglected in most studies, contribute to two thirds of the total cost of SAV services and considering the full cost, SAVs may not be low enough to replace every known mode. Though a low cleaning frequency and costs are assumed in the study, the cleaning costs contribute in large level (29\%) to the operating cost of SAVs. Further, automated buses are found to be cheaper than SAVs in high demand regions. Grush \& Niles (2018) convey that the cost savings achievable can be overrun by the need for customized services for certain segment of the population (e.g. disabled individuals). Salazar et al. (2018) conclude that an integrated PT-SAV system can substantially reduce transport costs of individuals. Arbib \& Seba (2017) express that the revenue sources from the entertainment and advertising industry can ultimately lead to free SAV services. Savings per family will then amount to more than $\$ 5,600$ per year. Thus, it can be concluded that a SAV service can become cheaper than using a personal vehicle through optimization of cleaning costs, integration of PT and SAV service and profits from entertainment and advertising systems. On the other hand, additional taxes and customized services for certain segment of the population can lead to SAV service being costlier to personal vehicle. The results from Vosooghi et al. (2019) show that a $20 \%$ difference in price between car-sharing SAV system $(\$ 0.56 / \mathrm{km})$ and ride-sharing SAV system $(\$ 0.44 / \mathrm{km})$ can persuade travellers to shift from individual rides to shared rides, leading to improvements in the performance indicators. However, larger differences do not cause proportionate improvements in performance indicators.

Clements \& Kockelman (2017) express that technology firms may be the highest beneficiary of autonomous vehicle development, since they may emerge as providers of entertainment systems and artificial intelligence applications, and may also become significant players in the vehicle-production process (software). Keeney (2017) states a 10\% increase in global public equity markets. Furthermore, they proclaim that introduction of SAVs can add $\$ 28$ billion to the global beverage industry, due to the absence of the need for designated drivers, and $\$ 100$ billion can be added to the entertainment and advertising industry, due to the increased usage of streaming and social media services like Netflix and Facebook. Although some industries will experience a positive impact, Täihagh \& Lim (2019) argue that growth of autonomous vehicles will increase economic inequality, because of employment redistribution of low-skilled workers, e.g. vehicle drivers. Furthermore, Clements \& Kockelman (2017) indicate that development of SAVs can also decrease revenue in auto repair shops, medical industry, insurance companies and legal services.

\subsection{Transport Supply}

An increase in road capacity can be expected due to the introduction of autonomous vehicles, mainly attributed to reduced headways (Friedrich, 2015; Tientrakool et al., 2011). The increase in road capacity is estimated to be between $40 \%$ to $273 \%$ (larger values are due to the efficient communication between the autonomous cars based on Vehicle-to-Vehicle (V2V) technologies combined with decreased headways). Talebpour \& Mahmassani (2016) conclude that the road capacity increases with an increase in penetration 
Table 3: Summary of the Economy-related impacts

\begin{tabular}{|c|c|c|}
\hline Variable & Study & Effect \\
\hline Cost per & Childress et al. (2015) & $1.03^{1}$ \\
\hline Kilometre & Corwin et al. (2015) & 0.19 \\
\hline \multirow[t]{8}{*}{$(\$ / \mathrm{km})$} & Chen et al. (2016) & 0.26 to 0.30 \\
\hline & Walker \& Johnson (2016) & 0.19 \\
\hline & Burgstaller et al. (2017) & 0.77 \\
\hline & Keeney (2017) & 0.22 \\
\hline & Kröger \& Kickhöfer (2017) & 0.45 (car-sharing) \\
\hline & & 0.11 (ride-sharing) \\
\hline & Bauer et al. (2018) & 0.18 to 0.38 \\
\hline & Litman (2018) & 0.19 to 0.62 \\
\hline $\begin{array}{l}\text { Cost per per- } \\
\text { son per day }(\$)\end{array}$ & Brownell \& Kornhauser (2014) & 16.30 to 23.50 \\
\hline \multirow[t]{9}{*}{ Economy } & Arbib \& Seba (2017) & Automobile market: (-) \\
\hline & & Family savings / year: $\$ 5,600$ \\
\hline & Clements \& Kockelman (2017) & Digital media \& technology firms: $(+)$ \\
\hline & & $\begin{array}{l}\text { Auto repair, Medical industry, insurance companies \& } \\
\text { legal services: }(-)\end{array}$ \\
\hline & Keeney (2017) & U.S. GDP: $+\$ 2$ trillion \\
\hline & & Global public equity markets: $+10 \%$ \\
\hline & & Global beverage industry: $+\$ 28$ billion \\
\hline & & Entertainment \& advertising industry: $+\$ 100$ billion \\
\hline & Täihagh \& Lim (2019) & Increase in inequality \\
\hline \multirow[t]{2}{*}{ Revenue } & Burgstaller et al. (2017) & Increase in opportunities \\
\hline & Fagnant \& Kockelman (2018) & $+19 \%$ (profit) \\
\hline
\end{tabular}

Note: Studies are sorted by year and then alphabetically on authors per each category. Where applicable, green and red text highlights lowest and highest values respectively; $(+)$ indicates increase and (-) indicates decrease; Readers are referred to Table A1 in the Appendix for a description of the studies included in this table.

${ }^{1}$ Assumed to be the same as current prices of Uber.

rate for autonomous vehicles. Mena-Oreja et al. (2018) observe a decrease in capacity till a penetration rate of $20 \%$, and an increase thereafter. Olia et al. (2018) find that the road capacity increase for autonomous vehicles without connectivity is low and presence of connectivity results in significant increase in road capacity. Milakis et al. (2017), through their review on automated driving, conclude that a clear positive impact on road capacity can be achieved. While it can be argued that the change in road capacity affects traffic system, and hence, this variable must be added in the other category, we have added it under transport supply since the variable is usually treated as a supply parameter in literature.

SAV services can be made available $24 \times 7$ and, hence, if seen as an extension of Public Transport, can enable provision of services during extended operating hours (International Association of Public Transport, 2017). With regards to spatial coverage of SAV services, Loeb et al. (2018), Lokhandwala \& Cai (2018) and Zhang \& Guhathakurta (2018) conclude that suburban areas will be under-served and the quality of service will be better in urban areas. In all three cases, the conclusions have been based on a combination of agent-based simulation tools.

On accessibility, Meyer et al. (2017) found that most municipalities in Switzerland will experience an increase of accessibility ( $85 \%$ of the cases). For the remaining $15 \%$ of the cases (mostly cities), there will be a substantial loss of accessibility of up to $29 \%$. Meyer et al. (2017) assume different scenarios and examine various values of road capacities. Through the impact they have on congestion and induced demand, changes in accessibility have been evaluated, and the results are in the same direction as in Childress et al. (2015). 
Table 4: Summary of the Transport Supply-related impacts

\begin{tabular}{|c|c|c|}
\hline Variable & Study & Effect \\
\hline Accessibility & Meyer et al. (2017) & $+1.4 \%$ to $+10.3 \%$ \\
\hline \multirow[t]{11}{*}{ Road capacity } & Tientrakool et al. (2011) & $+43 \%$ to $273 \%$ (highway) \\
\hline & Friedrich (2015) & $+40 \%$ (Urban) \\
\hline & & $+80 \%$ (Highway) \\
\hline & Talebpour \& Mahmassani (2016) & $\begin{array}{l}(+) \text {, with increase in penetration rate for autonomous } \\
\text { vehicles }\end{array}$ \\
\hline & Mena-Oreja et al. (2018) & $(-)$, till penetration rate of $20 \%$ \\
\hline & & $(+)$ for penetration rate above $20 \%$ \\
\hline & & $+9.39 \%$ to $+39.21 \%$ at $100 \%$ penetration rate \\
\hline & Olia et al. (2018) & $2,046 \mathrm{veh} / \mathrm{h} /$ lane at zero penetration rate to 6,450 \\
\hline & & $\begin{array}{l}\text { veh } / \mathrm{h} / \text { lane at } 100 \% \text { penetration rate for connected au- } \\
\text { tonomous vehicles }\end{array}$ \\
\hline & & In case of autonomous vehicles without connectivity, very \\
\hline & & little capacity improvement $(\leq 2,238 \mathrm{veh} / \mathrm{h} /$ lane $)$ \\
\hline \multirow[t]{4}{*}{$\begin{array}{l}\text { Spatial } \\
\text { coverage }\end{array}$} & Legacy et al. (2018) & $\begin{array}{l}\text { Certain areas will be under-serviced if not strongly } \\
\text { regulated }\end{array}$ \\
\hline & Loeb et al. (2018) & Urban areas served better \\
\hline & Lokhandwala \& Cai (2018) & Suburban areas under-served ${ }^{1}$ \\
\hline & Zhang \& Guhathakurta (2018) & Urban areas served better compared to suburbs \\
\hline
\end{tabular}

Note: Studies are sorted by year and then alphabetically on authors per each category. (+) indicates increase and

(-) indicates decrease; Readers are referred to Table A1 in the Appendix for a description of the studies included in this table.

${ }^{1}$ Conventional taxis compared to SAVs with ride-sharing

\subsection{Land use}

In majority of the studies that focus on parking-related aspects of land use (Table 5), a substantial reduction in parking space requirements is concluded (Dia \& Javanshour, 2017; Fournier et al., 2017; International Transport Forum, 2015; Keeney, 2017; Kondor et al., 2018; Lang et al., 2018; Vleugel \& Bal, 2018; Zhang et al., 2015; Zhang \& Guhathakurta, 2017). Zhang et al. (2015) conclude that the reduction can reach up to $90 \%$. Their analysis allowed empty vehicle cruising for parking in a distant location without accounting for parking prices. Based on two simulated scenarios (passenger waiting time of 0 and up to 5 minutes) for Melbourne (Australia), Dia \& Javanshour (2017) estimate a reduction of up to 83\%. Also using simulation-based methods, Zhang \& Guhathakurta (2017) suggest a reduction of $4.5 \%$ for a penetration of $5 \%$, mentioning that each SAV can free more than 20 parking spots. On a different note, Grush et al. (2016) expect that parking demand will increase in the next three decades, because of mixed traffic (non-, semiand fully autonomous vehicles) and increased car usage.

With regards to housing locations, Gelauff et al. (2017) and Soteropoulos et al. (2018) indicate that introduction of SAV services will result in urbanisation. Soteropoulos et al. (2018), however, warns that the studies usually differentiate only between urban and suburban areas and the result can be because of this simplification. Nevertheless, Zhang \& Guhathakurta (2018) conducted an analysis at a more detailed level, by combining a SAV simulation model with a residential location choice model, and conclude that introduction of SAV services will not result in unfettered sprawl. Further, they show that elder generations may move slightly closer to the city centre. Although younger generations may move a little away from the city centre, they will stay within 25 miles from the city centre. Bansal et al. (2016) conclude that larger households and individuals with bachelor's degrees or higher will move away from the downtown and full-time working males, tech-savvy and higher income individuals will move closer to the downtown. 
Table 5: Summary of the Land-Use-related impacts

\begin{tabular}{|c|c|c|}
\hline Variable & Study & Effect \\
\hline \multirow[t]{11}{*}{ Parking } & $\begin{array}{l}\text { International Transport Forum } \\
(2015)\end{array}$ & On-street: $-20 \%$ \\
\hline & & Off-street: $-80 \%$ \\
\hline & Zhang et al. (2015) & $-90 \%$ \\
\hline & Grush et al. (2016) & $(+)^{1}$ \\
\hline & Dia \& Javanshour (2017) & $-58 \%$ to $-83 \%$ (on-street) \\
\hline & Fournier et al. (2017) & $(-)$ \\
\hline & Keeney (2017) & -250 million spaces (USA) \\
\hline & Zhang \& Guhathakurta (2017) & $-4.5 \%$ (for $5 \%$ penetration) \\
\hline & Kondor et al. (2018) & $-50 \%$ \\
\hline & Lang et al. (2018) & $-48 \%$ \\
\hline & Vleugel \& Bal (2018) & $-50 \%$ \\
\hline \multirow{6}{*}{$\begin{array}{l}\text { Residential } \\
\text { Location } \\
\text { Choice }\end{array}$} & Bansal et al. (2016) & $\begin{array}{l}\text { A) Larger households and Individuals with Bachelor's de- } \\
\text { grees or higher - move away from central Austin }\end{array}$ \\
\hline & & $\begin{array}{l}\text { B) Full-time working, tech-savvy and higher income peo- } \\
\text { ple - move closer to central Austin }\end{array}$ \\
\hline & Gelauff et al. (2017) & Urbanisation \\
\hline & Zhang \& Guhathakurta (2018) & A) No chaotic sprawl \\
\hline & & B) Elder - move slightly closer to the CBD \\
\hline & & C) Younger - move out, within 25 miles from CBD \\
\hline
\end{tabular}

Note: Studies are sorted by year and then alphabetically on authors per each category. Where applicable, green and red text highlights lowest and highest values respectively; $(+)$ indicates increase and (-) indicates decrease; Readers are referred to Table A1 in the Appendix for a description of the studies included in this table.

${ }^{1}$ Mixed traffic (conventional + autonomous)

\subsection{Environment}

Results related to energy consumption are mainly connected to the anticipated use of Electric Vehicles (EV) in SAV services, and show a decrease in consumption (Arbib \& Seba, 2017; Bauer et al., 2018; Fagnant \& Kockelman, 2018; Fulton et al., 2017; Jäger et al., 2018; Moorthy et al., 2017; Ross \& Guhathakurta, 2017). Bauer et al. (2018) state that, unless there is a dramatic drop in oil prices or conventional car prices, electric vehicles will become cheaper. In an exploration of different scenarios, Fulton et al. (2017) conclude that the decrease of energy consumption will only be present with an electric fleet and if the vehicles are conventionally powered, then any improvements in efficiency will be compensated by the increase in $\mathrm{VMT} / \mathrm{VKT}$ that shared autonomous systems will bring.

Studies related to emissions show that emissions will be significantly reduced, especially with the application of electric vehicles (Arbib \& Seba, 2017; Bauer et al., 2018; Fagnant \& Kockelman, 2014; Fournier et al., 2017; Fulton et al., 2017; Greenblatt \& Saxena, 2015; Lokhandwala \& Cai, 2018; Martinez \& Viegas, 2017; Salazar et al., 2018; Vleugel \& Bal, 2018). A common observation from most of these studies is that the emission reduction majorly depends on application of efficient electric vehicles in SAV services. However, shifting of source of power generation from fossil fuels to renewable energy is a necessity. Lokhandwala \& Cai (2018) show that emission reduction is dependent on ride-sharing participation. Furthermore, Salazar et al. (2018) conclude that integrating SAV services with public transport will result in reduced emission, along with reduction in traffic and transport cost. Jones \& Leibowicz (2019) conclude a reduction in emissions, when electric SAVs replace VMT/VKT of private vehicles by $70 \%$, although VMT/VKT is doubled. There is a further reduction in emissions, when the vehicle charging is optimally scheduled. They also conclude that incentivizing fleet operators to charge their SAVs during those times that are optimal for the energy system is a more important environmental policy, than implementing carbon tax. They state that imposing demand charges will suppress fleet operators from drawing significant instantaneous power from the grid at unfavourable times with high GHG emissions. Penetration rate of electric SAVs and their geographic 
distribution will determine the charging profile required and affect the electricity load distribution across the day (Weiss et al., 2017). According to Milakis et al. (2017), lower emissions and fuel savings are expected in short term, while, the impacts are uncertain in the long term.

Table 6: Summary of the Environment-related impacts

\begin{tabular}{lll}
\hline Variable & Study & Effect \\
\hline Energy & Arbib \& Seba (2017) & $-80 \%$ \\
Consumption & Fulton et al. (2017) & $-70 \%$ \\
& Moorthy et al. (2017) & $-37 \%$ \\
& Ross \& Guhathakurta (2017) & $(-)$ \\
& Bauer et al. (2018) & $-58 \%$ \\
& Jäger et al. (2018) & $-56 \%$ \\
\hline Emissions & Fagnant \& Kockelman (2014) & $(-)$ \\
& Greenblatt \& Saxena (2015) & $-87 \%$ to $-94 \%$ (per km) \\
& Arbib \& Seba (2017) & $-90 \%$ \\
& Fournier et al. (2017) & $-10 \%$ to $-35 \%$ \\
& Fulton et al. (2017) & $-80 \%$ \\
& Martinez \& Viegas (2017) & $-40 \%$ \\
& Bauer et al. (2018) & $-73 \%$ \\
& Lokhandwala \& Cai (2018) & -725 metric tonnes per day ${ }^{2}$ \\
& Salazar et al. (2018) & $(-)^{3}$ \\
& Vleugel \& Bal (2018) & $(-)$ \\
& Jones \& Leibowicz (2019) & $(-)^{4}$ \\
\hline
\end{tabular}

Note: Studies are sorted by year and then alphabetically on authors per each category. Where applicable, green and red text highlights lowest and highest values respectively; $(+)$ indicates increase and (-) indicates decrease; Readers are referred to Table A1 in the Appendix for a description of the studies included in this table.

${ }^{1}$ Comparison with bus fleet; ${ }^{2}$ Conventional taxis compared to SAVs with ride-sharing; ${ }^{3}$ Integrated PT - SAV services compared with independent SAV services; ${ }^{4} \mathrm{SAV}$ s replacing VMT/VKT of private vehicles by $70 \%$

\subsection{Governance}

Legacy et al. (2018) expect merging of private and public transportation. Further, the role of public transport authorities will change from owning and managing the transportation assets to managing SAV service providers to ensure equitable and sustainable transport service and also to curtail the possible vested interests of corporations. Fulton et al. (2017) and Grush \& Niles (2018) also express a similar train of thought, and put emphasis on regulatory controls to direct the growth towards sustainability. All these will result in new stakeholders entering the mobility market and new forms of cooperation will thus emerge (Weiss et al., 2017). Apart from the formation of new forms of cooperation, apportioning liability and insurance risks between different parties involved in autonomous vehicle designs call for a new legal framework (Täihagh \& Lim, 2019).

From the above, it can be understood that SAVs integrated with public transport systems, instead of being implemented as an alternative to public transports, is a more sustainable paradigm and several studies recommend this route (Bösch et al., 2018b; International Association of Public Transport, 2017; Fraedrich et al., 2018; Salazar et al., 2018). Although conventional taxi systems do not account for a large mode share, pertinent research anticipates that replacing the current taxi system with integrated PT-SAV system will be more efficient. Currie (2018) explains why public transportation systems need to be promoted and concludes that public transport fusion (adoption and integration of best features of different modes into public transport modes and services) is a better solution for the future. Furthermore, new forms of cooperation between private operators and government bodies are required, along with regulatory measures to support shared services and at the same time to control the vested interests of corporations. When the above aspects are taken into account, the introduction of SAVs can potentially lead to a better transportation system. 


\section{SAV Demand: Penetration, Acceptance and Mode Choice}

Estimating the impact of SAVs is related to the estimation of the actual demand that SAVs will attract. However, predicting the demand for SAVs involves uncertainty. Methods that are used to estimate the demand for SAV services include (i) Technology adoption S-curves (Trommer et al., 2016; Walker \& Johnson, 2016), (ii) Disruption framework (Arbib \& Seba, 2017) and (iii) Stated preference surveys. Technology adoption S-curves denote the life cycle of technological adoption and technological diffusion, while disruption framework is a technology adoption framework that considers several technologies and innovations converging together to cause a substantial disruption. In the third method, researchers conduct stated preference surveys and predict the demand either descriptively from the surveyed data (Bansal et al., 2016; Bansal \& Kockelman, 2018; Krueger et al., 2016; Haboucha et al., 2017; Pakusch et al., 2018; Nazari et al., 2018; Zmud

${ }_{630} \&$ Sener, 2017), or by using the data as an input to a discrete choice model, which is part of a simulation system (Moreno et al., 2018). The addition of an SAV mode into an existing simulation system to predict demand without any new survey data is also found in literature (Liu et al., 2017; Heilig et al., 2017). For a summary of the studies considered in this section, the readers are referred to Table A1, available in the Appendix.

\subsection{SAV Penetration}

Most of the reviewed studies converge to penetration rates, in terms of trips performed using SAV services in the near future, much lower than $100 \%$. The only study that gives a value closer to $100 \%$ penetration rate is Arbib \& Seba (2017) and the study concludes that 95\% of the passenger miles (considered here as proxy to SAV penetration rate) travelled in USA will be in a SAV by 2030. In fact, Bösch et al. (2018a)

${ }_{640}$ and Pakusch et al. (2018) affirm that private cars will continue to exist. Although Pettigrew et al. (2019) conclude high interest for SAVs in Australia, 29\% of the survey participants are found to be non-adopters of any kind of autonomous vehicle. Based on consumer adoption rules and using a market dissemination model called ECAN (Exclusivity, Choice, Access and Need), Grush \& Niles (2018) affirm the dominance of private vehicles for next 30 years. Urban transit professionals deem large vehicles on regular schedules and routes that cover a majority of its residents as efficient (urban operational efficiency), while urban commuters and travelers perceive efficiency in terms of getting from point-to-point quickly and comfortably (personal efficiency). This conflict causes a rationality gap, which creates a barrier in giving up vehicle ownership and using public transport and shared services. Watkins (2018) states that loss aversion will be a reason hindering the individuals from giving up their personal car(s). Menon et al. (2018) have found that 27.5\% of the 1214 respondents surveyed are extremely unlikely and $26.7 \%$ are unlikely to relinquish their personal vehicle. Despite the finding that $61 \%$ of the respondents prefer ride-sharing SAVs over private autonomous vehicles, Stoiber et al. (2019) conclude that shedding a personal car is harder to induce. Webb et al. (2019) estimate that $40 \%$ of the people are willing to use SAVs for $80 \%$ of their trips and $44 \%$ are willing to use for $50 \%$ of their trips. But, remaining $16 \%$ will continue to use their private vehicle for all their trips. Haboucha et al. (2017) show that 100\% penetration rate of SAV service may not be achieved, even if the service is offered for free. Based on the range of values observed in the literature (Figure 5), we expect that the mode share of SAV services will be less than $50 \%$ in the next 10-15 years.

The authors would like to note that the development of a shared autonomous mobility service still requires a wide variety of developments, ranging from data security and road safety measures to vehicle and mobility service system design. Pendleton et al. (2017) review the development of autonomous vehicle software systems and conclude that there are still issues to be solved to enhance the driving capabilities of autonomous vehicles. Schatzinger et al. (2018) assert that shared autonomous mobility services are least likely to be implemented anytime soon because of the technical and social complexities associated with autonomous technology.

\subsection{Effect of SAV service on mode choice behaviour of people}

A common observation found in the literature is that SAV services will mainly attract users of sustainable modes of transport, i.e., PT, walking and bicycling (Bösch et al., 2018b; Cyganski et al., 2018; Pakusch et al., 2018; Soteropoulos et al., 2018). Lang et al. (2018) conclude that both public transport and personal car 


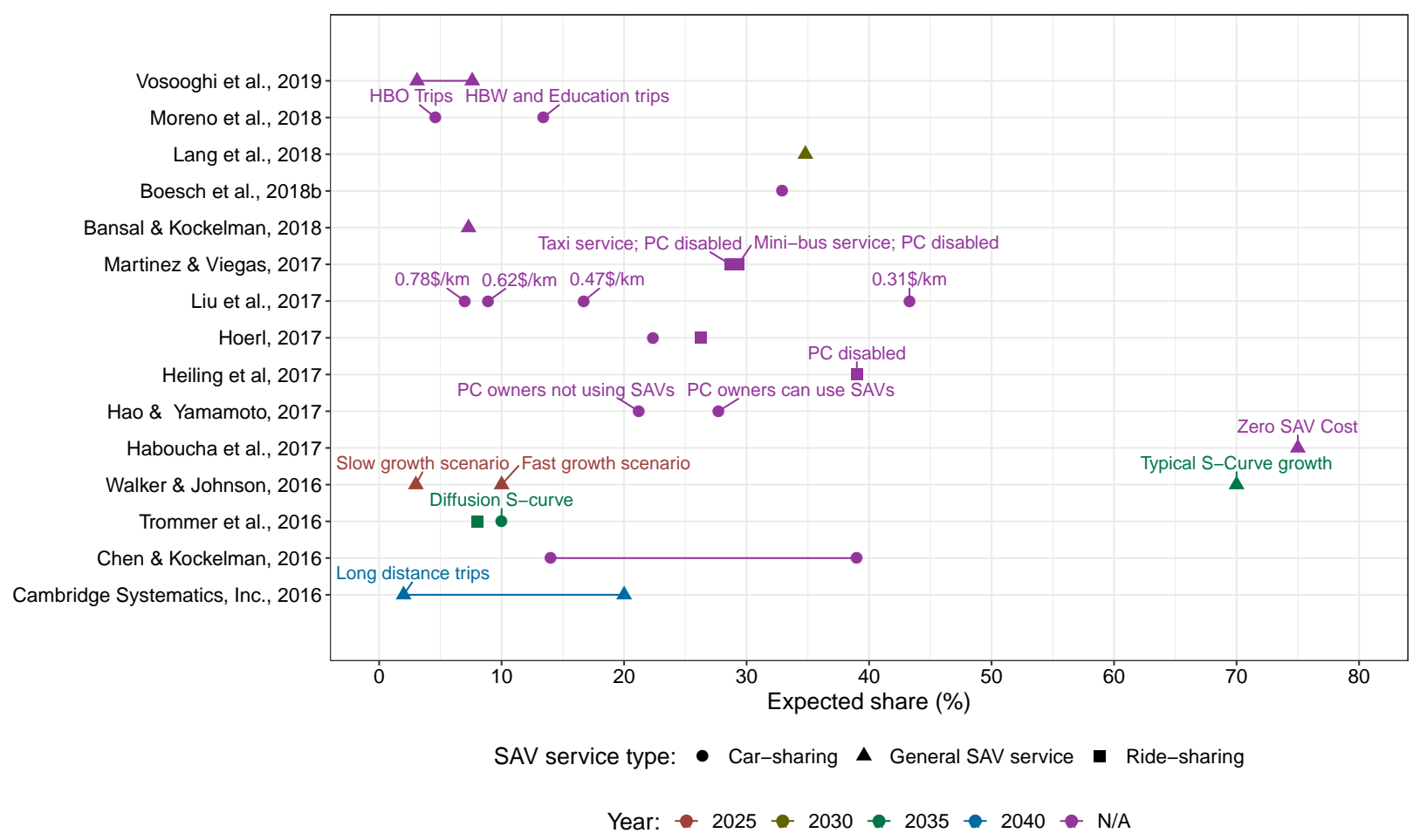

Figure 5: Expected demand for SAV services from different studies. Straight lines represent intervals

usage will be replaced in urban areas. In suburban areas and areas outside the city proper, private car usage will be mainly replaced. The conclusions of Liu et al. (2017) also support this, who state that SAVs will be preferred over conventional private cars in rural areas at lower fares ( $\$ 0.31$ or $\$ 0.47$ per $\mathrm{km}$ compared to $\$ 0.62$ and $\$ 0.78$ per $\mathrm{km}$ ). In a situation wherein private car usage is disabled, Heilig et al. (2017) have found that the majority of car users will switch to SAV services (and not PT or other modes). Users who did short trips, less than two kilometres, formerly in cars shifted to walking and bicycling. Some previous car users shifted to PT.

Haboucha et al. (2017) suggest that younger people, students and more educated citizens will be the early adopters, while another study, Arbib \& Seba (2017), suggest that very rich, tech-laggards and people from highly rural areas will be non-adopters. Bansal et al. (2016) predict that the frequent users of SAV services will be high income tech-savvy males, individuals living in urban areas and densely populated neighbourhoods and individuals having greater crash experience. Non-frequent users will be licensed drivers and older persons. Krueger et al. (2016) state that multi-modal users are expected to use SAV systems more and users who only use private cars are expected to be reluctant to shift to shared mobility services. PT users are more likely to switch to autonomous car-sharing systems, while current car-sharing users are more likely to switch to an autonomous ride-sharing system. Wang \& Akar (2019) ascertain that public transit riders, current users of car-sharing systems, individuals who have flexible work schedules and urban residents are more likely to use ride-sharing SAVs for commuting. But, individuals residing in neighborhoods with dense public transit services will be less likely to use SAVs for daily commuting. Also, individuals currently commuting alone in their private vehicles will continue to commute alone using their vehicles. Gurumurthy \& Kockelman (2020) conclude that SAVs may become popular for long-distance business travel.

\subsection{Suitability of $S A V$ services}

Bösch et al. (2018a) state that SAVs can serve the demand efficiently, wherever substantial bundling of demand is not possible, i.e. SAVs can be an efficient mode in suburban and rural areas. However, SAV 
services in suburban and rural areas may not be profitable to the operators, when compared to urban areas, and can also result in increased VKT. Where substantial bundling is possible, public transport may be more itable.

Though many positive impacts from autonomous ride-sharing services are expected, Cyganski et al. (2018) observe a lower acceptance for ride-sharing, compared to autonomous taxi-based services in Brunswick (Germany). Lang et al. (2018) make a similar observation for Bostonians (USA). Tachet et al. (2017) propose a simple model to ascertain potential for ride-sharing in any city based on the taxi requests and conclude that the potential for sharing is high, even for low trip density of taxi requests. Although the model is built upon the data of conventional taxis, we believe that the conclusions will also be applicable to autonomous vehicles. The study considers only spatial and temporal aspects and not people's willingness to join such systems. It is in the hands of public authorities to motivate people and increase willingness for ride-sharing.

\subsection{Factors affecting the acceptance of $S A V$ services}

Nazari et al. (2018) conclude that adoption of SAVs may be hindered due to safety concerns, and that policies aimed at reducing such safety concerns will be beneficial. Usage of private autonomous vehicles and SAVs for commuting will be significantly influenced by current commute mode, working schedules and residential location (Wang \& Akar, 2019). Philipsen et al. (2019) identify exact pickup time at the origin and arrival time at the destination as important factors for SAV acceptance, while route of journey and determination of co-passengers have minor importance. Vehicle equipment and entertainment systems (including $\mathrm{Wi}-\mathrm{Fi}$ ) are unimportant. The majority of the users are unwilling to pay extra charges for individualization (ride-sharing to car-sharing). Amanatidis et al. (2018) conclude that users have different expectations for autonomous vehicle user interface, based on whether the vehicle is owned or shared. This shows the different trajectory of development required for private autonomous vehicles and SAVs. Webb et al. (2019) have found cost to be a significant variable for the choice between private conventional vehicle and SAV. In addition, they conclude that providing added information on the benefits of SAVs is persuasive for certain individuals, in particular wealthier, better educated and younger people living close to the downtown. Dowling et al. (2018) explore the socio-material relationship that an individual has with the shared car and how the sharing experience can be disrupted in the presence of an issue. Understanding this will help one to comprehend why and how private users can be shifted to a car-sharing system. Also, it can help to design the car-sharing system in a way attractive to people, which will in turn boost the share of this market. Lee et al. (2019) conclude that the factors, perceived usefulness, self-efficacy, perceived risk and psychological ownership, significantly affect the intention to use autonomous vehicles. Furthermore, psychological ownership affects the intention to use, but not the perceived usefulness of autonomous vehicles.

${ }_{725}$ Thus, encouraging an individual to form a psychological bond with a SAV service may be an effective strategy for promoting shared use of autonomous vehicles. The positive benefit of psychological bond (i.e., psychological ownership), as found out in this study, is in line with the conclusions of Dowling et al. (2018). In case of ride-sharing, the results from Lavieri \& Bhat (2019) show that the users are less sensitive to the presence of strangers for commute trips, when compared to leisure-activity trips. Besides, the extra detour

730 time is a greater barrier than the presence of a stranger. However, this barrier may be overcome by the possibility to use travel time productively.

Becker \& Axhausen (2017) give an overview of variables that affect acceptance of autonomous vehicles (both personal and shared), based on a review of different research works that are published before 2017. The categories identified as influential included socio-demographic variables (gender, age, income and presence of children), attitudinal variables (technology awareness, sensation seeking, passion for driving, acceptance of advanced driving systems and data privacy concerns), variables related to current behaviour (mileage, car-sharing, autonomy level of current vehicle, ownership of premium vehicle, usage of multiple modes and past crash experiences) and trip characteristics (travel in highways and congested areas, population density in the travel area and presence of dedicated autonomous vehicle lanes).

Through their survey on autonomous vehicle adoption, Acheampong \& Cugurullo (2019) have found that the environmental attitudes, collaborative consumption attitudes and pro-technology attitudes correlate positively with each other. They also have found that attainment of higher educational level correlates 
positively with the above mentioned attitudes, but correlates negatively with attitude towards car ownership/use. Furthermore, the results from the study show that the perceived potential benefits of autonomous vehicles are affected by the acceptance of autonomous vehicles by others in the community.

Gkartzonikas \& Gkritza (2019) review survey studies on autonomous vehicles, by categorizing the studies based on study objectives, methodologies employed and study population. The study identified several barriers to autonomous vehicle deployment along with opportunities. Some of the barriers identified include legal, liability and ethical issues, security concerns, data privacy challenges, learning curve to use the vehicle, environmental concerns and lack of control. Opportunities identified include new models of vehicle ownership, new business models, innovative road pricing, demand responsive routing and proactive land-use transportation planning and policy.

\section{Policy and operational framework}

Technological advances in transport will not necessarily positively impact the performance of the transportation system on their own. In many of the policy related papers reviewed, regulation is found to be required in order to make the introduction of autonomous vehicles sustainable (International Association of Public Transport, 2017; Lang et al., 2018; Sprei, 2018). Cohen \& Cavoli (2019) substantiate the necessity for channelising autonomous vehicle development, absence of which may result in socially undesirable outcomes. They discuss the effect of a laissez-faire governance approach (absence of government intervention), when governing autonomous vehicle development. They conclude that the outcomes will be less sustainable with such an approach and an interventionist approach is needed to achieve a more socially desirable outcome. Grush \& Niles (2018) also share this thought.

From a policy makers perspective, the study of Fraedrich et al. (2018) explores the effects of autonomous vehicles (both private and shared) and their compatibility to municipalities' existing objectives. Fraedrich et al. (2018) conclude that autonomous vehicle development has to be steered in a way to complement public transport. Along the same lines, International Association of Public Transport (2017) affirm that it is now the time to create a suitable policy framework for autonomous vehicles and recommend introduction of autonomous vehicles as SAVs in a way reinforcing public transport system and supporting walking and cycling. The study suggests promotion of shared mobility services along with the creation of multimodal 770 mobility platforms. Sprei (2018) concludes that the automation needs to be steered towards sustainability in combination with shared mobility system.

Cohen \& Cavoli (2019) suggests that interventions in planning/land-use, regulation/policy, infrastructure/technology, service provision and economic instruments will be required in the era of (shared) autonomous vehicles for enhancing sustainability. Stoiber et al. (2019) state that push and pull measures on comfort, cost and time are likely to increase the proportion of SAV users. Given the high uncertainty involved, an adjustable policy framework that reacts to new changes during the transition phase will be a necessity (Crute et al., 2018). Walker \& Marchau (2017) propose a Dynamic Adaptive Policymaking (DAP) framework to govern the growth of SAV services and illustrate the policy approach for a hypothetical city. The policy system consists of a design phase and an implementation phase. The design phase includes five steps, namely stage setting, developing a basic policy, increasing the robustness of the basic policy, setting up the monitoring system and preparing the trigger responses. The framework allows for adaptations over time as knowledge about performance and acceptance of the SAV service system evolves. Grush \& Niles (2018) propose a performance-based regulatory system called Harmonization Management System (HMS), which dynamically responds and adapts to changes. The system consists of a jurisdiction demand manager (specifies SAV service performance criteria and metrics), travellers and transportation service providers. It is designed to enable dynamic nudges and aims to create a performance-based public mobility market. The performance metrics are based on maximization of vehicle occupancy, minimization of private vehicles, safeguarding of social equity and leveraging of existing transit, which can be utilised to make fleet operators address the livability and environmental externalizations. While HMS is a government-authorized B2B system, MaaS (Mobility-as-a-Service) is a B2C system. The authors conclude that the two may form a complete digital management system. Following a gradual spatial expansion approach, Grush \& Niles (2018) suggest transit leap in five stages over next three decades to gradually minimise vehicle ownership 
and improve transit growth. The suggestion also aims at preparing the policy makers to move from acquireand-operate model to specify-and-regulate governance for transit provision. The authors recommend usage

of behavioural economics to cautiously nudge mobility supply and demand in desired direction and convey that pricing nudges are preferred over restrictions or outright bans. Behavioural biases that are relevant to nudge for reduced car-ownership include consistency and commitment, choice architecture, endowment effect, framing effect, habit, halo effect, hedonic adaptation, herd behaviour, inertia, loss aversion, prospect theory, regret aversion, social norm, status quo bias, sunk-cost fallacy, experience utility, remembered utility, instant utility, social utility, procedural utility and zero price effect.

On infrastructure, Schlossberg et al. (2018) suggest street redesign strategies for urban arterial roads and residential streets, considering the opportunities that will be available due to the development of autonomous vehicles. Their strategies range from reduction of lane width to removal of certain lanes. The readers are also recommended to refer to Crute et al. (2018) for street redesign strategies. Földes \& Csiszar (2018) emphasize the need for coordination between the operation service centre, traffic control centre, local municipalities and infrastructure operators. They describe two planning functions required for SAV operations, namely preliminary service planning and operative planning. Similarly, Szigeti et al. (2017) propose a functional model and a system architecture for managing demand responsive SAV services. It is to be noted that data sharing is considered an integral part of demand responsive services, establishing the need for architectures that allow handling of sensitive user data (Shaheen et al., 2017). The system architecture proposed in Szigeti et al. (2017) includes six components, namely (i) Smart passenger, (ii) Operational control centre, (iii) Traffic control centre, (iv) Autonomous road vehicle, (v) Smart stop and (vi) Maintenance.

To conclude, by taking into account the emerging partners and the uncertainties involved, the current policy system needs to be adjusted to foster the growth of autonomous vehicles towards sustainability. Several initiatives towards this can be found: Stocker \& Shaheen (2018) summarise the current pilot projects and policies related to SAVs in USA. Bloomberg Philanthropies (2017) provide a comprehensive overview of pilot projects and policy initiatives related to autonomous vehicles, that are started in different cities around the world. The data is continuously updated and includes data of 136 cities as of November 2019. European Commission (2018) gives an overview of the stand of EU commission on the development of autonomous vehicles.

\section{Conclusions and Research Gaps}

Multiple business models currently exist in the domain of shared autonomous mobility and it is still uncertain, which service model will attain popularity. However, it is certain that the emergence of autonomous vehicle technology services are to be taken into account by public authorities to prevent negative effects. The current state-of-the-art methodologies for modelling the operations and impacts of SAVs are developed on the basis of long-existing models, which, due to the lack of realistic indications of operation, are impossible to verify and validate. The majority of studies evaluate SAV services by modifying existing simulation models, which have been used to model existing mobility services such as ride-hailing and car-sharing. Although the validity of these models is debatable, their results mostly point towards similar directions in terms of SAV impacts. Most studies point towards an increase of mobility (VKT, user-groups served) and an increase of efficiency for the transportation system (vehicle replacement and utilization, as well as emission reduction). However, researchers and policy makers need to be aware of the aspects of congestion and equity, which will inevitably arise.

Several authors update their modelling methodology in subsequent years and a presumption is that the value of impact variables may change with more advanced models. But, based on the values in Table 1 - 6, we are not able to identify and conclude significant changes over the years, except for the parking requirements. Concerning parking requirements, comparing studies from 2015 and 2018, one can observe a decrease in potential of SAVs to reduce parking requirements. While the two studies from 2015 use agent-based simulations, three studies from 2018 use different methodologies (one study uses data-driven modology, another uses a model built in MS-Excel and the third uses an agent based simulation). While the agent-based simulation studies from 2015 use assumptions for SAV penetration (fixed values), the agent- 
based simulation study from 2018 use survey data for mode choice. As concluded by Levin et al. (2017) and Vosooghi et al. (2019), usage of more realistic models shows comparatively lower benefits from SAV services.

Many of the benefits of SAVs are dependent on a critical mass for the service. But, the results on demand for SAV services are rather scattered, with the majority of them to be less than $50 \%$ of the current trips performed (in a horizon up to 2040). However, as Vosooghi et al. (2017) state, the current tools used to estimate demand for shared services have limited capabilities. Several components are still missing in simulation systems and the main challenges are data detail, accessibility and reliability, high computational time, calibration and validation. In addition, as Hawkins \& Nurul Habib (2018) conclude, some types of models, such as Integrated Land Use and Transport (ILUT) models, are not capable to adequately model autonomous vehicles. Further, Wang \& Akar (2019) have found out that individuals' interests towards autonomous vehicles are not temporally stable. Hawkins \& Nurul Habib (2018) suggest using stated adaption surveys instead of stated preference surveys, inclusion of cusp effects when forecasting autonomous vehicle usage and inclusion of a specification in the model structure to account for the inter-temporal nature of autonomous vehicle adoption.

Although autonomous vehicles may become a norm in the future, we can safely assume that mixed traffic (non-, semi- and fully autonomous vehicles) is expected to be the reality for at least the next couple of decades. Such a situation can result in only limited improvements in traffic safety. Also, parking demand may continue to increase because of greater vehicle usage (Grush et al., 2016). In addition, a penetration rate of more than $20 \%$ is required to experience an increase in road capacity (Mena-Oreja et al., 2018), and presence of connectivity between the vehicles will significantly improve the road capacity (Olia et al., 2018).

From a policy perspective, autonomous vehicles have to be introduced in shared mobility services. Further, shared mobility services in the form of independent system can induce risk of modal shift from public transport and hence, such services have to be integrated with an efficient public transport system. Ridesharing has to be encouraged and incentivised, and public transport fusion is recommended. Policy makers have to understand the nuances of these and carefully foster the deployment of autonomous vehicles. Also, the capabilities of current modelling and decision support tools need to be improved to enable better planning. Without these, there is a greater risk of unsustainable growth of SAV services or, in the worst case, personal cars continuing to be a dominant transport mode.

Though a vast amount of research is being published every year, a considerable number of research gaps still exist. The actual way that autonomous vehicles (and consequently SAVs) will work is still under investigation, resulting in most studies inevitably basing their analyses on strong assumptions. Most impact studies use demand based on existing travel survey data, data from existing land-use and transport models, travel records from transit smart card or cell phone data. All these demand data correspond to the present day and studies performing impact analysis using demand based on future projections are seldom seen. Future population projections, economic predictions and inputs from other sectors (such as land use changes) can be used in future studies, and collaboration between researchers working on these inputs is worth pursuing.

Furthermore, how individuals will respond to the introduction of autonomous vehicles is yet to be observed. Thus, the current modelling methodologies and the analyses of impacts of SAVs need to include a set of scenarios based on plausible assumptions, e.g. inter-temporal nature of autonomous vehicle adoption. Instead of making assumptions over historical values, field observations from the growing number of pilot projects and test beds can be used to compute parameter values. Additionally, while many studies use agent-based simulation methods for modelling SAVs, many cities still use traditional four-step models, making the adoption of SAV modelling into the city planning impossible. Until agent-based and activity-based models become the norm, an intermediate step that includes the development of interfaces is required to bridge the two modelling techniques and research is needed in this direction.

With regards to SAV operations, regular trips (e.g., commuting trips) and pre-planned trips (e.g., trips to the airport) can be suitable for reservation-based services. Many policy related papers recommend to explore ways to shift private users to SAV services. Reservation-based systems ensure vehicle availability, which can be a factor in increasing preference towards shared mobility services, thereby influencing the mode shift of personal car users to shared operations. In addition, the mix of reservation-based and dynamic operations is believed to prevail at the end. Thus, efforts are required in understanding their impact. It is to be noted 
that, without substantial demand for reservation-based services, the service operators may consider the reservation requests as on-demand requests, and the benefits obtainable will be lower.

From a policy perspective, deployment of SAVs in first and last mile services (integrated PT-SAV system) can contribute to the sustainability of the transportation system. However, the majority of impact studies concentrate on evaluating independent systems. This trend needs to change and focus shall be placed on research pertaining to the integration of PT-SAV systems. This includes studies on both the operational side, as well as aspects of demand, such as acceptance, adoption and satisfaction. Since the first and last mile characteristics vary from city to city across the world, appropriate methods need to be developed to address different challenges.

Changes in the available transport modes will result in a change of supply, in terms of total transport system capacity. Studies suggesting an increase in capacity are based on just automation (e.g., Friedrich, 2015; Mena-Oreja et al., 2018; Olia et al., 2018; Talebpour \& Mahmassani, 2016; Tientrakool et al., 2011). From a system perspective, this increase can be much higher when considering ride-sharing and better utilization of vehicles enabled with the introduction of SAV. However, an exploration of these effects is still missing. Few studies test scenarios in which the communicating capabilities of SAVs are used at intersections for passing the intersection (e.g. Bichiou \& Rakha, 2019), without the use of conventional signals. Although such a system may increase intersection capacity for the autonomous vehicles, it will have negative effects to bicyclists and pedestrians in urban areas, as the automobile traffic may never stop (Crute et al., 2018). If a break in traffic needs to be created to allow bicyclists and pedestrians, then the efficiency of the automobile traffic may be hampered. This calls for special attention and such nuances are not yet been studied in literature. Finally, (shared) autonomous vehicles enable design of roads with narrower lanes, because of their precise movement (Crute et al., 2018). This, in turn, can enable addition of new lanes for automobiles or bicycles and pedestrians. Impacts due to this effect have not yet to been studied.

Though several studies talk about the creation of free space due to an expected reduction in parking space requirements, to the best of our knowledge, no study takes into account the necessity for pick-up and drop-off points in case of SAVs becoming a popular mode. Design of such spaces to optimize flows and the impacts of such spaces are still missing in the literature. It is to be remembered that such zones can also impede bicyclists and pedestrians (Crute et al., 2018).

Hyland \& Mahmassani (2017) point out the lack of research in terms of fleet size elasticity, short-term car-sharing system and dynamic pricing structure. These research gaps are yet to be explored. Milakis et al. (2017) identified non-existence of research on impacts of vehicle automation on economy, social equity and public health. Except the impact on economy, the impacts on social equity and public health are still missing. Review papers like Becker \& Axhausen (2017) and Philipsen et al. (2019) identify various factors that will affect penetration rates for SAVs. But no review studies exist, to the authors' best knowledge, that consolidates the factors that affect each of the impacts of SAVs and the direction of effect. Effects of network topology on the efficiency of SAV services and influence of spatial distribution of requests are yet to be researched. Area based pricing strategies (e.g., different pricing schemes for inner city and outer areas), comparison of effects of single versus multiple operators, application of ride-sharing during peak time and car-sharing during other times, and usage of heterogeneous fleets are some of the other missing research works. Given the impacts in multiple fields and uncertainty of such impacts, application of system dynamics approaches to study the impacts is an option for future research.

Emerging technologies enable digitization of public transportation, which can aid the modal decisions of the public transport users and also improve their experience (Shaheen \& Cohen, 2018). With car automation, advanced technologies may become cheaper and policy decision makers can leverage this to revamp the public transport systems. Future research needs to be steered also towards this direction.

Finally, cities need to start preparing for this new mode of transport, that is coming, in a proactive way. They have to create guidelines and strategies for the changes foreseen, in terms of SAV introduction, and develop required policies in order to ensure sustainability and an equitable transportation system. 


\section{Acknowledgements}

This research has been supported by European Union's Horizon 2020 research and innovation programme under grant agreement No 815069 [project MOMENTUM (Modelling Emerging Transport Solutions for Urban Mobility)], Horizon 2020 Framework COST (European Cooperation in Science and Technology) programme [WISE-ACT project CA16222], and the German Research Foundation - Deutsche Forschungsgemeinschaft (DFG) [Project number 392047120, Research grants in collaboration with China]. We would like to express our sincere gratitude to the three anonymous reviewers, who helped to improve our manuscript substantially.

\section{References}

Acheampong, R. A., \& Cugurullo, F. (2019). Capturing the behavioural determinants behind the adoption of autonomous vehicles: Conceptual frameworks and measurement models to predict public transport, sharing and ownership trends of self-driving cars. Transportation Research Part F: Traffic Psychology and Behaviour, 62, 349-375. doi:10.1016/j.trf. 2019.01.009.

Alam, M. J., \& Habib, M. A. (2018). Investigation of the impacts of shared autonomous vehicle operation in Halifax, Canada, using a dynamic traffic microsimulation model. Procedia Computer Science, 130, 496-503. doi:10.1016/j.procs.2018.04. 066.

Alazzawi, S., Hummel, M., Kordt, P., Sickenberger, T., Wieseotte, C., \& Wohak, O. (2018). Simulating the impact of shared, autonomous vehicles on urban mobility - A case study of Milan. In SUMO 2018 - Simulating Autonomous and Intermodal Transport Systems (pp. 94-110). volume 2. doi:10.29007/2n4h.

Allahviranloo, M., \& Chow, J. Y. (2019). A fractionally owned autonomous vehicle fleet sizing problem with time slot demand substitution effects. Transportation Research Part C: Emerging Technologies, 98, 37-53. doi:10.1016/j.trc.2018.11.006.

Alonso-Mora, J., Samaranayake, S., Wallar, A., Frazzoli, E., \& Rus, D. (2017). On-demand high-capacity ride-sharing via dynamic trip-vehicle assignment. Proceedings of the National Academy of Sciences of the United States of America, 114, 462-467. doi:10.1073/pnas.1611675114.

Amanatidis, T., Langdon, P., \& Clarkson, P. J. (2018). Needs and expectations for fully autonomous vehicle interfaces. In Companion of the 2018 ACM/IEEE International Conference on Human-Robot Interaction (pp. 51-52). New York, USA: Association for Computing Machinery. doi:10.1145/3173386.3177054.

Arbib, J., \& Seba, T. (2017). Rethinking transportation 2020-2030: The disruption of transportation and the collapse of the internal-combustion vehicle and oil industries. URL: https://static1.squarespace.com/static/ 585c3439be65942f022bbf9b/t/591a2e4be6f2e1c13df930c5/1494888038959/RethinkX+Report_051517.pdf.

Azevedo, C. L., Marczuk, K., Raveau, S., Soh, H., Adnan, M., Basak, K., Loganathan, H., Deshmunkh, N., Lee, D.-H., Frazzoli, E., \& Ben-Akiva, M. (2016). Microsimulation of demand and supply of autonomous mobility on demand. Transportation Research Record: Journal of the Transportation Research Board, 2564, 21-30. doi:10.3141/2564-03.

975 Babicheva, T., Burghout, W., Andreasson, I., \& Faul, N. (2018). The matching problem of empty vehicle redistribution in autonomous taxi systems. Procedia Computer Science, 130,119-125. doi:10.1016/j.procs.2018.04.020.

Bai, W., Quan, J., Fu, L., Gan, X., \& Wang, X. (2017). Online fair allocation in autonomous vehicle sharing. In 2018 IEEE Global Communications Conference (GLOBECOM) (pp. 1-6). New York: IEEE. doi:10.1109/GLOCOM.2017.8254671.

Bansal, P., \& Kockelman, K. M. (2018). Are we ready to embrace connected and self-driving vehicles? A case study of Texans. Transportation, 45, 641-675. doi:10.1007/s11116-016-9745-z.

Bansal, P., Kockelman, K. M., \& Singh, A. (2016). Assessing public opinions of and interest in new vehicle technologies: An Austin perspective. Transportation Research Part C: Emerging Technologies, 67, 1-14. doi:10.1016/j.trc.2016.01.019.

Bauer, G. S., Greenblatt, J. B., \& Gerke, B. F. (2018). Cost, energy, and environmental impact of automated electric taxi fleets in Manhattan. Environmental science 83 technology, 52, 4920-4928. doi:10.1021/acs.est.7b04732.

985 Becker, F., \& Axhausen, K. W. (2017). Literature review on surveys investigating the acceptance of automated vehicles. Transportation, 44, 1293-1306. doi:10.1007/s11116-017-9808-9.

Becker, H., Ciari, F., \& Axhausen, K. W. (2016). Comparing car-sharing schemes in Switzerland: User groups and usage patterns. In 16th Swiss Transport Research Conference (STRC 2016). URL: https://www.ethz.ch/content/dam/ethz/ special-interest/baug/ivt/ivt-dam/vpl/reports/1101-1200/ab1155.pdf.

990 Bichiou, Y., \& Rakha, H. A. (2019). Real-time optimal intersection control system for automated/cooperative vehicles. International Journal of Transportation Science and Technology, 8, 1-12. doi:10.1016/j.ijtst.2018.04.003.

Bischoff, J., \& Maciejewski, M. (2016). Autonomous taxicabs in Berlin - a spatiotemporal analysis of service performance. Transportation Research Procedia, 19, 176-186. doi:10.1016/j.trpro.2016.12.078.

Bischoff, J., Maciejewski, M., \& Nagel, K. (2017). City-wide shared taxis: A simulation study in Berlin. In 2017 IEEE 20th International Conference on Intelligent Transportation Systems (ITSC) (pp. 275-280). doi:10.1109/ITSC.2017.8317926.

Bloomberg Philanthropies (2017). Global atlas of autonomous vehicles in cities. URL: https://avsincities.bloomberg.org/.

BMW Group (2016). BMW group, Intel and Mobileye team up to bring fully autonomous driving to streets by 2021. URL: https://www.press.bmwgroup.com/global/article/detail/T0261586EN/ bmw-group-intel-and-mobileye-team-up-to-bring-fully-autonomous-driving-to-streets-by-2021?language=en. 
Bongiovanni, C., Kaspi, M., \& Geroliminis, N. (2019). The electric autonomous dial-a-ride problem. Transportation Research Part B: Methodological, 122, 436-456. URL: http://www.sciencedirect.com/science/article/pii/S0191261517309669. doi:10.1016/j.trb.2019.03.004.

Bösch, P. M., Becker, F., Becker, H., \& Axhausen, K. W. (2018a). Cost-based analysis of autonomous mobility services. Transport Policy, 64, 76-91. doi:10.1016/j.tranpol.2017.09.005.

Bösch, P. M., Ciari, F., \& Axhausen, K. W. (2016). Autonomous vehicle fleet sizes required to serve different levels of demand. Transportation Research Record: Journal of the Transportation Research Board, 2542, 111-119. doi:10.3141/2542-13.

Bösch, P. M., Ciari, F., \& Axhausen, K. W. (2018b). Transport policy optimization with autonomous vehicles. Transportation Research Record: Journal of the Transportation Research Board, 83, 036119811879139. doi:10.1177/0361198118791391.

Braekers, K., Caris, A., \& Janssens, G. K. (2014). Exact and meta-heuristic approach for a general heterogeneous dial-a-ride problem with multiple depots. Transportation Research Part B: Methodological, 67, 166-186. doi:10.1016/j.trb.2014.05. 007.

Brown, T. (2018). The impact of driverless technology on independent driving jobs. URL: https://www.itchronicles.com/ artificial-intelligence/the-impact-of-driverless-technology-on-independent-driving-jobs/.

Brownell, C., \& Kornhauser, A. (2014). A driverless alternative: fleet size and cost requirements for a statewide autonomous taxi network in New Jersey. Transportation Research Record, 2416, 73-81. doi:10.3141/2416-09.

Burgstaller, S., Flowers, D., Tamberrino, D., Terry, H. P., \& Yang, Y. (2017). Rethinking mobility: The pay as you go car: Ride hailing just the start. URL: https://orfe.princeton.edu/ alaink/SmartDrivingCars/PDFs/Rethinking\%20Mobility_ GoldmanSachsMay2017.pdf.

Cambridge Systematics, I. (2016). California high-speed rail business plan ridership and revenue risk analysis. URL: http: //hsr.ca.gov/docs/about/ridership/DR1_2016_CAHSRA_Business_Plan_Risk_Analysis_Documentation.pdf.

Chen, T. D., \& Kockelman, K. M. (2016). Management of a shared autonomous electric vehicle fleet: Implications of pricing schemes. Transportation Research Record: Journal of the Transportation Research Board, 2572, 37-46. doi:10.3141/ 2572-05.

Chen, T. D., Kockelman, K. M., \& Hanna, J. P. (2016). Operations of a shared, autonomous, electric vehicle fleet: Implications of vehicle \& charging infrastructure decisions. Transportation Research Part A: Policy and Practice, 94, 243-254. doi:10. $1016 / j . t r a .2016 .08 .020$.

Childress, S., Nichols, B., Charlton, B., \& Coe, S. (2015). Using an activity-based model to explore the potential impacts of automated vehicles. Transportation Research Record: Journal of the Transportation Research Board, 2493, 99-106. doi:10.3141/2493-11.

Clements, L. M., \& Kockelman, K. M. (2017). Economic effects of automated vehicles. Transportation Research Record, 2606, 106-114. doi:10.3141/2606-14.

Cohen, T., \& Cavoli, C. (2019). Automated vehicles: exploring possible consequences of government (non)intervention for congestion and accessibility. Transport Reviews, 39, 129-151. doi:10.1080/01441647.2018.1524401.

Cordeau, J.-F. (2006). A branch-and-cut algorithm for the dial-a-ride problem. Operations Research, 54, 573-586. doi:10. 1287 /opre.1060.0283.

Cordeau, J.-F., \& Laporte, G. (2007). The dial-a-ride problem: models and algorithms. Annals of Operations Research, 153, 29-46. doi:10.1007/s10479-007-0170-8.

Corwin, S., Vitale, J., Kelly, E., \& Cathles, E. (2015). The future of mobility. how transportation technology and social trends are creating a new business ecosystem. Deloitte LLP,

rute, J., Riggs, W., Chapin, T. S., \& Stevens, L. (2018). Planning for autonomous mobility volume 592 of PAS report. Chicago: American Planning Association. URL: https://www.planning.org/publications/report/9157605/.

Currie, G. (2018). Lies, damned lies, AVs, shared mobility, and urban transit futures. Journal of Public Transportation, 21, 19-30. doi:10.5038/2375-0901.21.1.3.

Cyganski, R., Heinrichs, M., von Schmidt, A., \& Krajzewicz, D. (2018). Simulation of automated transport offers for the city of Brunswick. Procedia Computer Science, 130, 872-879. doi:10.1016/j.procs.2018.04.083.

Daimler AG (2017). Daimler and Uber join forces to bring (a) Daimler-and-Uber-join-forces-to-bring-more-self-driving-vehicles-on-the-road.xhtml?oid=15453638.

Dandl, F., Hyland, M., Bogenberger, K., \& Mahmassani, H. S. (2019). Evaluating the impact of spatio-temporal demand forecast aggregation on the operational performance of shared autonomous mobility fleets. Transportation, . doi:10.1007/ s11116-019-10007-9.

Defense Advanced Research Projects Agency (2014). The DARPA Grand Challenge - ten years later: Autonomous vehicle challenge led to new technologies and invigorated the prize challenge model of promoting innovation. URL: https://www. darpa.mil/news-events/2014-03-13.

Dia, H., \& Javanshour, F. (2017). Autonomous shared mobility-on-demand: Melbourne pilot simulation study. Transportation Research Procedia, 22, 285-296. doi:10.1016/j.trpro.2017.03.035.

Dormehl, L., \& Edelstein, S. (2018). Sit back, relax, and enjoy a ride through the history of self-driving cars. URL: https: //www.digitaltrends.com/cars/history-of-self-driving-cars-milestones/.

Dowling, R., Maalsen, S., \& Kent, J. L. (2018). Sharing as sociomaterial practice: Car sharing and the material reconstitution of automobility. Geoforum, 88,10-16. doi:10.1016/j.geoforum.2017.11.004.

European Commission (2018). On the road to automated mobility: An eu strategy for mobility of the future. URL: https: //ec.europa.eu/transport/sites/transport/files/3rd-mobility-pack/com20180283_en.pdf.

Fagnant, D. J., \& Kockelman, K. (2015). Preparing a nation for autonomous vehicles: opportunities, barriers and policy recommendations. Transportation Research Part A: Policy and Practice, 77, 167-181. doi:10.1016/j.tra.2015.04.003. 
Fagnant, D. J., \& Kockelman, K. M. (2014). The travel and environmental implications of shared autonomous vehicles, using agent-based model scenarios. Transportation Research Part C: Emerging Technologies, 40, 1-13. doi:10.1016/j.trc.2013. 12.001.

Fagnant, D. J., \& Kockelman, K. M. (2018). Dynamic ride-sharing and fleet sizing for a system of shared autonomous vehicles in Austin, Texas. Transportation, 45, 143-158. doi:10.1007/s11116-016-9729-z.

Farhan, J., \& Chen, T. D. (2018). Impact of ridesharing on operational efficiency of shared autonomous electric vehicle fleet. Transportation Research Part C: Emerging Technologies, 93, 310-321. doi:10.1016/j.trc.2018.04.022.

Ferlis, R. A. (2007). The dream of an automated highway. URL: https://www.fhwa.dot.gov/publications/publicroads/ 07july/07.cfm.

Ferrero, F., Perboli, G., Rosano, M., \& Vesco, A. (2018). Car-sharing services: An annotated review. Sustainable Cities and Society, 37, 501-518. doi:10.1016/j.scs.2017.09.020.

Földes, D., \& Csiszar, C. (2018). Framework for planning the mobility service based on autonomous vehicles. In 2018 Smart City Symposium Prague (SCSP) (pp. 1-6). doi:10.1109/SCSP.2018.8402651.

Forrest, A., \& Konca, M. (01/05/2007). Autonomous cars and society. URL: https://web.wpi.edu/Pubs/E-project/ Available/E-project-043007-205701/unrestricted/IQPOVP06B1.pdf.

Fournier, G., Pfeiffer, C., Baumann, M., \& Worner, R. (2017). Individual mobility by shared autonomous electric vehicle fleets: Cost and $\mathrm{CO}_{2}$ comparison with internal combustion engine vehicles in Berlin, Germany. In R. Jardim-Gonçalves (Ed.), 2017 International Conference on Engineering, Technology and Innovation (ICE/ITMC) (pp. 368-376). [Piscataway, New Jersey]: IEEE. doi:10.1109/ICE.2017.8279909.

Fraedrich, E., Heinrichs, D., Bahamonde-Birke, F. J., \& Cyganski, R. (2018). Autonomous driving, the built environment and policy implications. Transportation Research Part A: Policy and Practice, . doi:10.1016/j.tra.2018.02.018.

Friedrich, B. (2015). Verkehrliche wirkung autonomer fahrzeuge. In M. Maurer, J. C. Gerdes, B. Lenz, \& H. Winner (Eds.), Autonomes Fahren: Technische, rechtliche und gesellschaftliche Aspekte (pp. 331-350). Berlin, Heidelberg: Springer Berlin Heidelberg. doi:10.1007/978-3-662-45854-9_16.

Fulton, L., Mason, J., \& Meroux, D. (2017). Three revolutions in urban transportation. URL: https://www.itdp.org/ wp-content/uploads/2017/04/UCD-ITDP-3R-Report-FINAL.pdf.

Gelauff, G., Ossokina, I., \& Teulings, C. (2017). Spatial effects of automated driving: Dispersion, concentration or both? URL: https://www.kimnet.nl/binaries/kimnet/documenten/papers/2017/09/19/ spatial-effects-of-automated-driving-dispersion-concentration-or-both/Spatial+effects+of+automated+ driving+_+dispersion\%2C+concentration+or+both.pdf.

Gkartzonikas, C., \& Gkritza, K. (2019). What have we learned? A review of stated preference and choice studies on autonomous vehicles. Transportation Research Part C: Emerging Technologies, 98, 323-337. URL: http://www.sciencedirect.com/ science/article/pii/S0968090X18303589. doi:10.1016/j.trc.2018.12.003.

Greenblatt, J. B., \& Saxena, S. (2015). Autonomous taxis could greatly reduce greenhouse-gas emissions of US light-duty vehicles. Nature Climate Change, 5, 860-863. doi:10.1038/nclimate2685.

1100 Greenblatt, J. B., \& Shaheen, S. (2015). Automated vehicles, on-demand mobility, and environmental impacts. Current Sustainable/Renewable Energy Reports, 2, 74-81. doi:10.1007/s40518-015-0038-5.

Grush, B., Niles, J., \& Baum, E. (2016). Ontario must prepare for vehicle automation: Automated vehicles can influence urban form, congestion and infrastructure delivery. URL: http://rccao.com/research/files/RCCAO_Vehicle-Automation OCT2016_WEB.pdf.

1105 Grush, B., \& Niles, J. S. (2018). The end of driving: Transportation systems and public policy planning for autonomous vehicles. Amsterdam: Elsevier. URL: https://www.elsevier.com/books/the-end-of-driving/grush/978-0-12-815451-9.

Gurumurthy, K. M., \& Kockelman, K. M. (2018). Analyzing the dynamic ride-sharing potential for shared autonomous vehicle fleets using cellphone data from Orlando, Florida. Computers, Environment and Urban Systems, 71, 177-185. doi:10.1016/j.compenvurbsys.2018.05.008.

1110 Gurumurthy, K. M., \& Kockelman, K. M. (2020). Modeling Americans' autonomous vehicle preferences: A focus on dynamic ride-sharing, privacy \& long-distance mode choices. Technological Forecasting and Social Change, 150, 119792. URL: https://www.sciencedirect.com/science/article/pii/S0040162518316056. doi:10.1016/j.techfore.2019.119792.

Gurumurthy, K. M., Kockelman, K. M., \& Simoni, M. D. (2019). Benefits and costs of ride-sharing in shared automated vehicles across Austin, Texas: Opportunities for congestion pricing. Transportation Research Record: Journal of the Transportation Research Board, (p. 036119811985078). doi:10.1177/0361198119850785.

Haboucha, C. J., Ishaq, R., \& Shiftan, Y. (2017). User preferences regarding autonomous vehicles. Transportation Research Part C: Emerging Technologies, 78, 37-49. doi:10.1016/j.trc.2017.01.010.

Hadian, M., Altuwaiyan, T., \& Liang, X. (2017). Privacy-preserving time-sharing services for autonomous vehicles. In 2017 IEEE 86th Vehicular Technology Conference (VTC-Fall) (pp. 1-5). doi:10.1109/VTCFall.2017.8288280.

Hao, M., \& Yamamoto, T. (2017). Analysis on supply and demand of shared autonomous vehicles considering household vehicle ownership and shared use. In 2017 IEEE 20th International Conference on Intelligent Transportation Systems (ITSC) (pp. 185-190). doi:10.1109/ITSC.2017.8317920.

Hawkins, J., \& Nurul Habib, K. (2018). Integrated models of land use and transportation for the autonomous vehicle revolution. Transport Reviews, 24, 1-18. doi:10.1080/01441647.2018.1449033.

1125 Hayes, B. (2011). Leave the driving to it. American Scientist, 99, 362. doi:10.1511/2011.92.362.

Heilig, M., Hilgert, T., Mallig, N., Kagerbauer, M., \& Vortisch, P. (2017). Potentials of autonomous vehicles in a changing private transportation system - a case study in the Stuttgart region. Transportation Research Procedia, 26, 13-21. doi:10. 1016/j.trpro.2017.07.004.

Hörl, S. (2017). Agent-based simulation of autonomous taxi services with dynamic demand responses. Procedia Computer 
Hyland, M., \& Mahmassani, H. S. (2018). Dynamic autonomous vehicle fleet operations: Optimization-based strategies to assign AVs to immediate traveler demand requests. Transportation Research Part C: Emerging Technologies, 92, $278-297$. doi:10.1016/j.trc.2018.05.003.

Hyland, M. F., \& Mahmassani, H. S. (2017). Taxonomy of shared autonomous vehicle fleet management problems to inform future transportation mobility. Transportation Research Record: Journal of the Transportation Research Board, 2653, 26-34. doi:10.3141/2653-04.

Iacobucci, R., McLellan, B., \& Tezuka, T. (2018). Model predictive control of a shared autonomous electric vehicles system with charge scheduling and electricity price response. In 2018 3rd IEEE International Conference on Intelligent Transportation Engineering (ICITE) (pp. 110-114). IEEE. doi:10.1109/ICITE.2018.8492676.

1140 Iacobucci, R., McLellan, B., \& Tezuka, T. (2019). Optimization of shared autonomous electric vehicles operations with charge scheduling and vehicle-to-grid. Transportation Research Part C: Emerging Technologies, 100, 34-52. URL: http: //www.sciencedirect.com/science/article/pii/S0968090X18309197. doi:10.1016/j.trc.2019.01.011.

Iglesias, R., Rossi, F., Zhang, R., \& Pavone, M. (2018). A BCMP network approach to modeling and controlling autonomous mobility-on-demand systems. The International Journal of Robotics Research, 2, 027836491878033. doi:10. $1177 / 0278364918780335$

International Association of Public Transport (2017). Autonomous vehicles: A potential game changer for urban mobility. URL: https://www.uitp.org/sites/default/files/cck-focus-papers-files/PolicyBrief_Autonomous_Vehicles_ LQ_20160116.pdf.

International Transport Forum (2015). Urban mobility system upgrade: How shared self-driving cars could change city traffic. URL: https://ideas.repec.org/p/oec/itfaac/6-en.html.

International Transport Forum (2018). Safer roads with automated vehicles? URL: https://www.itf-oecd.org/sites/ default/files/docs/safer-roads-automated-vehicles.pdf.

Jäger, B., Agua, F. M. M., \& Lienkamp, M. (2017). Agent-based simulation of a shared, autonomous and electric on-demand mobility solution. In 2017 IEEE International Conference on Intelligent Transportation Systems (ITSC) (pp. 250-255). doi:10.1109/ITSC. 2017.8317947.

Jäger, B., Brickwedde, C., \& Lienkamp, M. (2018). Multi-agent simulation of a demand-responsive transit system operated by autonomous vehicles. Transportation Research Record: Journal of the Transportation Research Board, $77,036119811878664$. doi:10.1177/0361198118786644

Jones, E. C., \& Leibowicz, B. D. (2019). Contributions of shared autonomous vehicles to climate change mitigation. Transportation Research Part D: Transport and Environment, 72, 279-298. URL: http://www.sciencedirect.com/science/article/ pii/S1361920918310861. doi:10.1016/j.trd.2019.05.005.

Keeney, T. (2017). Mobility-as-a-service: Why self-driving cars could change everything. URL: https://research.ark-invest. com/hubfs/1_Download_Files_ARK-Invest/White_Papers/Self-Driving-Cars_ARK-Invest-WP.pdf.

Kim, S.-W., Gwon, G.-P., Hur, W.-S., Hyeon, D., Kim, D.-Y., Kim, S.-H., Kye, D.-K., Lee, S.-H., Lee, S., Shin, M.-O., \& Seo, S.-W. (2017). Autonomous campus mobility services using driverless taxi. IEEE Transactions on Intelligent Transportation Systems, 18, 3513-3526. doi:10.1109/TITS.2017.2739127.

Kondor, D., Zhang, H., Tachet, R., Santi, P., \& Ratti, C. (2018). Estimating savings in parking demand using shared vehicles for home-work commuting. IEEE Transactions on Intelligent Transportation Systems, (pp. 1-10). doi:10.1109/TITS.2018. 2869085 .

1170 Korosec, K. (2018). Ford plans to spend $\$ 4$ billion on autonomous vehicles by 2023. URL: https://techcrunch.com/2018/07/ 24/ford-plans-to-spend-4-billion-on-autonomous-vehicles-by-2023/.

Kröger, L., \& Kickhöfer, B. (2017). Autonomous car- and ride-sharing systems: A simulation-based evaluation of various supply options for different regions. In 2017 ITEA Annual Conference on Transportation Economics. URL: https://elib. dlr.de/117851/.

1175 Krueger, R., Rashidi, T. H., \& Rose, J. M. (2016). Preferences for shared autonomous vehicles. Transportation Research Part C: Emerging Technologies, 69, 343-355. doi:10.1016/j.trc.2016.06.015.

Lamotte, R., de Palma, A., \& Geroliminis, N. (2017). On the use of reservation-based autonomous vehicles for demand management. Transportation Research Part B: Methodological, 99, 205-227. doi:10.1016/j.trb.2017.01.003.

Lang, N. S. L., Ruessmann, M., Collie, B. E., Wegscheider, A. K., Moavenzadeh, J., \& Loane, M. (2018). Reshaping urban mobility with autonomous vehicles: Lessons from the city of Boston. URL: http://www3. weforum.org/docs/WEF_Reshaping_ Urban_Mobility_with_Autonomous_Vehicles_2018.pdf.

Lavieri, P. S., \& Bhat, C. R. (2019). Modeling individuals' willingness to share trips with strangers in an autonomous vehicle future. Transportation Research Part A: Policy and Practice, 124, 242-261. URL: http://www.sciencedirect.com/ science/article/pii/S0965856418309819. doi:10.1016/j.tra.2019.03.009.

LeBeau, P. (2018). Waymo starts commercial ride-share service. waymo-starts-commercial-ride-share-service.html.

Lee, J., Lee, D., Park, Y., Lee, S., \& Ha, T. (2019). Autonomous vehicles can be shared, but a feeling of ownership is important: Examination of the influential factors for intention to use autonomous vehicles. Transportation Research Part C: Emerging Technologies, 107, 411-422. URL: http://www.sciencedirect.com/science/article/pii/s0968090X19301895. doi:10.1016/j.trc.2019.08.020.

Legacy, C., Ashmore, D., Scheurer, J., Stone, J., \& Curtis, C. (2018). Planning the driverless city. Transport Reviews, 75, 1-19. doi:10.1080/01441647.2018.1466835.

Levin, M. W. (2017). Congestion-aware system optimal route choice for shared autonomous vehicles. Transportation Research Part C: Emerging Technologies, 82, 229-247. doi:10.1016/j.trc.2017.06.020. 
Levin, M. W., Kockelman, K. M., Boyles, S. D., \& Li, T. (2017). A general framework for modeling shared autonomous vehicles with dynamic network-loading and dynamic ride-sharing application. Computers, Environment and Urban Systems, 64, 373-383. doi:10.1016/j. compenvurbsys.2017.04.006.

Litman, T. (2018). Autonomous vehicle implementation predictions: Implications for transport planning. Technical Report.

Liu, J., Kockelman, K. M., Boesch, P. M., \& Ciari, F. (2017). Tracking a system of shared autonomous vehicles across the Austin, Texas network using agent-based simulation. Transportation, 44, 1261-1278. doi:10.1007/s11116-017-9811-1.

Liu, Z., Miwa, T., Zeng, W., Bell, M. G., \& Morikawa, T. (2019). Dynamic shared autonomous taxi system considering on-time arrival reliability. Transportation Research Part C: Emerging Technologies, 103, 281-297. URL: http://www. sciencedirect.com/science/article/pii/S0968090X18306922. doi:10.1016/j.trc.2019.04.018.

Liu, Z., Miwa, T., Zeng, W., Bell, M. G. H., \& Morikawa, T. (2018). Shared autonomous taxi system and utilization of collected travel-time information. Journal of Advanced Transportation, 2018, 1-13. doi:10.1155/2018/8919721.

Loeb, B., Kockelman, K. M., \& Liu, J. (2018). Shared autonomous electric vehicle (SAEV) operations across the Austin, Texas network with charging infrastructure decisions. Transportation Research Part C: Emerging Technologies, 89, $222-233$. doi:10.1016/j.trc.2018.01.019.

Lokhandwala, M., \& Cai, H. (2018). Dynamic ride sharing using traditional taxis and shared autonomous taxis: A case study of New York City. Transportation Research Part C: Emerging Technologies, 97, 45-60. doi:10.1016/j.trc.2018.10.007.

Ma, J., Li, X., Zhou, F., \& Hao, W. (2017). Designing optimal autonomous vehicle sharing and reservation systems: A linear programming approach. Transportation Research Part C: Emerging Technologies, 84, 124-141. doi:10.1016/j.trc.2017. 08.022.

Mahmassani, H. S. (2018). Integrating shared autonomous fleet services in urban mobility: Dynamic network modeling. URL: https://its.berkeley.edu/node/13274.

Marchau, V., Walker, W. E., \& van Wee, G. P. (2010). Dynamic adaptive transport policies for handling deep uncertainty. Technological Forecasting and Social Change, 77, 940-950. doi:10.1016/j.techfore.2010.04.006.

Martinez, L. M., \& Viegas, J. M. (2017). Assessing the impacts of deploying a shared self-driving urban mobility system: An agent-based model applied to the city of Lisbon, Portugal. International Journal of Transportation Science and Technology, 6, 13-27. doi:10.1016/j.ijtst.2017.05.005.

Masoud, N., \& Jayakrishnan, R. (2017). Autonomous or driver-less vehicles: Implementation strategies and operational concerns. Transportation Research Part E: Logistics and Transportation Review, 108, 179-194. doi:10.1016/j.tre.2017. 10.011.

McVitie, D. G., \& Wilson, L. B. (1970). Stable marriage assignment for unequal sets. BIT Numerical Mathematics, 10, 295-309. doi:10.1007/BF01934199.

Mena-Oreja, J., Gozalvez, J., \& Sepulcre, M. (2018). Effect of the configuration of platooning maneuvers on the traffic flow under mixed traffic scenarios. In 2018 IEEE Vehicular Networking Conference (VNC) (pp. 1-4). doi:10.1109/VNC.2018.8628381.

Mendes, L. M., Bennàssar, M. R., \& Chow, J. Y. J. (2017). Comparison of light rail streetcar against shared autonomous vehicle fleet for Brooklyn-Queens Connector in New York City. Transportation Research Record: Journal of the Transportation Research Board, 2650, 142-151. doi:10.3141/2650-17.

Menon, N., Barbour, N., Zhang, Y., Pinjari, A. R., \& Mannering, F. (2018). Shared autonomous vehicles and their potential impacts on household vehicle ownership: An exploratory empirical assessment. International Journal of Sustainable Transportation, 37, 1-12. doi:10.1080/15568318.2018.1443178.

Meyer, J., Becker, H., Bösch, P. M., \& Axhausen, K. W. (2017). Autonomous vehicles: The next jump in accessibilities? Research in Transportation Economics, 62, 80-91. doi:10.1016/j.retrec.2017.03.005.

Milakis, D., van Arem, B., \& van Wee, B. (2017). Policy and society related implications of automated driving: A review of literature and directions for future research. Journal of Intelligent Transportation Systems, 21, 324-348. doi:10.1080/ 15472450.2017 .1291351 .

Miller, J., \& How, J. P. (2017). Demand estimation and chance-constrained fleet management for ride hailing. In 2017 IEEE/RSJ International Conference on Intelligent Robots and Systems (IROS) (pp. 4481-4488). doi:10.1109/IROS.2017. 8206315.

Monaghan, A. (28/08/2018). Toyota to invest $\$ 500 \mathrm{~m}$ in uber for self-driving car programme. The guardian, . URL: https: //www . theguardian.com/business/2018/aug/28/toyota-to-invest-500m-in-uber-for-self-driving-car-programme.

Moorthy, A., de Kleine, R., Keoleian, G., Good, J., \& Lewis, G. (2017). Shared autonomous vehicles as a sustainable solution to the last mile problem: A case study of Ann Arbor-Detroit area. SAE International Journal of Passenger Cars - Electronic and Electrical Systems, 10. doi:10.4271/2017-01-1276.

Moreno, A. T., Michalski, A., Llorca, C., \& Moeckel, R. (2018). Shared autonomous vehicles effect on vehicle-km traveled and average trip duration. Journal of Advanced Transportation, 2018, 1-10. doi:10.1155/2018/8969353.

Nazari, F., Noruzoliaee, M., \& Mohammadian, A. (2018). Shared versus private mobility: Modeling public interest in autonomous vehicles accounting for latent attitudes. Transportation Research Part C: Emerging Technologies, 97, $456-477$. doi:10.1016/j.trc.2018.11.005.

O'Kane, S. (2018). Former google self-driving wiz will help Volkswagen and Hyundai build fully autonomous cars. The Verge, URL: https://www.theverge.com/2018/1/4/16846526/aurora-chris-urmson-volkswagen-hyundai-self-driving-cars.

Olia, A., Razavi, S., Abdulhai, B., \& Abdelgawad, H. (2018). Traffic capacity implications of automated vehicles mixed with regular vehicles. Journal of Intelligent Transportation Systems, 22, 244-262. doi:10.1080/15472450.2017.1404680.

Pakusch, C., Stevens, G., Boden, A., \& Bossauer, P. (2018). Unintended effects of autonomous driving: A study on mobility preferences in the future. Sustainability, 10, 2404. doi:10.3390/su10072404.

Paquette, J., Cordeau, J.-F., Laporte, G., \& Pascoal, M. M. (2013). Combining multicriteria analysis and tabu search for dial-a-ride problems. Transportation Research Part B: Methodological, 52, 1-16. doi:10.1016/j.trb.2013.02.007. 
Parent, M., \& Daviet, P. (1993). Automatic driving for small public urban vehicles. In Intelligent vehicles '93 (pp. 402-407). IEEE. doi:10.1109/IVS.1993.697360.

Parent, M., \& de La Fortelle, A. (2005). Cybercars : Past, present and future of the technology. URL: https://arxiv.org/ pdf/cs/0510059.

Pavone, M. (2015). Autonomous mobility-on-demand systems for future urban mobility. In M. Maurer, J. C. Gerdes, B. Lenz, \& H. Winner (Eds.), Autonomes Fahren (pp. 399-416). Berlin: Springer Vieweg volume 58. doi:10.1007/978-3-662-45854-9_ 19.

Pendleton, S., Andersen, H., Du, X., Shen, X., Meghjani, M., Eng, Y., Rus, D., \& Ang, M. (2017). Perception, planning, control, and coordination for autonomous vehicles. Machines, 5, 6. doi:10.3390/machines5010006.

Petit, J., \& Shladover, S. E. (2014). Potential cyberattacks on automated vehicles. IEEE Transactions on Intelligent Transportation Systems, (pp. 1-11). doi:10.1109/TITS.2014.2342271.

Pettigrew, S., Dana, L. M., \& Norman, R. (2019). Clusters of potential autonomous vehicles users according to propensity to use individual versus shared vehicles. Transport Policy, 76, 13-20. doi:10.1016/j.tranpol.2019.01.010.

Philipsen, R., Brell, T., \& Ziefle, M. (2019). Carriage without a driver - User requirements for intelligent autonomous mobility services. In N. A. Stanton (Ed.), Advances in human aspects of transportation [electronic resource] (pp. 339-350). Cham: Springer volume 786 of Advances in intelligent systems and computing, 2194-5357. doi:10.1007/978-3-319-93885-1_31.

Pimenta, V., Quilliot, A., Toussaint, H., \& Vigo, D. (2017). Models and algorithms for reliability-oriented dial-a-ride with autonomous electric vehicles. European Journal of Operational Research, 257, 601-613. doi:10.1016/j.ejor.2016.07.037.

Pinto, H. K., Hyland, M. F., Mahmassani, H. S., \& Verbas, I. Ö. (2019). Joint design of multimodal transit networks and shared autonomous mobility fleets. Transportation Research Part C: Emerging Technologies, . URL: http://www.sciencedirect. com/science/article/pii/S0968090X18317728. doi:10.1016/j.trc.2019.06.010.

Rahman, S. A., Walker, W. E., Marchau, \& Vincent (2008). Coping with uncertainties about climate change in infrastructure planning - An adaptive policymaking approach. URL: https://www.rli.nl/sites/default/files/Achtergrondstudie\% 20Coping\%20with\%20Uncertainties.pdf.

Ross, C., \& Guhathakurta, S. (2017). Autonomous vehicles and energy impacts: A scenario analysis. Energy Procedia, 143, 47-52. doi:10.1016/j.egypro.2017.12.646.

Rossi, F., Zhang, R., Hindy, Y., \& Pavone, M. (2018). Routing autonomous vehicles in congested transportation networks: Structural properties and coordination algorithms. Autonomous Robots, 42, 1427-1442. doi:10.1007/s10514-018-9750-5.

SAE International (2018). Taxonomy and definitions for terms related to on-road motor vehicle automated driving systems. URL: https://www.sae.org/standards/content/j3016_201806.

Salazar, M., Rossi, F., Schiffer, M., Onder, C. H., \& Pavone, M. (2018). On the interaction between autonomous mobility-ondemand and public transportation systems. In 2018 International Conference on Intelligent Transportation Systems (ITSC) (pp. 2262-2269). doi:10.1109/ITSC.2018.8569381.

Schatzinger, S., Lim, C. Y. R., \& Braun, S. (2018). Rethinking the taxi: Case study of Hamburg on the prospects of urban fleets for enhancing sustainable mobility. In A. Bisello, D. Vettorato, P. Laconte, \& S. Costa (Eds.), Smart and Sustainable Planning for Cities and Regions (pp. 663-683). Cham: Springer International Publishing volume 1 of Green Energy and Technology. doi:10.1007/978-3-319-75774-2_45.

Schlossberg, M., Riggs, W. B., Millard-Ball, A., \& Shay, E. (2018). Rethinking the street in an era of driverless cars. URL: https://cpb-us-e1.wpmucdn.com/blogs.uoregon.edu/dist/f/13615/files/2018/01/Rethinking_Streets_ AVs_012618-27hcyr6.pdf.

A org/wp-content/uploads/Innovative-Mobility-Industry-Outlook_SM-Spring-2015.pdf.

Shaheen, S., Chan, N., Bansal, A., \& Cohen, A. (2015). Shared mobility: Definitions, industry development, and early understanding. URL: http://innovativemobility.org/wp-content/uploads/2015/11/SharedMobility_WhitePaper_FINAL.pdf.

Shaheen, S., \& Cohen, A. (2016). Innovative mobility carsharing outlook. URL: http://innovativemobility.org/wp-content/ uploads/2016/02/Innovative-Mobility-Industry-Outlook_World-2016-Final.pdf.

Shaheen, S., \& Cohen, A. (2018). Is it time for a public transit renaissance? Navigating travel behavior, technology, and business model shifts in a brave new world. Journal of Public Transportation, 21, 67-81. doi:10.5038/2375-0901.21.1.8.

Shaheen, S., \& Cohen, A. (2019). Shared ride services in North America: Definitions, impacts, and the future of pooling. Transport Reviews, 39, 427-442. doi:10.1080/01441647.2018.1497728.

1310 Shaheen, S., Cohen, A., Yelchuru, B., \& Sarkhili, S. (2017). Mobility on demand: Operational concept report. URL: http: //innovativemobility.org/wp-content/uploads/Mobility-on-Demand-Operational-Concept-Report-2017.pdf.

Shao, R., \& Chang, L. (5/4/2008 - 5/7/2008). A new maximum power point tracking method for photovoltaic arrays using golden section search algorithm. In 2008 Canadian Conference on Electrical and Computer Engineering (pp. 000619000622). IEEE. doi:10.1109/CCECE. 2008.4564609.

Shen, Y., Zhang, H., \& Zhao, J. (2018). Integrating shared autonomous vehicle in public transportation system: A supplyside simulation of the first-mile service in Singapore. Transportation Research Part A: Policy and Practice, 113, $125-136$. doi:10.1016/j.tra.2018.04.004.

Sherif, A., Alsharif, A., Moran, J., \& Mahmoud, M. (2017). Privacy-preserving ride sharing organization scheme for autonomous vehicles in large cities. In 2017 IEEE 86th Vehicular Technology Conference (VTC-Fall) (pp. 1-5). doi:10.1109/VTCFall. 2017.8288210

Simoni, M. D., Kockelman, K. M., Gurumurthy, K. M., \& Bischoff, J. (2019). Congestion pricing in a world of self-driving vehicles: An analysis of different strategies in alternative future scenarios. Transportation Research Part C: Emerging Technologies, 98, 167-185. URL: http://www.sciencedirect.com/science/article/pii/S0968090X1830370X. doi:10.1016/ j.trc. 2018.11.002. 
Singleton, P. A. (2018). Discussing the "positive utilities" of autonomous vehicles: Will travellers really use their time productively? Transport Reviews, 17, 1-16. doi:10.1080/01441647.2018.1470584.

Soteropoulos, A., Berger, M., \& Ciari, F. (2018). Impacts of automated vehicles on travel behaviour and land use: An international review of modelling studies. Transport Reviews, 94, 1-21. doi:10.1080/01441647.2018.1523253.

Sprei, F. (2018). Disrupting mobility. Energy Research ES Social Science, 37, 238-242. doi:10.1016/j.erss.2017.10.029.

Steck, F., Kolarova, V., Bahamonde-Birke, F., Trommer, S., \& Lenz, B. (2018). How autonomous driving may affect the value of travel time savings for commuting. Transportation Research Record: Journal of the Transportation Research Board, 77, 036119811875798. doi:10.1177/0361198118757980.

Stocker, A., \& Shaheen, S. (2017). Shared automated vehicles: Review of business models. URL: https://www.itf-oecd.org/ sites/default/files/docs/shared-automated-vehicles-business-models.pdf.

1335 Stocker, A., \& Shaheen, S. (2018). Shared automated vehicle (SAV) pilots and automated vehicle policy in the U.S.: Current and future developments. In G. Meyer, \& S. Beiker (Eds.), Road Vehicle Automation 5 (pp. 131-147). Cham: Springer volume 143 of Lecture Notes in Mobility. doi:10.1007/978-3-319-94896-6_12.

Stoiber, T., Schubert, I., Hoerler, R., \& Burger, P. (2019). Will consumers prefer shared and pooled-use autonomous vehicles? A stated choice experiment with Swiss households. Transportation Research Part D: Transport and Environment, 71, $265-282$. URL: http://www.sciencedirect.com/science/article/pii/S1361920918303304. doi:10.1016/j.trd.2018.12.019.

Szigeti, S., Csiszár, C., \& Földes, D. (2017). Information management of demand-responsive mobility service based on autonomous vehicles. Procedia Engineering, 187, 483-491. doi:10.1016/j.proeng.2017.04.404.

Tachet, R., Sagarra, O., Santi, P., Resta, G., Szell, M., Strogatz, S. H., \& Ratti, C. (2017). Scaling law of urban ride sharing. Scientific reports, 7, 42868. doi:10.1038/srep42868.

Täihagh, A., \& Lim, H. S. M. (2019). Governing autonomous vehicles: emerging responses for safety, liability, privacy, cybersecurity, and industry risks. Transport Reviews, 39, 103-128. doi:10.1080/01441647.2018.1494640.

Talebpour, A., \& Mahmassani, H. S. (2016). Influence of connected and autonomous vehicles on traffic flow stability and throughput. Transportation Research Part C: Emerging Technologies, 71, 143-163. doi:10.1016/j.trc.2016.07.007.

Teoh, E. R., \& Kidd, D. G. (2017). Rage against the machine? Google's self-driving cars versus human drivers. Journal of safety research, 63, 57-60. doi:10.1016/j.jsr.2017.08.008.

The Ford Company (2016). Ford targets fully autonomous vehicle for ride sharing in 2021; invests in new tech companies, doubles Silicon Valley team. URL: https://media.ford.com/content/fordmedia/fna/us/en/news/2016/08/16/ ford-targets-fully-autonomous-vehicle-for-ride-sharing-in-2021.html.

Thomas, M., \& Deepti, T. (2018). Reinventing carsharing as a modern and profitable service. URL: https://ridecell.com/ wp-content/uploads/White-Paper-Presentation_Reinventing-Carsharing-As-A-Modern-And-Profitable-Service.pdf.

Tientrakool, P., Ho, Y.-C., \& Maxemchuk, N. F. (2011). Highway capacity benefits from using vehicle-to-vehicle communication and sensors for collision avoidance. In IEEE Vehicular Technology Conference (VTC Fall), 2011 (pp. 1-5). Piscataway, NJ: IEEE. doi:10.1109/VETECF.2011.6093130.

Trivedi, A. (2018). Honda and toyota are piling billions of dollars into autonomous cars. URL: https://www.bloomberg.com/ opinion/articles/2018-10-04/japan-s-carmakers-throw-money-at-the-future-of-driving.

Trommer, S., Kolarova, V., Fraedrich, E., Kröger, L., Kickhöfer, B., Kuhnimhof, T., Lenz, B., \& Phleps, P. (2016). Autonomous driving: The impact of vehicle automation on mobility behaviour. URL: https://elib.dlr.de/110337/1/ifmo_ 2016_Autonomous_Driving_2035_en.pdf.

Vleugel, J. M., \& Bal, F. (2018). More space and improved living conditions in cities with autonomous vehicles. International Journal of Design \& Nature and Ecodynamics, 12, 505-515. doi:10.2495/DNE-V12-N4-505-515.

Vosooghi, R., Puchinger, J., Jankovic, M., \& Sirin, G. (2017). A critical analysis of travel demand estimation for new oneway carsharing systems. In 2017 IEEE 20th International Conference on Intelligent Transportation Systems (ITSC) (pp. 199-205). doi:10.1109/ITSC.2017.8317917.

Vosooghi, R., Puchinger, J., Jankovic, M., \& Vouillon, A. (2019). Shared autonomous vehicle simulation and service design. Transportation Research Part C: Emerging Technologies, 107, 15-33. URL: http://www.sciencedirect.com/science/ article/pii/S0968090X19304449. doi:10.1016/j.trc.2019.08.006.

Walker, J., \& Johnson, C. (2016). Peak car ownership: The market opportunity of electric automated mobility services. URL: https://rmi.org/insight/peak-car-ownership-report/.

Walker, W. E., \& Marchau, V. A. (2017). Dynamic adaptive policymaking for the sustainable city: The case of automated taxis. International Journal of Transportation Science and Technology, 6, 1-12. doi:10.1016/j.ijtst.2017.03.004.

Walker, W. E., Rahman, S., \& Cave, J. (2001). Adaptive policies, policy analysis, and policy-making. European Journal of Operational Research, 128, 282-289. URL: http://www.sciencedirect.com/science/article/pii/S0377221700000710. doi:10.1016/S0377-2217(00)00071-0.

Wall, T. A., Walker, W. E., Marchau, V. A. W. J., \& Bertolini, L. (2015). Dynamic adaptive approach to transportationinfrastructure planning for climate change: San Francisco Bay Area case study. Journal of Infrastructure Systems, 21, 05015004. doi:10.1061/(ASCE) IS.1943-555X.0000257.

Wang, F., Yang, M., \& Yang, R. (2006). Dynamic fleet management for cybercars. In 2006 IEEE Intelligent Transportation Systems Conference (pp. 1246-1250). IEEE. doi:10.1109/ITSC.2006.1707393.

Wang, H., Cheu, R., \& Lee, D.-H. (2014). Intelligent taxi dispatch system for advance reservations. Journal of Public Transportation, 17, 115-128. doi:10.5038/2375-0901.17.3.8.

Wang, K., \& Akar, G. (2019). Factors affecting the adoption of autonomous vehicles for commute trips: An analysis with the 2015 and 2017 Puget Sound travel surveys. Transportation Research Record: Journal of the Transportation Research Board, 2673, 13-25. doi:10.1177/0361198118822293.

Watkins, S. J. (2018). Driverless cars - Advantages of not owning them: Car share, active travel and total mobility. Proceedings 
of the Institution of Civil Engineers - Municipal Engineer, 171, 26-30. doi:10.1680/jmuen.16.00067.

Webb, J., Wilson, C., \& Kularatne, T. (2019). Will people accept shared autonomous electric vehicles? A survey before and after receipt of the costs and benefits. Economic Analysis and Policy, 61, 118-135. URL: https://www.sciencedirect. com/science/article/pii/S0313592618303795. doi:10.1016/j.eap.2018.12.004.

Weiss, J., Hledik, R., Lueken, R., Lee, T., \& Gorman, W. (2017). The electrification accelerator: Understanding the implications of autonomous vehicles for electric utilities. The Electricity Journal, 30, 50-57. doi:10.1016/j.tej.2017.11.009.

Yi, Z., Smart, J., \& Shirk, M. (2018). Energy impact evaluation for eco-routing and charging of autonomous electric vehicle fleet: Ambient temperature consideration. Transportation Research Part C: Emerging Technologies, 89, 344-363. doi:10. $1016 / j . \operatorname{trc} .2018 .02 .018$.

Zhang, R., \& Pavone, M. (2016). Control of robotic mobility-on-demand systems: A queueing-theoretical perspective. The International Journal of Robotics Research, 35, 186-203. doi:10.1177/0278364915581863.

Zhang, W., \& Guhathakurta, S. (2017). Parking spaces in the age of shared autonomous vehicles: How much parking will we need and where? Transportation Research Record: Journal of the Transportation Research Board, 2651, 80-91. doi:10. 3141/2651-09.

Zhang, W., \& Guhathakurta, S. (2018). Residential location choice in the era of shared autonomous vehicles. Journal of Planning Education and Research, 45, 0739456X1877606. doi:10.1177/0739456X18776062.

Zhang, W., Guhathakurta, S., Fang, J., \& Zhang, G. (2015). Exploring the impact of shared autonomous vehicles on urban parking demand: An agent-based simulation approach. Sustainable Cities and Society, 19,34-45. doi:10.1016/j.scs.2015. 07.006.

Zhao, Y., \& Kockelman, K. M. (2018). Anticipating the regional impacts of connected and automated vehicle travel in Austin, Texas. Journal of Urban Planning and Development, 144, 04018032. doi:10.1061/(ASCE) UP.1943-5444.0000463.

Zmud, J. P., \& Sener, I. N. (2017). Towards an understanding of the travel behavior impact of autonomous vehicles. Transportation Research Procedia, 25, 2500-2519. doi:10.1016/j.trpro.2017.05.281. 
Appendix

Table A1: Description of impact and demand related studies

Study type - A: Studies based on surveys/workshops; B: Simulation based studies; C: Review/Opinion/discussion papers; D - Optimization programming; O - Others

\begin{tabular}{|c|c|c|c|}
\hline Study & $\begin{array}{l}\text { Study } \\
\text { type }\end{array}$ & $\begin{array}{l}\text { Model/Analysis } \\
\text { framework }\end{array}$ & Remarks \\
\hline $\begin{array}{l}\text { Tientrakool } \\
\text { et al. }(2011)\end{array}$ & $\mathrm{O}$ & Analytical model & $\begin{array}{l}\text { Determination of highway capacity change caused by non-connected \& connected autonomous vehicles. Estimation } \\
\text { is based on average safe inter-vehicle distance, calculated based on certain rules for using the two systems to prevent } \\
\text { collisions with preceding vehicles. Place of study: NA/NA }\end{array}$ \\
\hline $\begin{array}{l}\text { Brownell \& } \\
\text { Kornhauser } \\
(2014)\end{array}$ & $\mathrm{O}$ & Analytical model & $\begin{array}{l}\text { Exploration of impacts of two different SAV models: Personal Rapid Transit (PRT) \& Smart Paratransit (SPT). In case } \\
\text { of former, riders with common origin-destination and pickup time within a certain time interval are served together. In } \\
\text { case of the latter, riders book a ride and they are picked at a nearby central transit point. Along the way, the vehicle } \\
\text { stops at other transit points to pick up additional passengers. The analysis is carried out by segmenting New Jersey } \\
\text { into pixelated transit grids, assuming an average speed of } 48 \mathrm{kmph}(30 \mathrm{mph}) \text {. Two reposition methods (instant \& 1-h } \\
\text { repositing time) are tested. Place of study: New Jersey }\end{array}$ \\
\hline $\begin{array}{l}\text { Fagnant } \\
\text { Kockelman } \\
(2014)\end{array}$ & $\mathrm{B}$ & $\begin{array}{l}\text { Agent-based simu- } \\
\text { lation }\end{array}$ & $\begin{array}{l}25 \text { scenarios are studied by varying trip generation rates, trip distribution patterns, network congestion levels, service } \\
\text { area size, vehicle relocation strategies \& fleet size. A SAV penetration rate of } 3.5 \% \text { is assumed and trip generation is } \\
\text { based on Poisson distribution with a } 5 \text {-min time step. SAVs are assumed to travel with fixed speeds, which are pre-set } \\
\text { by time of day. SAV maintenance \& cleaning are assumed to not impact the service operation. Place of study: Gridded } \\
\text { city based on Austin }\end{array}$ \\
\hline $\begin{array}{l}\text { Petit } \\
\text { Shladover } \\
(2014)\end{array}$ & $\mathrm{O}$ & $\begin{array}{l}\text { Failure Modes \& Ef- } \\
\text { fects Analysis }\end{array}$ & Investigation of cyberattacks on non-connected \& connected autonomous vehicles. Place of study: NA/NA \\
\hline $\begin{array}{l}\text { Childress et al. } \\
(2015)\end{array}$ & $\mathrm{B}$ & $\begin{array}{l}\text { SoundCast (Seattle } \\
\text { region's activity- } \\
\text { based travel model) }\end{array}$ & $\begin{array}{l}\text { Investigation of travel behaviour impacts. Base year is } 2010 \& \text { private vehicle trips are assumed to be absent. Cost of } \\
\text { SAV service is } \$ 1.03 / \mathrm{km} \& \text { there is no road capacity increase due to automation. Modes available include SAV, transit } \\
\& \text { walking. Place of study: Puget Sound region }\end{array}$ \\
\hline $\begin{array}{l}\text { Corwin et al. } \\
(2015)\end{array}$ & $\mathrm{O}$ & $\begin{array}{l}\text { Data-driven } \\
\text { methodology }\end{array}$ & $\begin{array}{l}\text { Analysis of cost per mile for SAV services, based on cost for vehicle financing, depreciation, maintenance, fuel and } \\
\text { profits. Assumptions include availability of lighter-weight vehicles (two-person pods for } \$ 10,000) \text { \& high rates of asset } \\
\text { utilization (greater than } 4 \% \text { ). Place of study: NA/NA }\end{array}$ \\
\hline $\begin{array}{l}\text { Fagnant } \\
\text { Kockelman } \\
(2015)\end{array}$ & $\mathrm{C}$ & - & $\begin{array}{l}\text { Estimation of crash reduction potential of SAVs, based on the existing literature related to fatal crashes. Place of } \\
\text { study: USA }\end{array}$ \\
\hline $\begin{array}{l}\text { Friedrich } \\
(2015)\end{array}$ & $\mathrm{B}$ & Sumo & $\begin{array}{l}\text { Analysis of road capacity increase due to automation. All vehicles on the road are assumed to be autonomous, which } \\
\text { have a shorter reaction times compared to humans \& maintain a time gap of } 0.5 \mathrm{~s} \text { between the vehicles. Place of study: } \\
\text { Braunschweig }\end{array}$ \\
\hline $\begin{array}{l}\text { Greenblatt \& } \\
\text { Saxena }(2015)\end{array}$ & $\mathrm{O}$ & $\begin{array}{l}\text { Urban Dynamome- } \\
\text { ter Driving Sched- } \\
\text { ule, Highway Fuel } \\
\text { Economy Test \& US } \\
\text { Supplemental Fed- } \\
\text { eral Test Procedure }\end{array}$ & $\begin{array}{l}\text { Estimation of Greenhouse-gas emissions for 2030, using data from the US Energy Information Administration. A } \\
\text { hypothetical small-occupancy Battery-Electric Vehicle (BEV) was assumed for SAV services. The vehicle was modelled } \\
\text { using powertrain simulation tool Autonomie. Standard EPA efficiency was calculated as a weighted sum of the UDDS } \\
(55 \%) \& \text { HWFET ( } 45 \% \text { ). BEV efficiencies relative to an average light-duty vehicle were calculated by assuming } 56 \% \\
\text { passenger cars \& } 44 \% \text { light trucks in } 2030 \text {. Place of study: USA }\end{array}$ \\
\hline
\end{tabular}


Table A1: Description of impact and demand related studies

Study type - A: Studies based on surveys/workshops; B: Simulation based studies; C: Review/Opinion/discussion papers; D - Optimization programming; O - Others

\begin{tabular}{|c|c|c|c|}
\hline Study & $\begin{array}{l}\text { Study } \\
\text { type }\end{array}$ & $\begin{array}{l}\text { Model/Analysis } \\
\text { framework }\end{array}$ & Remarks \\
\hline $\begin{array}{l}\text { International } \\
\text { Transport } \\
\text { Forum (2015) }\end{array}$ & $\mathrm{B}$ & $\begin{array}{l}\text { Agent-based simu- } \\
\text { lation }\end{array}$ & $\begin{array}{l}\text { Scenarios were built on two SAV service types (car-sharing \& ride-sharing), availability of a high-capacity public } \\
\text { transport, penetration rates of SAVs }(50 \% \text { \& } 100 \% \text { ) \& simulation time period (full day \& peak periods). Modes } \\
\text { available included private cars, public transport, SAVs, walking \& cycling. Access time \& search time for parking } \\
\text { spaces were not included for private vehicles. Place of study: Lisbon }\end{array}$ \\
\hline Pavone (2015) & $\mathrm{O}$ & $\begin{array}{l}\text { Spatial queueing- } \\
\text { theoretical model }\end{array}$ & $\begin{array}{l}\text { Modelling impacts of autonomous car-sharing system using two approaches, namely lumped \& distributed approach. } \\
\text { In the former approach, which exploits the theory of Jackson networks, customers are assumed to arrive at a set of } \\
\text { stations located within a given environment. In the latter, the number of stations is considered to represent a continuum } \\
\text { \& customers can arrive at any point in a given bounded environment. Place of study: Manhattan \& Singapore }\end{array}$ \\
\hline $\begin{array}{l}\text { Zhang et al. } \\
(2015)\end{array}$ & $\mathrm{B}$ & $\begin{array}{l}\text { Agent-based simu- } \\
\text { lation }\end{array}$ & $\begin{array}{l}\text { Evaluation of impact of SAVs on urban parking demand. } 2 \% \text { penetration rate is assumed for SAV services. An } \\
\text { individual's willingness to share ride is randomly determined based on the aggregated level of willingness to share }(25 \% \\
\text { to } 100 \% \text { with increments of } 25 \% \text { ) \& one SAV can serve a maximum of two clients. Trip generation is based on poisson } \\
\text { distribution \& model time-step is } 1 \text { minute. Different thresholds for empty cruising time are considered ( } 0 \text { to } 30 \mathrm{~min} \\
\text { with increments of } 5 \mathrm{~min}) \text {. Average speed is assumed to be } 48 \mathrm{kmph}(30 \mathrm{mph}) \text { during off-peak \& } 34 \mathrm{kmph}(21 \mathrm{mph}) \text { during } \\
\text { peak hour. Place of study: } 10 \text { mile x } 10 \text { mile hypothetical grid city }\end{array}$ \\
\hline $\begin{array}{l}\text { Bansal et al. } \\
(2016)\end{array}$ & $\mathrm{A}$ & Ordered probit & $\begin{array}{l}\text { Investigation of willingness-to-pay for automation technology. The authors conducted an internet-based survey con- } \\
\text { sisting of } 347 \text { participants. Place of study: Austin }\end{array}$ \\
\hline $\begin{array}{l}\text { Bischoff \& } \\
\text { Maciejewski } \\
(2016)\end{array}$ & $\mathrm{B}$ & Matsim & $\begin{array}{l}\text { Simulation of a city-wide replacement of private cars with SAVs. Access \& egress time are assumed to be one \& two } \\
\text { minutes, respectively. After servicing a customer, SAVs are parked at the drop off location until the next dispatch. The } \\
\text { initial fleet distribution in the morning is based on the population density in the area. Two other scenarios, reduction } \\
\text { of SAV service to city center \& a } 10 \% \text { shift of public transport users to SAV service, are tested. Place of study: Berlin }\end{array}$ \\
\hline $\begin{array}{l}\text { Bösch et al. } \\
(2016)\end{array}$ & $\mathrm{B}$ & $\begin{array}{l}\text { Matsim + SAV sim- } \\
\text { ulation model }\end{array}$ & $\begin{array}{l}\text { Analysis of fleet size required to serve different levels of demand. Travel times are calculated using Matsim. Only trips } \\
\text { made with private cars are assumed to be replaced by SAV services \& the maximum waiting time is } 10 \mathrm{~min} \text {. Place of } \\
\text { study: greater Zurich }\end{array}$ \\
\hline $\begin{array}{l}\text { Cambridge } \\
\text { Systematics } \\
(2016)\end{array}$ & $\mathrm{O}$ & - & $\begin{array}{l}\text { The study uses California Statewide Travel Demand Model to forecast ridership for California high-speed rail in } 2040 . \\
\text { Within the study, using the assumption that the households in denser areas are more likely to use SAVs \& the market } \\
\text { penetration will follow a triangular distribution, penetration rate for SAVs is asserted based on professional judgement. } \\
\text { Place of study: California }\end{array}$ \\
\hline $\begin{array}{l}\text { Chen \& Kock- } \\
\text { elman }(2016)\end{array}$ & $\mathrm{B}$ & $\begin{array}{l}\text { Agent-based simu- } \\
\text { lation system }\end{array}$ & $\begin{array}{l}\text { Examination of market potential of a fleet of electric SAVs. Mode choice includes private vehicle, transit, \& electric } \\
\text { SAVs. Trips less then } 0.62 \mathrm{~km}(1 \mathrm{mile}) \text { are neglected \& the assumptions include the following: Value of travel time - } \\
50 \% \text { of hourly wage for personal trips \& } 100 \% \text { of hourly wage for business or work trips; Transit mode - local city bus } \\
\text { service; Pricing scheme: origin- \& destination-based; Price - between } \$ 0.46 / \mathrm{km} \& \$ 0.62 / \mathrm{km} \text {. Place of study: A midsize } \\
\text { city (100mile x 100mile, modeled roughly based on Austin) }\end{array}$ \\
\hline $\begin{array}{l}\text { Chen et al. } \\
(2016)\end{array}$ & B & $\begin{array}{l}\text { Discrete-time } \\
\text { agent-based simula- } \\
\text { tion }\end{array}$ & $\begin{array}{l}\text { Examination of the operational characteristics of electric SAVs. } 10 \% \text { of the population are assumed to be served by } \\
\text { electric SAVs. Vehicle range of } 80 \text { miles \& } 160 \text { miles \& charging time of } 30 \mathrm{~min} \& 240 \mathrm{~min} \text { are tested. Place of study: } \\
\text { 100mile x 100mile gridded metropolitan area \& Austin }\end{array}$ \\
\hline $\begin{array}{l}\text { Grush et al. } \\
(2016)\end{array}$ & $\mathrm{C}$ & - & $\begin{array}{l}\text { The authors explore the implications of autonomous vehicles based on conclusions from various researches. Place of } \\
\text { study: NA/NA }\end{array}$ \\
\hline
\end{tabular}


Table A1: Description of impact and demand related studies

Study type - A: Studies based on surveys/workshops; B: Simulation based studies; C: Review/Opinion/discussion papers; D - Optimization programming; O - Others

\begin{tabular}{|c|c|c|c|}
\hline Study & $\begin{array}{l}\text { Study } \\
\text { type }\end{array}$ & $\begin{array}{l}\text { Model/Analysis } \\
\text { framework }\end{array}$ & Remarks \\
\hline $\begin{array}{l}\text { Krueger et al. } \\
(2016)\end{array}$ & $\mathrm{A}$ & Mixed logit model & $\begin{array}{l}\text { Identification of the characteristics of users who are likely to adopt SAV services, based on a survey of } 435 \text { individuals. } \\
\text { Place of study: Major metropolitan areas of Australia }\end{array}$ \\
\hline $\begin{array}{l}\text { Talebpour \& } \\
\text { Mahmassani } \\
(2016)\end{array}$ & B & $\begin{array}{l}\text { Microscopic simula- } \\
\text { tion }\end{array}$ & $\begin{array}{l}\text { Analysis of the string stability of mixed traffic streams, with varying percentages of conventional, normal autonomous } \\
\& \text { connected autonomous vehicles. The simulation system used in the study distinguishes between autonomous \& } \\
\text { connected autonomous vehicles based on car-following behaviour. Place of study: a one-lane highway with an on-ramp }\end{array}$ \\
\hline $\begin{array}{l}\text { Trommer et al. } \\
(2016)\end{array}$ & B & $\begin{array}{l}\text { Space-invariant } \\
\text { travel demand } \\
\text { model }\end{array}$ & $\begin{array}{l}\text { Investigation of impact of vehicle automation on mobility behavior. The modelling set up consists of components to } \\
\text { generate future population \& calculate total trip volumes, a diffusion model to predict penetration rates for SAVs in } \\
2035 \text { \& a combined destination \& mode choice model. Place of study: Germany }\end{array}$ \\
\hline $\begin{array}{lr}\text { Walker } & \& \\
\text { Johnson } & (2016)\end{array}$ & $\mathrm{O}$ & $\begin{array}{l}\text { Technology adop- } \\
\text { tion S-curves }\end{array}$ & $\begin{array}{l}\text { The study uses consumer-adoption trends \& data from other researches to estimate the cost of SAV services \& pene- } \\
\text { tration rates for SAV services in } 2025 \& 2035 \text {. The exact analysis procedure is not clear. Place of study: USA }\end{array}$ \\
\hline $\begin{array}{l}\text { Zhang } \quad \& \\
\text { Pavone (2016) }\end{array}$ & $\mathrm{D}$ & Linear program & $\begin{array}{l}\text { Modelling of SAVs within the framework of Jackson network using a queueing theoretical approach. The authors } \\
\text { try to address the problem of synthesizing a rebalancing policy, \& the control objective is to minimize the number of } \\
\text { (autonomously) rebalancing vehicles on the roads, while keeping vehicle availabilities balanced throughout the network. } \\
\text { Assumptions include sufficient parking spaces in the mobility stations, capability of SAVs to anticipate future demand } \\
\& \text { exponential distribution for travel times. Effect of congestion is not considered. The proposed method is tested } \\
\text { using requests based on actual taxi rides in New York on March 1, 2012. Place of study: Manhattan }\end{array}$ \\
\hline $\begin{array}{l}\text { Arbib \& Seba } \\
(2017)\end{array}$ & $\mathrm{O}$ & $\begin{array}{l}\text { Seba technology } \\
\text { disruption frame- } \\
\text { work }\end{array}$ & $\begin{array}{l}\text { Analysis and forecasting of the speed and scale of technology-driven disruption and its implications across society. The } \\
\text { disruption framework is built upon technology-adoption S-curves \& incorporates systems dynamics, including feedback } \\
\text { loops, network effects \& market forces. The analysis of disruptions is based on the evaluation of data on the market, } \\
\text { consumer \& regulatory dynamics that work together to drive the disruption. Place of study: USA }\end{array}$ \\
\hline $\begin{array}{l}\text { Becker \& Ax- } \\
\text { hausen }(2017)\end{array}$ & A & - & $\begin{array}{l}\text { Assessment of the impact of SAVs and privately owned autonomous vehicles on mode choices. A paper-based stated } \\
\text { preference survey was conducted \& } 62 \text { individuals participated. The choice of modes included were car, bike, traditional } \\
\text { public transport \& SAVs (both car-sharing \& ride-sharing). The attribute levels were pivoted around the real values } \\
\text { of the participants' regular trips. Two scenarios were put forth. In the first scenario, private autonomous vehicles were } \\
\text { absent \& in the second they were included. Place of study: Zurich }\end{array}$ \\
\hline $\begin{array}{l}\text { Bischoff et al. } \\
(2017)\end{array}$ & $\mathrm{B}$ & Matsim & $\begin{array}{l}\text { Evaluation of potential for shared rides. An insertion-based algorithm was used to simulate SAV ride-sharing services. } \\
\text { The algorithm was tested using real-world dataset of taxi requests in Berlin (Taxi Berlin) \& a vehicle capacity between } \\
\text { between two \& four was assumed. Place of study: Berlin }\end{array}$ \\
\hline $\begin{array}{l}\text { Burgstaller } \\
\text { et al. }(2017)\end{array}$ & $\mathrm{O}$ & - & $\begin{array}{l}\text { The report discusses about the implications of autonomous vehicles based on forecasts built over data from various } \\
\text { sources related to ride-hailing market. Place of study: Global }\end{array}$ \\
\hline $\begin{array}{l}\text { Clements \& } \\
\text { Kockelman } \\
(2017)\end{array}$ & $\mathrm{C}$ & - & $\begin{array}{l}\text { Review of economic effects of autonomous vehicles in USA across industries related to automotive, technology, freight } \\
\text { movement, personal transport, auto repair, medical care, insurance, law, infrastructure, land development, digital } \\
\text { media, \& oil \& gas. Economic impacts on the overall economy are also discussed. Place of study: USA }\end{array}$ \\
\hline
\end{tabular}


Table A1: Description of impact and demand related studies

Study type - A: Studies based on surveys/workshops; B: Simulation based studies; C: Review/Opinion/discussion papers; D - Optimization programming; O - Others

\begin{tabular}{llll}
\hline Study & $\begin{array}{l}\text { Study Model/Analysis } \\
\text { type }\end{array}$ & $\begin{array}{l}\text { Agent-based simu- } \\
\text { framework }\end{array}$ \\
\hline $\begin{array}{l}\text { Dia \& Javan- } \\
\text { shour (2017) }\end{array}$ & B & $\begin{array}{l}\text { Ation } \\
\end{array}$ \\
& & & \\
\hline $\begin{array}{l}\text { Fournier et al. } \\
(2017)\end{array}$ & O & Analytical model \\
& & & \\
\hline $\begin{array}{l}\text { Fulton et al. } \\
(2017)\end{array}$ & & & $\begin{array}{l}\text { Adapted Mobility } \\
\text { Model (MoMo) }\end{array}$
\end{tabular}

$\stackrel{\infty}{\infty}$

\begin{tabular}{|c|c|c|c|}
\hline $\begin{array}{l}\text { Gelauff et al. } \\
(2017)\end{array}$ & B & $\begin{array}{l}\text { LUCA (Dutch spa- } \\
\text { tial general equilib- } \\
\text { rium model) }\end{array}$ & $\begin{array}{l}\text { Study of the impacts of automated driving on the residential location choice of individuals. The study differentiates two } \\
\text { automation cases, namely car automation \& public transport automation. In case of public transport automation, the } \\
\text { transport system is assumed to offer efficient automated door-to-door mobility service. The two cases are simulated, } \\
\text { both separately \& in combination. Both car-sharing \& ride-sharing SAV services are tested. Out-of-pocket (monetary) } \\
\text { costs are assumed to not change in the automation scenarios. Place of study: Netherlands }\end{array}$ \\
\hline $\begin{array}{l}\text { Haboucha et al. } \\
(2017)\end{array}$ & $\mathrm{A}$ & $\begin{array}{l}\text { Nested logit kernel } \\
\text { model with panel ef- } \\
\text { fect }\end{array}$ & $\begin{array}{l}\text { Investigation of autonomous vehicle adoption. } 721 \text { participants took part in the survey \& the mode choice included } \\
\text { were user's current mode, private autonomous vehicle \& SAV. Isreal \& North America (USA \& canada) }\end{array}$ \\
\hline $\begin{array}{l}\text { Hao \& Ya- } \\
\text { mamoto }(2017)\end{array}$ & $\mathrm{A}, \mathrm{B}$ & $\begin{array}{lr}\text { Artisoc } & \text { (agent- } \\
\text { based } & \text { simulation } \\
\text { model) } & \end{array}$ & $\begin{array}{l}\text { Analysis of autonomous vehicle ownership \& shared use. The authors surveyed } 803 \text { individuals. The individuals could } \\
\text { choose to own autonomous vehicles, own \& also share it for SAV services \& not own but use SAV services. Based on } \\
\text { the survey results \& using Artisoc (agent-based simulation model), penetration rates for SAV services were determined. } \\
\text { Place of study: Meito Ward, Nagoya (Japan) }\end{array}$ \\
\hline $\begin{array}{l}\text { Heilig et al. } \\
(2017)\end{array}$ & B & MobiTopp & $\begin{array}{l}\text { Evaluation of travel demand for on-demand SAV services. The study simulated travel demand for } 2.3 \text { million agents } \\
\text { over a period of one week. Private cars were assumed to be not in use \& a large SAV service was assumed to be } \\
\text { available. Other modes simulated include walking, cycling \& public transportation. Place of study: Stuttgart }\end{array}$ \\
\hline Hörl (2017) & B & Matsim & $\begin{array}{l}\text { Development of a simulation approach to capture the dynamic interplay between supply of and demand for SAV } \\
\text { services. An autonomous vehicle framework consisting of a fleet generator, vehicle dispatcher \& a pricing structure was } \\
\text { incorporated inside MATSIM to determine demand for SAV services. Assumed price for the SAV service was } \$ 0.49 / \mathrm{km} \\
\text { for car-sharing service \& } \$ 0.28 / \mathrm{km} \text { for ride-sharing service. Place of study: Sioux Falls }\end{array}$ \\
\hline
\end{tabular}

Development of models for simulating SAV services and assessment of the impacts of such services. $25 \%$ of existing private car users are assumed to use private autonomous cars \& the remaining $75 \%$ use SAVs. Two different scenarios, maximum waiting time of $0 \& 5 \mathrm{~min}$, are analysed. Only home based trips are considered \& the travel demand data is based on Victorian Integrated Survey of Travel \& Activity. For parking, the private vehicles return to home \& the SAVs will go to nearby waiting areas. Place of study: Melbourne

Comparison of energy consumption \& carbon footprint of electric SAVs \& conventional private cars (internal combustion engines). All the private car users are assumed to be served by SAV services. A well-to-wheel approach is used for the analysis. This approach is divided into a well-to-tank \& a tank-to-wheel analysis. In the former, producion, transportion \& distribution of a product are investigated \& in the latter, the energy consumption during the use phase is investigated. Four different compositions of electricity provision for the future, $26 \% .45 \%, 60 \%$ \& $100 \%$ renewable energy sources, are tested. Place of study: Berlin

Exploration of evolution and interaction of vehicle electrification, automation and shared mobility. The study analyses three scenarios: a business-as-usual scenario, a technology-dominated 2 Revolutions scenario (widespread vehicle electrification \& automation), \& a technology + high shared-mobility 3 Revolutions scenario (major use of electric SAVs). The analysis is carried out for the year 2050 \& carried out using a spreadsheet model based on Mobility Model (MoMo) created by the International Energy Agency. The analysis is based on linking different variables through basic arithmetic relationships. The data is validated for 2015 \& includes variables related to numbers of vehicles of all major types, their cost, daily \& annual travel, average passenger loadings, fuel use \& CO2 emissions. Place of study: Global

Study of the impacts of automated driving on the residential location choice of individuals. The study differentiates two both costs are assumed to not change in the automation scenarios. Place of study: Netherlands 
Table A1: Description of impact and demand related studies

Study type - A: Studies based on surveys/workshops; B: Simulation based studies; C: Review/Opinion/discussion papers; D - Optimization programming; O - Others

\begin{tabular}{|c|c|c|c|}
\hline Study & $\begin{array}{l}\text { Study } \\
\text { type }\end{array}$ & $\begin{array}{l}\text { Model/Analysis } \\
\text { framework }\end{array}$ & Remarks \\
\hline $\begin{array}{l}\text { International } \\
\text { Association of } \\
\text { Public Trans- } \\
\text { port }(2017)\end{array}$ & $\mathrm{O}$ & - & $\begin{array}{l}\text { An official policy brief which contains a SWOT analysis on SAV services, along with recommendations for chanellising } \\
\text { the growth of autonomous vehicles. Place of study: NA/NA }\end{array}$ \\
\hline $\begin{array}{l}\text { Jäger et al. } \\
(2017)\end{array}$ & B & $\begin{array}{l}\text { Discrete event sim- } \\
\text { ulation combined } \\
\text { with a multi-agent } \\
\text { approach }\end{array}$ & $\begin{array}{l}\text { Assessment of impacts of electric SAV services. A central dispatcher broadcasts customer requests \& electric SAVs } \\
\text { (lightweight two-seater vehicles) compete for the service. Customers are served based on first-come, first-serve strategy. } \\
\text { Routing, charging \& trip assignment are done dynamically \& autonomously by each vehicle. Power consumption is } \\
\text { assumed to be } 15 \mathrm{kWh} \text { per } 100 \mathrm{~km} \& \text { the battery capacity is } 30 \mathrm{kWh} \text {. Travel time is based on a factor (1.4 in off-peak } \\
\& 2.0 \text { in peak time) applied over predictions from Google Maps. The time period of simulation is one day. Place of } \\
\text { study: Munich }\end{array}$ \\
\hline Keeney (2017) & $\mathrm{O}$ & - & $\begin{array}{l}\text { Exploration of the impacts of SAV services. The report presents conclusions from the research carried out by ARK } \\
\text { Invest \& the exact research procedure is not clear. Place of study: USA }\end{array}$ \\
\hline $\begin{array}{l}\text { Kröger } \\
\text { Kickhöfer } \\
(2017)\end{array}$ & B & $\begin{array}{l}\text { Four-step } \quad \text { model } \\
\text { without } \quad \text { traffic } \\
\text { assignment step }\end{array}$ & $\begin{array}{l}\text { Analysis of two supply side parameters (user price \& fleet density), \& their difference for car-sharing \& ride-sharing } \\
\text { systems in rural, suburban, \& urban regions. A parametric approach was followed by systematically varying the supply } \\
\text { parameters to analyse their impact on operator profit, system travel time \& capacity utilization of the vehicles. Traffic } \\
\text { assignment step is omitted from the modelling \& hence the results are suitable only for sketch planning. Place of study: } \\
\text { Germany }\end{array}$ \\
\hline $\begin{array}{l}\text { Levin et al. } \\
(2017)\end{array}$ & $\mathrm{B}$ & $\begin{array}{l}\text { Event-based simula- } \\
\text { tion with cell trans- } \\
\text { mission model }\end{array}$ & $\begin{array}{l}\text { Development of an event-based framework to add SAVs to existing traffic simulators. The study includes evaluation } \\
\text { of both car-sharing \& ride-sharing SAV services. A heuristic approach is used for dynamic ride-sharing. A central } \\
\text { dispatched is assumed to make route \& passemger assignments. Personal vehicles are assumed to be not available, } \\
\text { i.e., only SAVs exists in the system. Morning peak hour is considered for simulation \& relocation happens overnight. } \\
\text { Centroids are assumed to have infinite parking space. Place of study: Austin downtown }\end{array}$ \\
\hline $\begin{array}{l}\text { Liu et al. } \\
(2017)\end{array}$ & B & MATSIM & $\begin{array}{l}\text { Analysis of demand for SAV services. The modelling method from Bösch et al. (2016) is used for simulation of SAV } \\
\text { operations. Assumed price for SAV services range from } \$ 0.31 / \mathrm{km} \text { to } \$ 0.78 / \mathrm{km} \text {. Place of study: Austin }\end{array}$ \\
\hline $\begin{array}{l}\text { Martinez \& } \\
\text { Viegas }(2017)\end{array}$ & B & $\begin{array}{l}\text { Agent-based simu- } \\
\text { lation }\end{array}$ & $\begin{array}{l}\text { Evaluation of impacts of SAV services. Synthetic data consisting of } 1,138,696 \text { daily trips was used for the analysis. } \\
\text { A rule-based lexicographic choice process based on socio-demographic \& mobility attributes of the user was used for } \\
\text { mode choice between walking, subway or rail, shared taxi \& taxi-bus. Place of study: Lisbon }\end{array}$ \\
\hline $\begin{array}{l}\text { Masoud \& } \\
\text { Jayakrishnan } \\
(2017)\end{array}$ & $\mathrm{D}$ & Binary program & $\begin{array}{l}\text { Development of an optimzation model for evaluating shared use of autonomous vehicles at the household level. The } \\
\text { study presented a Shared Vehicle Ownership \& Ridership (SVOR) program, in which a group of households jointly } \\
\text { own \& use a set of autonomous vehicles. Each group is called a cluster and the vehicles were rented out to general } \\
\text { public, when not serving a cluster member. Scenarios tried out include residence-based clustering, trip-overlap based } \\
\text { clustering, single cluster system \& absence of clustering. The optimization model was tested using data from } 1184 \\
\text { households, who carried out } 3306 \text { trips. Effect of congestion is not considered \& household travel patterns are assumed } \\
\text { to not change. Place of study: San Diego }\end{array}$ \\
\hline
\end{tabular}


Table A1: Description of impact and demand related studies

Study type - A: Studies based on surveys/workshops; B: Simulation based studies; C: Review/Opinion/discussion papers; D - Optimization programming; O - Others

\begin{tabular}{lllll}
\hline Study & & \multicolumn{2}{c}{$\begin{array}{l}\text { Study } \\
\text { type }\end{array}$} & $\begin{array}{l}\text { Model/Analysis } \\
\text { framework }\end{array}$ \\
\hline $\begin{array}{l}\text { Mendes } \\
(2017)\end{array}$ & et & al. & B & $\begin{array}{l}\text { Event-based simula- } \\
\text { tion }\end{array}$ \\
& & & &
\end{tabular}

Remarks

$(2017)$

Comparison of performance of SAVs with the light rail system for the forecasted demand in 2035, under the same demand patterns, route alignment, \& operating speeds. The demand forecast is from the projections of New York City Department of Transportation, made during the planning for the Select Bus Service in New York City. Induced demand is assumed on the basis of improved connectivity. The SAV system will run on the same alignment of the rail system. Simulation time period is 2 hours \& the first half-hour is considered as warm-up period. Passenger arrivals system. Simulation time period is 2 hours \& the first half-hour is considered as warm-up period. Passenger arrivals
are based on Monte Carlo simulation. SAV capacity is assumed to be $12 \&$ three scenarios, demand-responsive service are based on Monte Carlo simulation. SAV capacity is assumed to be $12 \&$ three scenarios, demand-responsive service
with garages located between stations, demand-responsive service with stations acting as garages \& fixed-route service operating in the same way as the rail system, are simulated. Place of study: Brooklyn-Queens Connector Streetcar line (New York)

Meyer et al. B Swiss national

Calculation of accessibility based on the travel times in assigned network. Work places are chosen as proxy for opportunities. Public transportation services are assumed to be unaffected by SAVs. Intra-zonal \& intra-urban demand are neglected, \& demand for freight traffic is assumed to be constant. Capacity increase for urban roads is assumed to be $40 \%$ \& for extra-urban roads, lower limit is $80 \%$ \& the upper limit is $270 \%$. Place of study: Switzerland

Milakis et al. C -

(2017)

The authors review existing studies for evaluating policy \& society related implications of autonomous vehicles. The authors use ripple effect concept to represent impacts at three different stages: first-order (traffic, travel cost, \& travel choices), second-order (vehicle ownership \& sharing, location choices \& land use \& transport infrastructure) \&

E

$\begin{array}{lll}\begin{array}{l}\text { Moorthy et al. } \\ (2017)\end{array} & \begin{array}{l}\text { Life Cycle Assess- } \\ \text { ment (LCA) model }\end{array}\end{array}$
third-order (energy consumption, air pollution, safety, social equity, economy \& public health). Place of study: NA/NA

Assessment of energy consumption and emissions for integrated PT-SAV system. SAV service is provided as a last mile transit service between Ann Arbor \& Detroit Wayne County Airport. The available mode options are passenger car, AAATA bus, AirRide bus, airport van shuttle \& SAV. SAV is modeled as a PHEV60 plug-in hybrid vehicle with a maximum capacity of four passengers. The maximum waiting time for SAV passengers is 15 minutes. Fuel economy is assumed to be not affected by passenger \& luggage loadings \& there is no seasonal impact on energy use \& emissions. Cost of an SAV vehicle is assumed to be $\$ 25,000$ with an autonomous vehicle incremental technology cost of $\$ 10,000$. Place of study: Southeast Michigan

\begin{tabular}{|c|c|c|c|}
\hline $\begin{array}{l}\text { Ross \& } \\
\text { Guhathakurta } \\
\text { (2017) }\end{array}$ & $\mathrm{O}$ & Meta-analysis & $\begin{array}{l}\text { The study conducted a meta-analysis based on the findings related to energy consumption from the existing litera- } \\
\text { ture. The study evaluates three scenarios: partial automation with private vehicle dominance, dominance of private } \\
\text { autonomous vehicles \& dominance of SAVs. The authors forecasted } 2017 \text { energy consumption by extrapolating the } \\
\text { energy consumption from } 2011 \text { to } 2014 \text {. Then they converted the findings related to energy consumption of autonomous } \\
\text { vehicles from the literature to percent changes \& applied it over the } 2017 \text { energy consumption. Place of study: USA }\end{array}$ \\
\hline $\begin{array}{l}\text { Teoh \& Kidd } \\
(2017)\end{array}$ & $\mathrm{O}$ & Analytical model & $\begin{array}{l}\text { Analysis of crash reduction potential of autonomous vehicles. The analysis was carried out by comparing crash rates } \\
\& \text { patterns of crashes of Google autonomous cars (from the narratives released by Google) \& human passenger ve- } \\
\text { hicle drivers (from varied sources like California Statewide Integrated Traffic Records System \& SHRP2 naturalistic } \\
\text { coded/video data). Place of study: Mountain View (California) }\end{array}$ \\
\hline $\begin{array}{l}\text { Walker \& Mar- } \\
\text { chau (2017) }\end{array}$ & $\mathrm{O}$ & $\begin{array}{l}\text { Dynamic adaptive } \\
\text { policymaking }\end{array}$ & $\begin{array}{l}\text { Development of a policy framework for the growth of autonomous vehicles. The framework is based on Walker et al. } \\
\text { (2001) \& does not rely on uncertain models. Such frameworks are already explored in various other applications, e.g., } \\
\text { flood risk management in Netherlands (Rahman et al., 2008), transportation infrastructure planning Wall et al. (2015), } \\
\text { \& congestion road pricing Marchau et al. (2010). Place of study: Hypothetical city }\end{array}$ \\
\hline
\end{tabular}


Table A1: Description of impact and demand related studies

Study type - A: Studies based on surveys/workshops; B: Simulation based studies; C: Review/Opinion/discussion papers; D - Optimization programming; O - Others

\begin{tabular}{|c|c|c|c|}
\hline Study & $\begin{array}{l}\text { Study } \\
\text { type }\end{array}$ & $\begin{array}{l}\text { Model/Analysis } \\
\text { framework }\end{array}$ & Remarks \\
\hline $\begin{array}{l}\text { Weiss et al. } \\
(2017)\end{array}$ & $\mathrm{O}$ & Analytical model & $\begin{array}{l}\text { Based on data from National Household Travel Survey (NHTS), the study illustrates potential driving \& charging } \\
\text { profiles for three different scenarios: Conventional ownership, Electric SAVs with centralized charging \& moderate } \\
\text { utilization \& Electric SAVs with distributed high-speed charging \& high utilization. We are not able to trace the } \\
\text { complete analysis procedure. Place of study: USA }\end{array}$ \\
\hline $\begin{array}{l}\text { Zhang \& } \\
\text { Guhathakurta } \\
\text { (2017) }\end{array}$ & B & $\begin{array}{l}\text { Discrete event simu- } \\
\text { lation }\end{array}$ & $\begin{array}{l}\text { Examination of change in parking demand when SAV services are introduced. The study uses calibrated link-level } \\
\text { travel speeds \& travel demand origin-destination matrix. Three parking scenarios, free parking, entrance-based charged } \\
\text { parking \& time-based charged parking, were simulated. } 5 \% \text { of the private car users are assumed to use SAVs \& no } \\
\text { induced demand is considered. The cost of the SAVs is } \$ 0.5 / \text { min for car-sharing \& } \$ 0.3 / \text { min for ride-sharing. A } \\
\text { customer requests is not served if the waiting time exceeds } 15 \text { min. The fixed travel times are adjusted for the morning } \\
\text { peak, midday, afternoon peak, \& night time periods. Loading \& unloading times are assumed to be } 1.5 \text { min. Closest } \\
\text { trips are served by the SAVs during off-peak hour \& first come, first served strategy is used during peak times. Trip } \\
\text { generation is based on Poisson distribution. Place of study: Atlanta }\end{array}$ \\
\hline $\begin{array}{l}\text { Zmud \& Sener } \\
(2017)\end{array}$ & A & $\begin{array}{l}\text { Car technology ac- } \\
\text { ceptance model }\end{array}$ & $\begin{array}{l}\text { Determination of acceptance for autonomous vehicles. The study includes a survey of } 556 \text { individuals. Place of study: } \\
\text { Austin }\end{array}$ \\
\hline $\begin{array}{l}\text { Alam \& Habib } \\
(2018)\end{array}$ & B & Vissim & $\begin{array}{l}\text { Evaluation of service performance of SAVs. The simulation is run for morning peak hour }(06.00-09.00) \text { \& includes } \\
57,694 \text { commute trips. } 16,900 \text { trips, which have both the origin \& destination ends within Halifax peninsula, are } \\
\text { assumed to be eligible for using SAVs. A Latin Hypercube (LH) sampling technique is used for calibrating driving } \\
\text { behaviour \& route choice parameters. The study uses a sequential modeling framework, which includes a regional } \\
\text { transport network model, a SAV operation model \& a DTA-based microsimulation model. The trips are assumed to } \\
\text { be carried out by conventional private vehicles, if the waiting time for the arrival of a SAV is more than a certain } \\
\text { threshold. Four scenarios are tested by varying the fleet size }(450,900,1800 \& 3600 \text { SAVs). Place of study: Halifax } \\
\text { (Canada) }\end{array}$ \\
\hline $\begin{array}{l}\text { Alazzawi et al. } \\
(2018)\end{array}$ & B & SUMO & $\begin{array}{l}\text { Assessment of the impact of SAV services on urban mobility. SAV service is simulated by including a custom TraCI } \\
\text { module to SUMO, thereby considering the effects of traffic queues \& spillback. The model framework can simulate a } \\
\text { conventional vehicle only scenario, SAV only scenario \& a scenarion wherein both vehicles are present. Four different } \\
\text { data sources were used in this study: OpenStreetMap for street maps of Milan, mobile phone usage data from Telecom } \\
\text { Italia Big Data Challenge } 2014 \text { for predicting time dependent OD matrix, traffic count data from Agenzia Mobilit } \\
\text { Ambiente e Territorio for calibration \& travel time data from Google Maps to evaluate the classical simulations against } \\
\text { real-world data. For simulation, Milan is spatially segmented into } 100 \times 100 \text { grid areas, each of size } 235 \mathrm{~m} \times 235 \mathrm{~m} \text {. } \\
\text { Private cars are assumed to have an average occupancy of } 1.3 \text { passengers, while SAVs have a maximum capacity of } \\
6 \text { passengers. Empty SAVs are rerouted to areas of high mobility demand \& a matching approach based on stable } \\
\text { marriage algorithm for unequal sets is used to pair passengers to SAVs. Simulation is split into two parts, a warm-up } \\
\text { phase \& a deployment phase. Place of study: Milan }\end{array}$ \\
\hline $\begin{array}{l}\text { Amanatidis } \\
\text { et al. }(2018)\end{array}$ & $\mathrm{A}$ & - & $\begin{array}{l}\text { The objective of this study is to understand user needs \& expectations for autonomous vehicle interfaces. The survey } \\
\text { included } 7 \text { participants \& covered all } 5 \text { categories of travellers defined in the UK Travellers Needs survey. Place of } \\
\text { study: UK }\end{array}$ \\
\hline $\begin{array}{l}\text { Bansal \& } \\
\text { Kockelman } \\
(2018)\end{array}$ & $\mathrm{A}$ & $\begin{array}{l}\text { Correlation analysis } \\
\& \text { interval regres- } \\
\text { sion model }\end{array}$ & $\begin{array}{l}\text { The objective of this study is to estimate an individual's SAV usage frequency \& the study includes a survey of } 1088 \\
\text { individuals. Place of study: Texas }\end{array}$ \\
\hline
\end{tabular}


Table A1: Description of impact and demand related studies

Study type - A: Studies based on surveys/workshops; B: Simulation based studies; C: Review/Opinion/discussion papers; D - Optimization programming; O - Others

\begin{tabular}{|c|c|c|c|}
\hline Study & $\begin{array}{l}\text { Study } \\
\text { type }\end{array}$ & $\begin{array}{l}\text { Model/Analysis } \\
\text { framework }\end{array}$ & Remarks \\
\hline $\begin{array}{l}\text { Bauer et al. } \\
(2018)\end{array}$ & $\mathrm{B}$ & $\begin{array}{l}\text { Agent-based simu- } \\
\text { lation }\end{array}$ & $\begin{array}{l}\text { Estimation of cost and environmental impact of SAV services. The study uses New York taxi-trip data }(349,026 \\
\text { trips) \& only those trips that started \& ended on Manhattan Island are included. The trip dates include } 04 / 02 / 2015 \text {, } \\
06 / 02 / 2015-15 / 02 / 2015 \text { (10-day period) \& } 07 / 08 / 2015-13 / 08 / 2015 \text { (for analysing flucatuation in seasonal demand). } \\
\text { Maximum waiting time is assumed as } 10 \text { min \& taxis are allowed to charge whenever they are idle. Google Maps is used } \\
\text { to estimate distance \& travel time between drop-offs \& pickups. A single operator manages the SAV service. Cost per } \\
\text { mile is estimated using a model with different cost components. An elimination method is used for locating chargers. } \\
\text { Battery range between } 10 \text { miles \& } 200 \text { miles in increments of } 10 \text { miles, number of individual chargers between } 1000 \text { \& } \\
4000 \text { in increments of } 250 \text {, number of charging locations between } 100 \& 1000 \text { in increments of } 100 \text { \& charging speeds } \\
\text { of } 7 \mathrm{~kW}, 11 \mathrm{kw}, 22 \mathrm{kw} \& 50 \mathrm{kw} \text { are considered for scenario analysis. Both accurate \& imperfect demand prediction for } \\
\text { relocation are considered. Following different cost model scenarios are tested: dynamic electricity rate, cheap batteries } \\
\& \text { expensive vehicles, cheap vehicles \& expensive batteries, no battery degradation, non-linear battery degradation \& } \\
\text { no parking costs. Both gasoline \& electric powered vehicles are simuated. Place of study: Manhattan city }\end{array}$ \\
\hline $\begin{array}{l}\text { Bösch et al. } \\
(2018 \mathrm{a})\end{array}$ & $\mathrm{O}$ & Analytical model & $\begin{array}{l}\text { Comprehensice analysis of different cost structures (overhead, parking, maintenance \& cleaning) related to SAV services. } \\
\text { Place of study: Zurich }\end{array}$ \\
\hline $\begin{array}{l}\text { Bösch et al. } \\
(2018 b)\end{array}$ & $\mathrm{B}$ & Matsim & $\begin{array}{l}\text { Investigation of the impacts of different policies for SAV services. Policies tested include subsidies for public transport, } \\
\text { taxation \& mobility pricing for private cars \& monopoly \& oligopoly market for SAV services. In base scenario, the } \\
\text { modes modelled include public transport, motorized individual transport, walking \& biking \& for the scenario analysis, } \\
\text { autonomous version of public transport \& motorized individual transport are assumed. Travel time \& total VKT are } \\
\text { used as performance indicators. Place of study: Zug (Switzerland) }\end{array}$ \\
\hline Currie (2018) & $\mathrm{C}$ & - & $\begin{array}{l}\text { The author challenges the thought that the public transport has no future \& discusses on automation \& sharing services, } \\
\text { based on various facts from the literature. Then, the author presents transit fusion as a way to enhance future of public } \\
\text { transport. Place of study: NA/NA }\end{array}$ \\
\hline $\begin{array}{l}\text { Cyganski et al. } \\
(2018)\end{array}$ & $\mathrm{B}$ & $\begin{array}{l}\text { TAPAS } \\
\text { based } \\
\text { model) }\end{array}$ & $\begin{array}{l}\text { Assessment of change in modal split due to the introduction of SAV services. Price for SAVs are assumed to be } \\
\$ 0.66 / \mathrm{km} \text { for car-sharing services \& } \$ 0.33 / \mathrm{km} \text { for ride-sharing services. Value of travel time used is } 3.87 \$ / \mathrm{hr} \text { for trip } \\
\text { distance less than or equal to } 10 \mathrm{~km} \& 5.3 \$ / \mathrm{hr} \text { for trips greater than } 10 \mathrm{~km} \text {. Place of study: Brunswick }\end{array}$ \\
\hline $\begin{array}{l}\text { Dowling et al. } \\
(2018)\end{array}$ & $\mathrm{A}$ & - & $\begin{array}{l}\text { Exploration of material entanglements that constitute car-sharing, based on an interview of } 35 \text { individuals. Place of } \\
\text { study: Sydney }\end{array}$ \\
\hline $\begin{array}{l}\text { Fagnant \& } \\
\text { Kockelman } \\
(2018)\end{array}$ & $\mathrm{B}$ & $\begin{array}{l}\text { Agent-based simu- } \\
\text { lation }\end{array}$ & $\begin{array}{l}\text { Evaluation of impacts of SAV services. This study builds on Fagnant \& Kockelman (2014), by including a Dynamic } \\
\text { Ride-Sharing (DRS) module. } 1.3 \% \text { of trips (2010 trip tables) in Austin are considered for the analysis. The original } \\
\text { model from } 2014 \text { contains SAV location \& trip assignment module, SAV fleet generation module, SAV movement } \\
\text { module \& SAV relocation module. Maximum waiting time is assumed to be } 10 \text { min. A non-DRS scenario, a DRS } \\
\text { scenario \& a mixed scenario are simulated. Scenario analysis is also carried out by increasing the } 1.3 \% \text { demand by } \\
\text { factors of } 2 \text { \& } 5 \text {. Texas statewide dataset is used to simulate day-to-day variations in travel demand. Trips with } \\
\text { travel distance more than } 50 \text { miles are not included, \& Golden Section Search optimization procedure (Shao \& Chang, } \\
5 / 4 / 2008-5 / 7 / 2008) \text { is used to run a series of simulations. Operating costs of } \$ 0.31 / \mathrm{km} \& \$ 0.16 / \mathrm{km} \text { are used. Place } \\
\text { of study: Austin }\end{array}$ \\
\hline
\end{tabular}


Table A1: Description of impact and demand related studies

Study type - A: Studies based on surveys/workshops; B: Simulation based studies; C: Review/Opinion/discussion papers; D - Optimization programming; O - Others

\begin{tabular}{|c|c|c|c|}
\hline Study & $\begin{array}{l}\text { Study } \\
\text { type }\end{array}$ & $\begin{array}{l}\text { Model/Analysis } \\
\text { framework }\end{array}$ & Remarks \\
\hline $\begin{array}{l}\text { Fraedrich et al. } \\
\text { (2018) }\end{array}$ & $\mathrm{A}, \mathrm{C}$ & - & $\begin{array}{l}\text { Examination of compatibility of the impacts of autonomous vehicles with municipalities' existing objectives. The study } \\
\text { includes a systematic review of literature, a quantitative online survey \& qualitative interviews with urban transport } \\
\text { planning authorities. A total of } 24 \text { respondents took part in the survey \& the interview. Place of study: Germany }\end{array}$ \\
\hline $\begin{array}{l}\text { Grush \& Niles } \\
(2018)\end{array}$ & $\mathrm{O}$ & Diffusion modelling & $\begin{array}{l}\text { The authors segment the adoption of vehicle automation into four phases, namely Early }(2018-2033) \text {, Rising }(2025- \\
\text { 2048), Plateau }(2032-2063) \& \text { Mature }(2039-2078) \text {, \& suggests ways to plan for the four autonomous vehicle eras. } \\
\text { They propose a performance-based regulatory system that adapts \& responds dynamically to continuous changes. Place } \\
\text { of study: NA/NA }\end{array}$ \\
\hline $\begin{array}{l}\text { Gurumurthy } \\
\& \quad \text { Kockelman } \\
(2018)\end{array}$ & B & Custom framework & $\begin{array}{l}\text { Assessment of dynamic ride-sharing potential for SAV services. Mobile data obtained from AirSage for a period of } \\
30 \text { consecutive days is used in this study. One hour aggregated mobile data is disaggregated to } 1 \text { min time-steps by } \\
\text { randomizing the trip departure times in the dataset for minute level \& then uniformly sampling the trips. Travel } \\
\text { times are based on shortest path travel times \& TransCAD is used for the same. Around } 2.8 \text { million single occupancy } \\
\text { vehicle trips are simulated. The simulation framework consists of three blocks: SAV allocation, SAV update \& waitlist } \\
\text { management. Maximum vehicle occupancy is assumed to be } 4 \text {. Different values of maximum delay (5min to } 30 \text { min in } \\
\text { increments of 5min) are simulated. Place of study: Orlando metropolitan area }\end{array}$ \\
\hline $\begin{array}{l}\text { International } \\
\text { Transport } \\
\text { Forum (2018) }\end{array}$ & $\mathrm{A}$ & - & $\begin{array}{l}\text { The report discusses about various road safety issues \& security vulnerabilities associated with autonomous vehicle, } \\
\text { based on the conclusions from the Workshop "Safety \& Security on the Road to Automated Transport: The Good, the } \\
\text { Uncertain \& the Necessary", held in November } 2017 \text { in Paris, France. Place of study: NA/NA }\end{array}$ \\
\hline $\begin{array}{l}\text { Jäger et al. } \\
(2018)\end{array}$ & $\mathrm{B}$ & $\begin{array}{l}\text { Agent-based dis- } \\
\text { crete event simula- } \\
\text { tion }\end{array}$ & $\begin{array}{l}\text { The study analyses the replacement of an existing citywide fixed-route bus system with demand responsive SAV service } \\
\text { (electric vehicles). The bus system consists of } 14 \text { bus depots \& } 4,923 \text { stops, including } 35 \text { hubs, } 35 \text { interchanges \& } 23 \\
\text { terminals. The road network is fetched from OpenStreetMap \& the demand data is obtained from Singapore's Land } \\
\text { Transport Authority (smart card data from the year 2013). A weekday sample is used for the analysis \& consecutive } \\
\text { bus trips are combined into a single journey. A } 2.3 \text { million requests are simulated \& the capacity of a SAV is assumed } \\
\text { to be } 6 \text {. Stops are pre-defined for boarding \& alighting. Travel time is calculated based on free-floating traffic \& a } \\
\text { speed factor distribution estimated using real traffic data. Place of study: Singapore }\end{array}$ \\
\hline $\begin{array}{l}\text { Kondor et al. } \\
(2018)\end{array}$ & $\mathrm{O}$ & $\begin{array}{l}\text { Data-driven } \\
\text { methodology }\end{array}$ & $\begin{array}{l}\text { Estimation of commuter parking needs. The study used mobile phone network logs to estimate home \& work locations } \\
\text { for a sample of over } 1 \text { million commuters. Travel times were calculated based on average travel times between a set } \\
\text { of road intersections, which was provided by the Land Transport Authority. Avergae travel time between 7AM \& } \\
8 \mathrm{AM} \text { for home to work \& between } 4 \mathrm{PM} \& 5 \mathrm{PM} \text { for work to home were used. Four scenarios, conventional private cars } \\
\text { with private parking, conventional private cars with shared parking, conventional shared vehicles \& SAV services, were } \\
\text { tested \& different values, were tried out for the maximum distance allowed between destination \& parking spot (upto } \\
1.5 \mathrm{~km}, \text {,). Place of study: Singapore }\end{array}$ \\
\hline $\begin{array}{l}\text { Lang et al. } \\
(2018)\end{array}$ & $\mathrm{A}, \mathrm{B}$ & $\begin{array}{l}\text { Conjoint analysis \& } \\
\text { Agent-based simu- } \\
\text { lation }\end{array}$ & $\begin{array}{l}\text { Exploration of impact of autonomous vehicles on urban mobility. The study included a survey of } 2,400 \text { individuals (a } \\
\text { representative sample across gender, age, location \& income) \& the choice of modes for the survey were bus/subway, } \\
\text { commuter rail, taxi/ride-hailing, personal vehicle, autonomous personal vehicle, autonomous taxi, autonomous shared } \\
\text { taxi, autonomous minibus. For the analysis, the survey data was grouped into mass transit, personal car \& mobility- } \\
\text { on-demand. A simulation was conducted using the survey results for the year } 2030 \text {. The simulation included } 2 \text { million } \\
\text { daily passenger vehicle trips (from INRIX \& City of Boston) \& } 10,000 \text { commercial vehicle trips (from INRIX \& UPS). } \\
\text { Based on SAV share, vehicle throughput is increased by } 6.3 \% \text {. The simulation included modelling of each vehicle's } \\
\text { behaviour \& vehicle-to-vehicle interaction. Place of study: Boston }\end{array}$ \\
\hline
\end{tabular}


Table A1: Description of impact and demand related studies

Study type - A: Studies based on surveys/workshops; B: Simulation based studies; C: Review/Opinion/discussion papers; D - Optimization programming; O - Others

\begin{tabular}{|c|c|c|c|}
\hline Study & $\begin{array}{l}\text { Study } \\
\text { type }\end{array}$ & $\begin{array}{l}\text { Model/Analysis } \\
\text { framework }\end{array}$ & Remarks \\
\hline $\begin{array}{l}\text { Legacy et al. } \\
(2018)\end{array}$ & $\mathrm{A}, \mathrm{C}$ & - & $\begin{array}{l}\text { The study included a review on existing literature to explore current research within three themes, namely neoclassical } \\
\text { modelling techniques, sustainable development approaches \& role of political economies to shape \& reproduce certain } \\
\text { transport trajectories. To understand the concerns of planners in the early stages of autonomous vehicle rollout, inter- } \\
\text { views with } 6 \text { public sector planners were conducted. Finally, a comparison was made between issues being considered } \\
\text { in the emerging academic literature \& questions identified from the interview. Place of study: Australia }\end{array}$ \\
\hline Litman (2018) & $\mathrm{C}$ & - & $\begin{array}{l}\text { This report derives conclusions on costs \& impacts of autonomous vehicles, based on an analysis of results from the } \\
\text { literature. Place of study: NA/NA }\end{array}$ \\
\hline $\begin{array}{l}\text { Loeb et al. } \\
(2018)\end{array}$ & B & Matsim & $\begin{array}{l}\text { Evaluation of the performance characteristics of electric SAVs. The study builds on Bösch et al. (2016), by modifying } \\
\text { their model to simulate a range-constrained electric SAV. } 5 \% \text { of trips in the area ( } 2010 \text { trip tables) are considered for } \\
\text { the analysis \& network capacity is reduced proportionally. } 2 \% \text { of the trips are assumed to be carried out in SAVs \& } \\
\text { trips with travel distance more than } 75 \mathrm{~km} \text { are excluded. Network data is obtained from OpenStreetMap. Charging } \\
\text { stations are placed based on initial model runs. The simulation consists of three steps, namley tour generation, traffic } \\
\text { assignment \& SAV simulation. While travel times for SAV trips are from Matsim, for empty vehicle movements, } \\
\text { beeline/Euclidean distance between each origin-destination pair, a trip-specific distance correction factor \& average } \\
\text { speed across the entire network are used. Fleet size is based on assumption on average ridership per vehicle (varied } \\
\text { from } 3: 1 \text { to } 9: 1 \text { in increments of } 1 \text { ). Scenario analysis include variation on the charging time ( } 30 \text { min to } 240 \mathrm{~min}) \text { in } \\
\text { increments of } 30 \mathrm{~min} \& \text { battery range (100km to } 325 \mathrm{~km} \text { in increments of } 25 \mathrm{~km} \text { ). Place of study: Austin }\end{array}$ \\
\hline $\begin{array}{l}\text { Lokhandwala } \\
\text { \& Cai (2018) }\end{array}$ & $\mathrm{B}$ & $\begin{array}{l}\text { Agent-based simu- } \\
\text { lation }\end{array}$ & $\begin{array}{l}\text { Analysis of impacts, when users switch from traditional taxis to SAVs. New York city taxi data from } 2014(07 / 05 / 2014) \\
\text { is used \& the morning peak from 7:00am to } 3: 00 \mathrm{pm} \& \text { the evening peak from } 5: 00 \mathrm{pm} \text { to midnight is considered for the } \\
\text { analysis. Vehicle capacity is assumed to be } 4 \& \text { maximum waiting time is assumed to be } 5 \text { min. Beyond } 5 \text { min, the user } \\
\text { exits the system unserved. Minimum deviation for ride-sharing is } 100 \mathrm{~m} \& \text { maximum is } 10 \mathrm{~km} \text {. Deviation tolerance } \\
\text { is assumed to follow a triangular distribution with mean as } 0.5 \& \text { minimum \& maximum values as } 0 \text { \& } 1 \text {. Scenario } \\
\text { analysis is carried out by varying fleet size }(3000,4000,5000,5500,6000,7000 \& 8000) \& \text { percentage of users willing } \\
\text { to share rides }(0 \%, 25 \%, 50 \%, 75 \% \& 100 \%) \text {. Place of study: NA/NA }\end{array}$ \\
\hline $\begin{array}{l}\text { Mena-Oreja } \\
\text { et al. (2018) }\end{array}$ & B & $\begin{array}{l}\text { PERMIT simulator } \\
\text { along with SUMO } \\
\text { \& Plexe }\end{array}$ & $\begin{array}{l}\text { Modelling of impact of automation on road capacity. A maximum platoon length of } 2 \text { vehicles \& a desired gap with the } \\
\text { front vehicle of } 10 \mathrm{~m}, 5 \mathrm{~m} \& 1 \mathrm{~m} \text { were assumed. A safe gap of } 1.25 \text { times the desired gap was used during the platooning } \\
\text { manoeuvres. Place of study: a } 10 \mathrm{~km} \text { ring road with } 2 \text { lanes }\end{array}$ \\
\hline $\begin{array}{l}\text { Menon et al. } \\
(2018)\end{array}$ & $\mathrm{O}$ & $\begin{array}{l}\text { Ordered } \\
\text { model }\end{array}$ & $\begin{array}{l}\text { Investigation of relinquishing of private vehicles in the presence of SAV services. Ordered probit models, one for single \& } \\
\text { another for multi vehicle households, were built based on the data from a survey comprising of } 1214 \text { individuals (faculty, } \\
\text { students, \& staff from University of South Florida \& the members of the American Automobile Association (AAA) } \\
\text { Foundation of the south eastern United States). The participants included } 417 \text { single-vehicle household members \& } \\
797 \text { multivehicle household members. Place of study: USA }\end{array}$ \\
\hline $\begin{array}{l}\text { Moreno et al. } \\
(2018)\end{array}$ & A, B & Matsim & $\begin{array}{l}\text { Estimation of the impact of SAVs on average trip duration and VMT/VKT. A two step selection process for mode } \\
\text { choice was implemented. In the first step, the available modes included auto, public transport (metro, tram, \& bus), } \\
\text { bicycling \& walking. In the second step, auto users had the choice to choose between private conventional vehicle } \\
\& \text { SAV. The probability to select SAV was based on a logit model estimated from a stated preference survey. The } \\
\text { stated preference survey included responses from } 106 \text { individuals. Ten different substitution rates, which represents the } \\
\text { number of SAVs that replace } 10 \text { private conventional vehicles, were tested \& the values tested range from } 1 \text {-for-10 to } \\
\text { 10-for-10. Place of study: greater Munich region }\end{array}$ \\
\hline
\end{tabular}


Table A1: Description of impact and demand related studies

Study type - A: Studies based on surveys/workshops; B: Simulation based studies; C: Review/Opinion/discussion papers; D - Optimization programming; O - Others

\begin{tabular}{|c|c|c|c|}
\hline Study & $\begin{array}{l}\text { Study } \\
\text { type }\end{array}$ & $\begin{array}{l}\text { Model/Analysis } \\
\text { framework }\end{array}$ & Remarks \\
\hline $\begin{array}{l}\text { Nazari et al. } \\
(2018)\end{array}$ & $\mathrm{A}$ & $\begin{array}{l}\text { Ordered } \\
\text { models }\end{array}$ & $\begin{array}{l}\text { The authors conducted a stated preference survey to assess public interest towards private autonomous vehicles \& } \\
\text { SAVs, including both car-sharing \& ride-sharing, \& to find correlations across the SAV service types. A total of } 2726 \\
\text { individuals participated in the survey. Place of study: Puget Sound region }\end{array}$ \\
\hline $\begin{array}{l}\text { Olia et al. } \\
(2018)\end{array}$ & B & $\begin{array}{l}\text { Paramics }(\text { mi- } \\
\text { crosimulation })\end{array}$ & $\begin{array}{l}\text { Analysis of the impact of mixed traffic on road capacity. A headway of } 1 \mathrm{~s} \text { is assumed for normal autonomous vehicles. } \\
\text { When a connected autonomous vehicle follows another connected autonomous vehicle, a headway of } 0.5 \mathrm{~s} \text { is assumed \& } \\
\text { in other cases, a value of } 1 \mathrm{~s} \text { is used. Place of study: a } 20 \mathrm{~km} \text { highway segment with two lanes \& an on-ramp }\end{array}$ \\
\hline $\begin{array}{l}\text { Pakusch et al. } \\
(2018)\end{array}$ & $\mathrm{A}$ & $\begin{array}{l}\text { Bradley-Terry-Luce } \\
\text { model }\end{array}$ & $\begin{array}{l}\text { Assessment of acceptance for autonomous vehicles. The study includes a survey of } 302 \text { individuals. Place of study: } \\
\text { Germany }\end{array}$ \\
\hline $\begin{array}{l}\text { Salazar et al. } \\
(2018)\end{array}$ & $\mathrm{D}$ & $\begin{array}{l}\text { Multi-commodity } \\
\text { network flow } \\
\text { (mesoscopic) opti- } \\
\text { mization model }\end{array}$ & $\begin{array}{l}\text { Study of models and coordination policies for integrated PT-SAV system. Electric SAVs are coupled with public } \\
\text { transport system, i.e., customer routes are optimized by accounting for both SAV \& public transportation services. } \\
\text { The goal is to maximize social welfare. Road capacity has been reduced to account for other vehicles in the road } \\
\text { network \& a scaling factor (varied between } 0 \& 10 \% \text { is used for the same. Travel requests are assumed to be time } \\
\text { invariant \& a simple threshold model, consistent with classical traffic flow theory, is used for estimating travel time. } \\
\text { Customer \& vehicle routes are represented as fractional flows. Stochastic nature of the customer arrival process \& } \\
\text { the residual traffic in the network are not considered. Only car-sharing is assumed for SAV service \& the customers } \\
\text { are assumed to set routes by themselves, using navigation apps. The study assumes perfect SAV service market, i.e., } \\
\text { the transportation prices are set by the market equilibrium. The value of travel time is assumed to be } \$ 24.40 / \mathrm{h} \& \\
\text { operational cost for SAV service (without consideration of electricity) is assumed to be } \$ 0.30 / \mathrm{mile} \text {. The data used for } \\
\text { analysis is New York Taxi data ( } 53,932 \text { taxi trips carried out on } 01 / 03 / 2012 \text { between } 6 \mathrm{pm} \mathrm{\&} 8 \mathrm{pm} \text { ). A pricing \& tolling } \\
\text { scheme to achieve social optimum is also designed \& tested. Place of study: Manhattan }\end{array}$ \\
\hline $\begin{array}{l}\text { Schatzinger } \\
\text { et al. }(2018)\end{array}$ & A & Gap analysis & $\begin{array}{l}\text { Evaluation of the potential of three different taxi services (electric taxi, autonomous taxi \& shared taxi) to enhance } \\
\text { urban mobility system. The study include expert interviews \& an expert workshop. The services are analysed for the } \\
\text { year } 2025 \text { \& a total of } 20 \text { taxi experts have taken part in the study. Place of study: Hamburg }\end{array}$ \\
\hline $\begin{array}{l}\text { Shen et al. } \\
(2018)\end{array}$ & B & AnyLogic & $\begin{array}{l}\text { The study analyses the effects of introducing SAV services for first-mile connectivity (connection to MRT stations), } \\
\text { during morning peak hours (06:00 to 09:00). The data used in this study is smart card data, corresponding to trips done } \\
\text { in August } 2013 \text {. SAVs are assumed to replace } 11 \text { low-demand buses }(10 \% \text { of the demand) \& the remaining } 16 \text { buses } \\
\text { ( } 90 \% \text { of the demand) continue to serve. Idle SAVs are sent to the parking lot of Tampines MRT station. Maximum } \\
\text { waiting time is assumed to be } 10 \text { min, the vehicle capacity is } 4 \& \text { bus dwell time is } 30 \text { s. The first hour of simulation } \\
\text { ((06:00 to 07:00) is considered as warm-up period \& the next two hours are used for analysis. The cost of service is } \\
\text { assumed to be } \$ 1 / \mathrm{km} \text {. Detour ratio is used to calculate discount for ride-sharing trips. Scenario analysis include } \\
\text { different fleet sizes (10 to } 35) \& \text { two extreme sharing settings (no one willing to share ride \& everyone willing to share). } \\
\text { Place of study: Tampines (Singapore) }\end{array}$ \\
\hline $\begin{array}{l}\text { Singleton } \\
(2018)\end{array}$ & $\mathrm{C}$ & - & $\begin{array}{l}\text { A position paper that argues on impact of autonomous vehicles on value of travel time, based on existing studies from } \\
\text { the literature. Place of study: NA/NA }\end{array}$ \\
\hline $\begin{array}{l}\text { Soteropoulos } \\
\text { et al. (2018) }\end{array}$ & $\mathrm{C}$ & - & $\begin{array}{l}\text { The paper reviews various modelling studies that are investigating the impacts of autonomous vehicles on travel } \\
\text { behaviour \& land use. Place of study: NA/NA }\end{array}$ \\
\hline
\end{tabular}


Table A1: Description of impact and demand related studies

Study type - A: Studies based on surveys/workshops; B: Simulation based studies; C: Review/Opinion/discussion papers; D - Optimization programming; O - Others

\begin{tabular}{|c|c|c|c|}
\hline Study & $\begin{array}{l}\text { Study } \\
\text { type }\end{array}$ & $\begin{array}{l}\text { Model/Analysis } \\
\text { framework }\end{array}$ & Remarks \\
\hline Sprei (2018) & $\mathrm{C}$ & - & $\begin{array}{l}\text { The author, based on conclusions from various other studies, examine the potential of electrification, shared mobility } \\
\& \text { autonomous vehicles (both individually \& toghether) to disrupt auto industry, transport system \& energy system. } \\
\text { Place of study: NA/NA }\end{array}$ \\
\hline $\begin{array}{lll}\text { Steck } & \text { et al. } \\
(2018) & & \end{array}$ & A & Mixed logit model & $\begin{array}{l}\text { Assessment of the impact of autonomous driving on value of travel time savings (VTTS) \& mode choice for commuting } \\
\text { trips. The study is based on an online survey of } 172 \text { respondents, representative of Germany by age ( }>18 \text { years) \& } \\
\text { gender. The modes available are walking, cycling, public transportation, private autonomous vehicle \& SAV. Place of } \\
\text { study: Germany }\end{array}$ \\
\hline $\begin{array}{l}\text { Stocker \& Sha- } \\
\text { heen }(2018)\end{array}$ & $\mathrm{C}$ & - & The study discusses on the current pilot projects \& policies related to autonomous vehicles. Place of study: USA \\
\hline $\begin{array}{l}\text { Vleugel \& Bal } \\
(2018)\end{array}$ & $\mathrm{O}$ & MS Excel & $\begin{array}{l}\text { Evaluation of the potential reduction in parking space \& emissions due to SAV services. The scenario analysed is for } \\
2040 \text {, where all private cars are replaced by electric SAVs \& small shuttle buses, integrated with mass transport, cycling } \\
\& \text { walking. Roads are assumed to take } 10 \% \text { of the space in the city \& the population in the city increases by } 30 \% \text { from } \\
\text { the base year. Average search time for parking is assumed to be } 5 \text { minutes. Place of study: Virtual city similar to } \\
\text { Amsterdam }\end{array}$ \\
\hline Watkins (2018) & $\mathrm{C}$ & - & An opinion paper based on the discussions within the Transport \& Health Study Group (UK). Place of study: NA/NA \\
\hline $\begin{array}{l}\text { Zhang \& } \\
\text { Guhathakurta } \\
\text { (2018) }\end{array}$ & $\mathrm{B}$ & $\begin{array}{l}\text { Agent-based simu- } \\
\text { lation }\end{array}$ & $\begin{array}{l}\text { Examination of the potential changes in residential location choice because of SAV services. In this study, a residential } \\
\text { location choice model (developed using } 2011 \text { Atlanta Travel Survey \& Zillow home sales data) is integrated with the } \\
\text { SAV simulation model of Zhang \& Guhathakurta (2017). Future home location choices are simulated based on current } \\
\text { home location \& real estate patterns. The demand in the region is assumed to be served by SAVs. Multinomial logit } \\
\text { model is used for residential location choice. Trip departure time distribution is from } 2011 \text { ARC travel survey, \& the } \\
\text { link level travel speeds are fetched from the travel demand model of Atlanta Regional Commission. Cost for SAV } \\
\text { service is assumed to be } \$ 0.12 / \mathrm{km}, \& \text { a scenario analysis is conducted based on reduction in in-vehicle travel time cost } \\
\text { ( } 25 \% \text { to } 100 \% \text { reduction). Place of study: Atlanta metropolitan area }\end{array}$ \\
\hline $\begin{array}{l}\text { Zhao \& Kockel- } \\
\text { man (2018) }\end{array}$ & $\mathrm{B}$ & $\begin{array}{l}\text { Modified four- } \\
\text { step model of the } \\
\text { CAMPO region }\end{array}$ & $\begin{array}{l}\text { Evaluation of the impacts of autonomous vehicles. In this study, the gravity model in a tradition four-step model for } \\
\text { destination choice was replaced with a multinomial logit model. Nested multinomial logit model for mode choice was } \\
\text { replaced with a simple multinomial logit model. Parameters were assumed based on the original model \& the National } \\
\text { Cooperative Highway Research Program's (NCHRP) Report } 716 \text {. Four modes, conventional car, private autonomous } \\
\text { vehicle, SAV \& Bus, were included for analysis, \& feedback between assignment step \& destination choice model was } \\
\text { implemented. Truck trip tables were directly added to the assignment step. The value of travel time for autonomous } \\
\text { vehicles was assumed to be half of the conventional vehicles. The analysis was done for a weekday morning peak } \\
\text { demand in } 2020 \text {. The operating costs of conventional car, private autonomous vehicle \& SAV were assumed to be } \\
\$ 0.12 / \mathrm{km}, \$ 0.25 / \mathrm{km} \& \$ 0.62 / \mathrm{km} \text {, respectively. Place of study: Austin }\end{array}$ \\
\hline $\begin{array}{l}\text { Acheampong } \\
\& \quad \text { Cugurullo } \\
(2019)\end{array}$ & A & $\begin{array}{l}\text { Confirmatory factor } \\
\text { analysis }\end{array}$ & $\begin{array}{l}\text { Development of behaviourally-consistent methodologies to study autonomous vehicle adoption. This study includes } \\
\text { a survey of } 507 \text { participants. It captures behavioural antecedents, including latent socio-psychological and socio- } \\
\text { demographic factors, to predict autonomous vehicle ownership and sharing, by validating around } 45 \text { pairs of hypothe- } \\
\text { sized relationships. Place of study: Greater Dublin Area }\end{array}$ \\
\hline
\end{tabular}


Table A1: Description of impact and demand related studies

Study type - A: Studies based on surveys/workshops; B: Simulation based studies; C: Review/Opinion/discussion papers; D - Optimization programming; O - Others

\begin{tabular}{|c|c|c|c|}
\hline Study & $\begin{array}{l}\text { Study } \\
\text { type }\end{array}$ & $\begin{array}{l}\text { Model/Analysis } \\
\text { framework }\end{array}$ & Remarks \\
\hline $\begin{array}{l}\text { Cohen \& } \\
\text { Cavoli (2019) }\end{array}$ & $\mathrm{A}, \mathrm{C}$ & - & $\begin{array}{l}\text { Assessment of the long-term effects of lack of intervention of the government to channelise the growth of autonomous } \\
\text { vehicles. The study includes results from a methodological literature review \& workshops. Place of study: UK \& } \\
\text { France }\end{array}$ \\
\hline $\begin{array}{l}\text { Gkartzonikas \& } \\
\text { Gkritza (2019) }\end{array}$ & $\mathrm{C}$ & - & A literature review of stated preference studies related to autonomous vehicles. Place of study: NA/NA \\
\hline $\begin{array}{l}\text { Jones \& Lei- } \\
\text { bowicz }(2019)\end{array}$ & $\mathrm{D}$ & $\begin{array}{lr}\text { Modified } & \text { Open } \\
\text { Source } & \text { Energy } \\
\text { Modeling } & \text { System } \\
(\text { OSeMOSYS) }\end{array}$ & $\begin{array}{l}\text { Development of an energy system optimization model that integrates the electricity and transport sectors, and inves- } \\
\text { tigation of interactions between SAVs and energy system in } 2050 \text {. The developed model distinguishes between SAVs } \\
\text { and private autonomous vehicles based on capital cost, efficiency, operational life and technology growth rate. SAVs } \\
\text { are assumed to replace } 70 \% \text { of the VMT of private vehicles. Ten different scenarios are constructed, differentiated by } \\
\text { SAV diffusion profiles, carbon policy, the effect of SAVs on travel demand, and whether electric SAV charging can be } \\
\text { centrally coordinated by the system optimizing agent. Place of study: Austin. Place of study: Austin }\end{array}$ \\
\hline $\begin{array}{l}\text { Lavieri \& Bhat } \\
(2019)\end{array}$ & A & $\begin{array}{l}\text { Generalized hetero- } \\
\text { geneous data model } \\
\text { (combination of la- } \\
\text { tent variable struc- } \\
\text { tural \& measure- } \\
\text { ment equation mod- } \\
\text { els) }\end{array}$ & $\begin{array}{l}\text { Examination of current choice and future intention with respect to shared rides, and estimation of individuals willingness } \\
\text { to share (money value attributed by an individual to traveling alone compared to riding with strangers) for two distinct } \\
\text { trip purposes, commute and leisure trips. This study includes a survey targeting commuters, and the survey includes } \\
1607 \text { respondents. The sample has an over-representation of men, individuals between } 45 \& 64 \text { years of age, Non- } \\
\text { Hispanic Whites, \& individuals with bachelors or post-graduate degrees. Majority of the sample are full time-employees } \\
\text { (around } 82 \% \text { ). Three-forth of the respondents live in non-urban areas, with more than } 50 \% \text { owning private vehicles. } \\
\text { Place of study: Dallas-Fort Worth Metropolitan Area }\end{array}$ \\
\hline $\begin{array}{l}\text { Lee et al. } \\
(2019)\end{array}$ & A & $\begin{array}{l}\text { Factor analysis \& } \\
\text { Structural equation } \\
\text { model }\end{array}$ & $\begin{array}{l}\text { Investigation of influential factors for intention to use autonomous vehicles and its perceived usefulness. } 313 \text { participants, } \\
\text { recruited from the research panel of Macromill Embrain, are surveyed in this study. } 190 \text { of the } 313 \text { participants have } \\
\text { a personal vehicle. Age of the participants is between } 14 \text { to } 67 \text {. Place of study: South Korea }\end{array}$ \\
\hline $\begin{array}{l}\text { Pettigrew et al. } \\
(2019)\end{array}$ & A & $\begin{array}{l}\text { Latent profile anal- } \\
\text { ysis }\end{array}$ & $\begin{array}{l}\text { Identification of clusters of potential autonomous vehicle users. The study includes a survey sample of } 1345 \text { individuals. } \\
\text { The sample is uniformly distributed across gender and age categories }(16-30,31-50 \& 50+) \text {. Place of study: Australia }\end{array}$ \\
\hline $\begin{array}{l}\text { Philipsen et al. } \\
\text { (2019) }\end{array}$ & A & $\begin{array}{l}\text { Cohen's d \& rank- } \\
\text { biserial correlations } \\
\& \quad \text { bayesian-based } \\
\text { methods }\end{array}$ & $\begin{array}{l}\text { The authors interviewed } 54 \text { individuals to identify user requirements for SAVs \& then conducted a questionnaire study } \\
\text { to quantify them. The questionnaire study included } 893 \text { participants \& Cohen's d \& rank-biserial correlations }(\mathrm{a}= \\
0.05) \& \text { bayesian-based methods with a prior based on Cauchy distribution }(\mathrm{r}=0.707) \text { were used for analysis. Place } \\
\text { of study: Germany }\end{array}$ \\
\hline $\begin{array}{l}\text { Simoni et al. } \\
(2019)\end{array}$ & B & Matsim & $\begin{array}{l}\text { Evaluation of the effects of different congestion pricing and tolling strategies. A sample of } 5 \% \text { of the total population } \\
\text { (45,000 agents) in the study are simulated. Two different future scenarios, AV- and SAV-oriented, are analysed. In the } \\
\text { SAV-oriented scenario, one vehicle is available for every } 10 \text { agents. The maximum flow allowed in a link depends on } \\
\text { the proportion of autonomous vehicles in the link. Pricing strategies evaluated are divided into two categories, namely } \\
\text { traditional and advanced schemes. Traditional schemes include a link-based (charging on most congested links during } \\
\text { peak hour) and a distance-based toll, while advanced schemes include a time-varying link-based toll (dynamic marginal } \\
\text { cost pricing scheme at link level) and a travel time-based charge that depends on network conditions. Place of study: } \\
\text { Austin. Place of study: Austin }\end{array}$ \\
\hline
\end{tabular}


Table A1: Description of impact and demand related studies

Study type - A: Studies based on surveys/workshops; B: Simulation based studies; C: Review/Opinion/discussion papers; D - Optimization programming; O - Others

\begin{tabular}{|c|c|c|c|}
\hline Study & $\begin{array}{l}\text { Study } \\
\text { type }\end{array}$ & $\begin{array}{l}\text { Model/Analysis } \\
\text { framework }\end{array}$ & Remarks \\
\hline $\begin{array}{l}\text { Stoiber et al. } \\
(2019)\end{array}$ & $\mathrm{A}$ & $\begin{array}{l}\text { Ordinal logistic } \\
\text { model with pro- } \\
\text { portional odds and } \\
\text { quasi-likelihood } \\
\text { estimation }\end{array}$ & $\begin{array}{l}\text { Assessment of user preference towards using ride-sharing SAVs. Details from around } 680 \text { survey respondents are used } \\
\text { to carry out the assessment. The original sample has over-representation of public transport subscription holders } \\
\text { and car-free households, and hence, has been weighted with respect to car ownership, based on the Mikrozensus data } \\
\text { (official Swiss mobility survey). The authors test the influence of } 15 \text { short-term and } 13 \text { long-term decision instruments } \\
\text { to encourage the use of ridesharing SAVs. Place of study: Switzerland }\end{array}$ \\
\hline $\begin{array}{l}\text { Täihagh \& Lim } \\
\text { (2019) }\end{array}$ & $\mathrm{C}$ & - & $\begin{array}{l}\text { The authors review the risks associated with autonomous vehicles (safety, liability, privacy, cybersecurity, \& industry } \\
\text { influence) \& explore strategies that can be adopted to address these risks. Also, current policy developments for } \\
\text { autonomous vehicles in different countries are critiqued. Place of study: Australia, China, EU, Germany, Japan, South } \\
\text { Korea, Singapore, US \& UK }\end{array}$ \\
\hline $\begin{array}{l}\text { Vosooghi et al. } \\
\text { (2019) }\end{array}$ & $\mathrm{B}$ & Matsim & $\begin{array}{l}\text { Investigation of the design of a SAV service, based on its demand responsiveness, user taste variations and traffic } \\
\text { in a multimodal context. The study incorporates a multimodal dynamic demand system with integrated SAV user } \\
\text { taste variation in Matsim. Scenarios are constructed based on fleet size }(2,000 \text { to } 6,000) \text {, vehicle capacity }(2,4, \& \\
6) \text {, rebalancing strategy and presence of ridesharing. In scenarios with rebalancing, rebalancing is carried out every } 5 \\
\text { minutes. For ride-sharing scenarios, detour time is is restricted to } 30 \% \text { of the direct travel time. Price is assumed to } \\
\text { be } \$ 0.56 / \mathrm{km} \text { for car-sharing system and } \$ 0.44 / \mathrm{km} \text { for ride-sharing system. Two more prices for ride-sharing system } \\
\$ 0.33 / \mathrm{km} \& \$ 0.22 / \mathrm{km} \text { are also tested. SAV fleet is initially distributed at four fixed points in the city. Place of study: } \\
\text { Rouen Normandie metropolitan area (France) }\end{array}$ \\
\hline $\begin{array}{l}\text { Wang \& Akar } \\
(2019)\end{array}$ & $\mathrm{A}$ & $\begin{array}{l}\text { Bivariate ordered } \\
\text { probit model }\end{array}$ & $\begin{array}{l}\text { Investigation of level of interest in (i) commuting alone using autonomous vehicles and (ii) commuting with others } \\
\text { using SAVs. The study uses the data of } 3,515 \text { respondents of the survey conducted by Puget Sound Regional Council } \\
\text { in } 2015 \text { and } 2017 \text {, regarding autonomous vehicles. No common respondent is found between both the years. Place of } \\
\text { study: Puget Sound region }\end{array}$ \\
\hline $\begin{array}{l}\text { Webb et al. } \\
(2019)\end{array}$ & $\mathrm{A}$ & $\begin{array}{l}\text { Multinomial } \\
\text { model }\end{array}$ & $\begin{array}{l}\text { Analysis of willingness to trade-off ownership of conventional internal combustion engine cars for electric SAVs. Two } \\
\text { step survey process is implemented. } 275 \text { individuals participated in the first survey and } 172 \text { participated in the second. } \\
\text { Almost all participants owns a car, and have access to or owns a second car. They live around } 11.5 \mathrm{~km} \text { from the } \\
\text { downtown, with } 50 \% \text { of them travelling to work place by car. The mean age is between } 48 \text { and } 49 \text { years, with mean } \\
\text { annual income level of around } \$ 87,000-88,000 \text {. People with age between } 10-25 \text { and those over } 65 \text { are under-represented. } \\
\text { Following three choices are displayed to the participants in the survey: i) } 50 \% \text { of their trips carried out using SAV and } \\
\text { the rest using their private vehicle, ii) } 80 \% \text { of their trips carried out using SAV and the rest using their private vehicle } \\
\text { \& iii) Continue to use their private vehicle for all the trips. Place of study: Brisbane }\end{array}$ \\
\hline $\begin{array}{l}\text { Gurumurthy } \\
\& \quad \text { Kockelman } \\
(2020)\end{array}$ & $\mathrm{A}$ & Hurdle model & $\begin{array}{l}\text { Assessment of preference towards automated vehicles. The study includes a survey of } 2588 \text { households. } 57 \% \text { of the } \\
\text { survey participants are females. While the younger people (aged between } 18 \text { to } 24 \text { ) are over-represented, older people } \\
\text { aged } 65 \& \text { above are under-represented. } 49 \% \text { of the participants use public transport for work/school trips , } 22 \% \text { use } \\
\text { private vehicle \& } 29 \% \text { use non-motorized transport modes. Place of study: USA }\end{array}$ \\
\hline
\end{tabular}

Note: Studies are sorted by year and then alphabetically by authors. 